Florida International University FIU Digital Commons

$6-1-2010$

\title{
Developing A Leadership Identity: A Case Study Exploring a Select Group of Hispanic Women at a Hispanic Serving Institution
}

Suzanne M. Onorato

Florida International University, onoratos@fiu.edu

DOI: $10.25148 /$ etd.FI10081204

Follow this and additional works at: https://digitalcommons.fiu.edu/etd

Part of the Higher Education Administration Commons

\section{Recommended Citation}

Onorato, Suzanne M., "Developing A Leadership Identity: A Case Study Exploring a Select Group of Hispanic Women at a Hispanic Serving Institution" (2010). FIU Electronic Theses and Dissertations. 253.

https://digitalcommons.fiu.edu/etd/253 


\section{FLORIDA INTERNATIONAL UNIVERSITY \\ Miami, Florida}

\section{DEVELOPING A LEADERSHIP IDENTITY: A CASE STUDY EXPLORING A SELECT GROUP OF HISPANIC WOMEN AT A HISPANIC SERVING INSTITUTION}

A dissertation submitted in partial fulfillment of the requirements for the degree of DOCTOR OF EDUCATION in HIGHER EDUCATION by

Suzanne M. Onorato 
To: Interim Dean Marie McDemmond

College of Education

This dissertation, written by Suzanne M. Onorato, and entitled Developing A Leadership Identity: A Case Study Exploring a Select Group of Hispanic Women at a Hispanic Serving Institution, having been approved in respect to style and intellectual content, is referred to you for judgment.

We have read this dissertation and recommend that it be approved.

$\begin{array}{r}\text { Benjamin Baez } \\ \hline \text { Roger Geertz-Gonzalez } \\ \hline \text { Suzanna Rose } \\ \hline \text { Glenda Droogsma Musoba, Major Professor }\end{array}$

Date of Defense: June 1, 2010

The dissertation of Suzanne M. Onorato is approved.

Interim Dean Marie McDemmond

College of Education

Interim Dean Kevin O'Shea

University Graduate School

Florida International University, 2010 


\section{DEDICATION}

I dedicate this paper to my family and loved ones without your support I would not have been able to accomplish such an incredible feat. Thank you for providing me with the foundation to believe in my goals and dreams. This work is witness that with

perseverance, passion, and belief in self, you can accomplish anything within the reach of your mind. 


\section{ACKNOWLEDGMENTS}

The mind is not a vessel to be filled but a fire to be kindled. $\sim$ Plutarch

I have been fortunate to develop meaningful relationships with people who have stoked my fire at times when I needed it most during my journey. In 1990, while an undergraduate at the University of Massachusetts, I met Dr. Gary Malaney and Dr. Elizabeth Williams who introduced me to field of Higher Education Administration, helped me connect philosophical thought and theory to my inherent understanding of educational oppression and connected me to a career in which I knew I would make a difference.

Since that fateful day a number of exceptional individuals have supported my professional and academic growth and development. First and foremost I would like to thank my chair Dr. Glenda Droogsma Musoba, who asked those tough questions and spent countless hours with me processing out loud which ultimately helped me come to the conclusions stated in this paper. Without your support and encouragement I do not know if I would have ever finished! A special thank you to my entire committee; Dr. Glenda Droogsma Musoba, Dr. Roger Geertz Gonzalez, Dr. Suzanna Rose and Dr. Benjamin Baez for your feedback and insight, and keeping me on track.

I would like to thank my supervisors Dr. Beverly Dalrymple and Dr. Larry Lunsford for supporting me through this entire process and for providing me with the flexibility to adjust my schedule when needed. To my mentor Barbara Bader, thank you for believing in me, your friendship, guidance and knowledge provided me with that reality check that I so often needed. To my peer reviewer Vicky Owles, thanks for sharing your insight into this process and for keeping me sane! It meant so much to have 
the support of someone who had achieved the end before me. A special thanks to Manuel Rosa for helping me edit this colossal document. In addition, thank you to my family in the Women's Center, you have inspired me in ways you cannot imagine.

To the amazing women who provided the data for this study, thank you for allowing me to share your stories and for contributing to enhancing our knowledge about Hispanic women student's leadership identity development. And finally, to my parents Sharon and Gene Onorato, my brothers Michael and David Onorato, my sis Laura Onorato and my partner Richard Louis, thank you for your never ending support and encouragement and your interest in my work. 


\section{ABSTRACT OF THE DISSERTATION \\ DEVELOPING A LEADERSHIP IDENTITY: A CASE STUDY EXPLORING A SELECT GROUP OF HISPANIC WOMEN AT A HISPANIC SERVING INSTITUTION}

by

Suzanne M. Onorato

Florida International University, 2010

Miami, Florida

\section{Professor Glenda Droogsma Musoba, Major Professor}

Leadership is a socially constructed concept shaped by the context, values and experiences of society (Klenke, 1996); the historical context of gender and ethnicity in society affects views about leadership and who merits a leadership role. Therefore, developing an understanding of Hispanic women students' leadership identity development is critical in broadening how we define leadership and develop leadership education.

The purpose of this qualitative case study was to explore and describe the leadership identity development of a select group of women leaders at a Hispanic Serving Institution (HSI) in the southeast. A psychosocial approach to the study was utilized. Indepth interviews and focus groups were conducted with 11 self-identified Hispanic women students of sophomore, junior or senior standing with varying degrees of involvement in leadership activities at Florida International University. Participants were asked questions related to four topics; (a) leadership, (b) gender, (c) ethnic identity, and (d) influences that contributed to their understanding of self as leader. Five topics 
emerged from the data presented by the participants': (a) encouraging relationships, (b) meaningful experiences, (c) self development, (d) the role of gender, and (e) impact of ethnicity. These themes contributed to the leadership identity development of the participants. Findings indicate that leadership identity development for Hispanic women college students at this HSI is complex. The concept of leadership identity development presented in the literature was challenged as findings indicate that the participants' experiences living and attending a school in a majority-minority city influenced their development of a leadership identity.

The data indicate that leadership is not gender or ethnicity neutral as differences exist in expectations of men and women in leadership roles. Gender expectations posed particular challenges for these women student leaders. The prescriptive nature of stagebased models was problematic as findings indicated leadership identity development a complicated and continuing process influenced strongly by relationships and experiences.

This study enhanced knowledge of the ways that Hispanic women students become leaders and the influences that shape their leadership experiences which can assist higher education professionals in developing leadership programs and courses that address gender, multiculturalism and awareness of self as leader. 


\section{TABLE OF CONTENTS}

\section{CHAPTER}

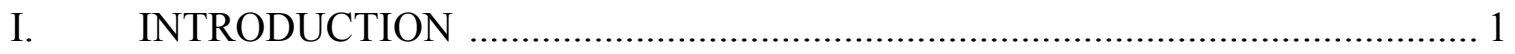

Background of the Study .......................................................................... 2

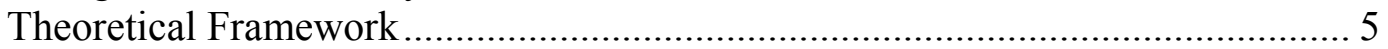

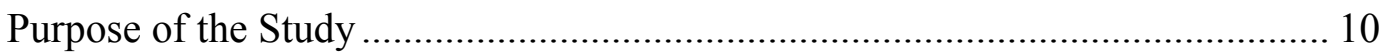

Research Questions .................................................................................... 10

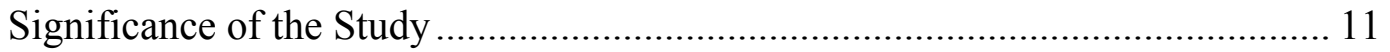

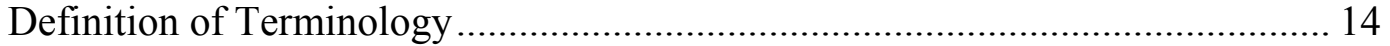

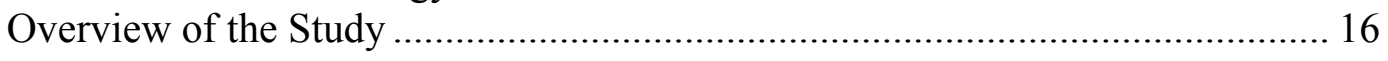

II. REVIEW OF RELATED LITERATURE ………............................................ 18

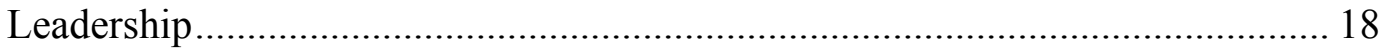

Leadership and Gender ..................................................................... 20

Leadership and College Students............................................................ 25

Leadership, gender and college students ...................................... 28

Leadership, ethnicity and college students ................................. 35

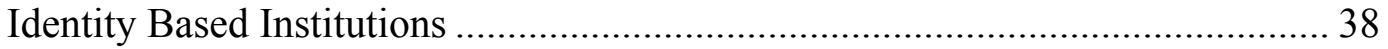

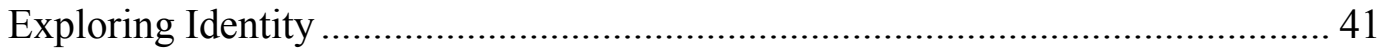

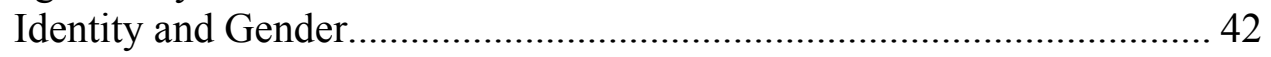

Identity and Ethnicity .............................................................................. 47

Identity and Leadership..................................................................... 51

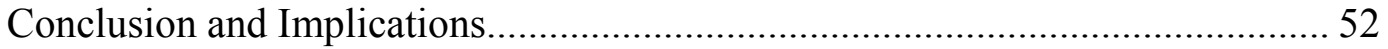

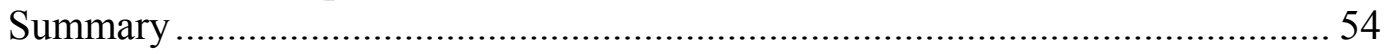

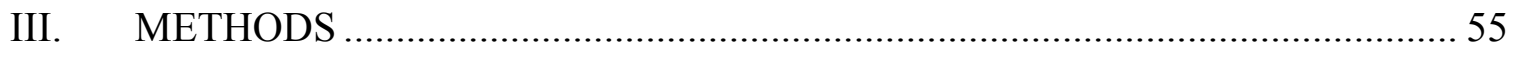

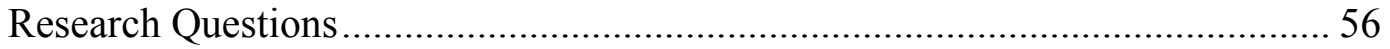

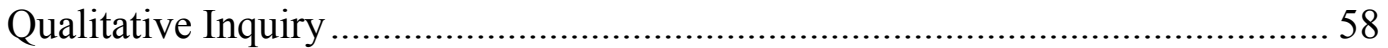

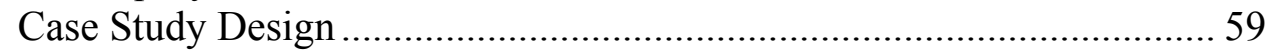

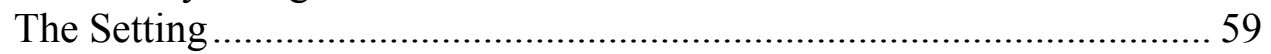

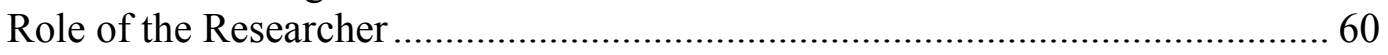

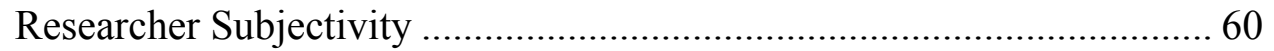

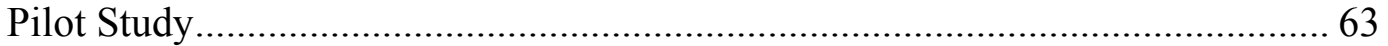

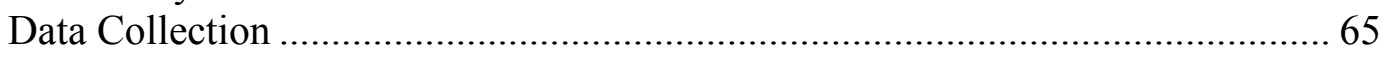

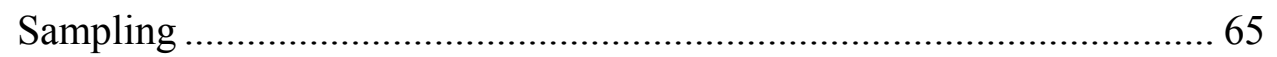

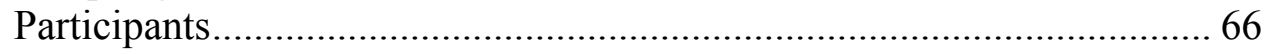

Interview Process and Protocol............................................................... 70

Observations of Leadership Classes and Programs …………………....... 74

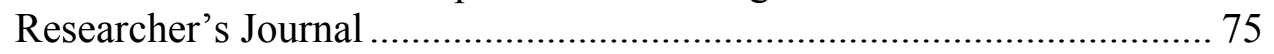

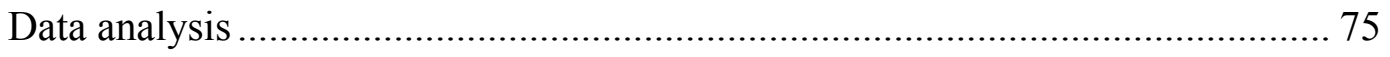

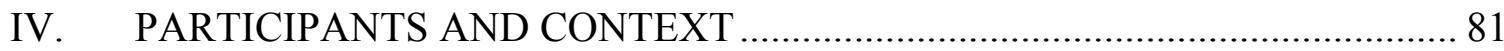

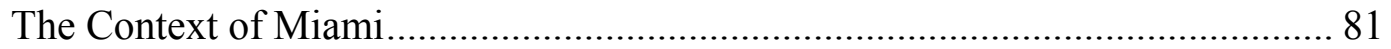




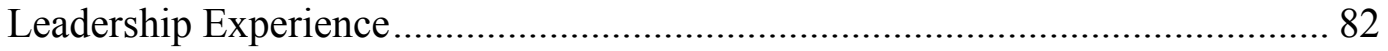

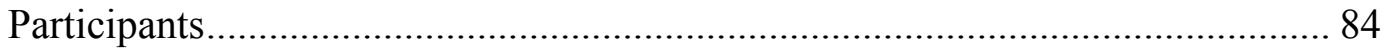

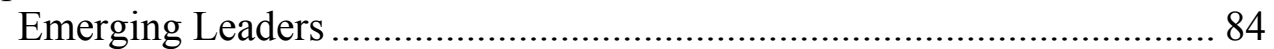

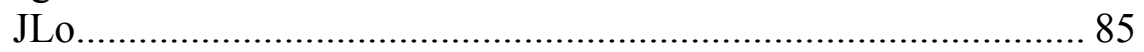

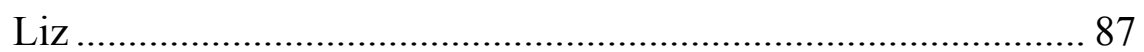

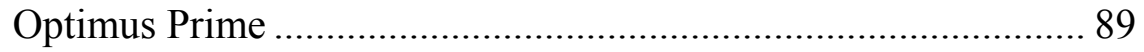

Intermediate Leaders...................................................................... 92

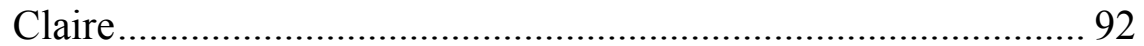

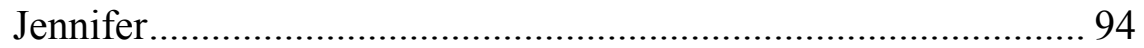

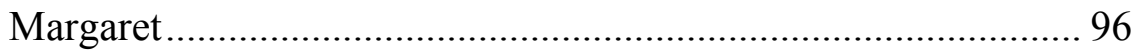

Experienced Leaders .......................................................................... 99

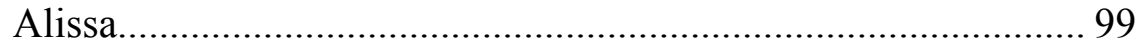

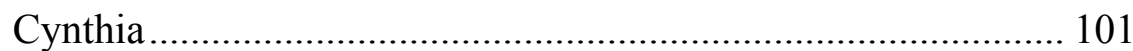

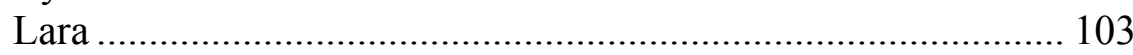

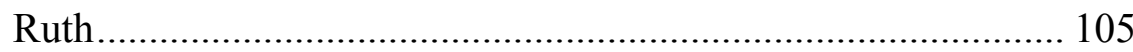

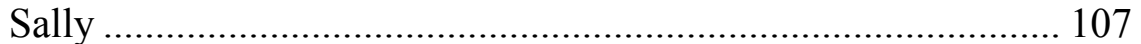

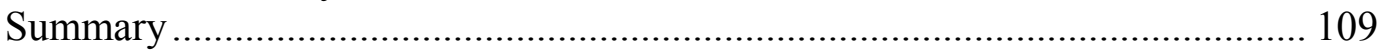

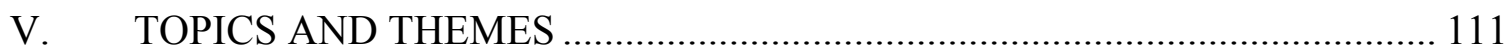

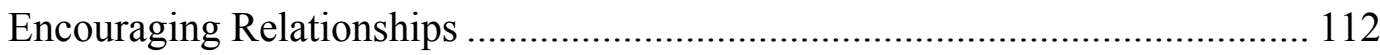

My Family Believes in Me ………………………….................... 114

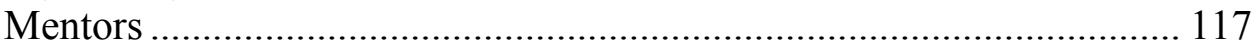

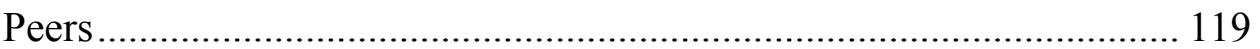

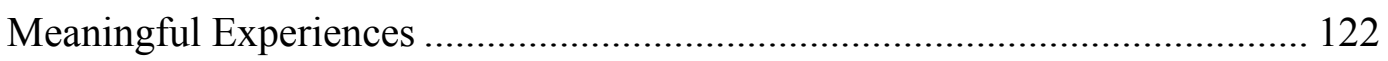

Being a Part of Something ............................................................. 124

Reflection on Experiences ................................................................ 129

Changing View of Leadership ........................................................... 131

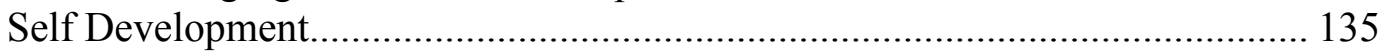

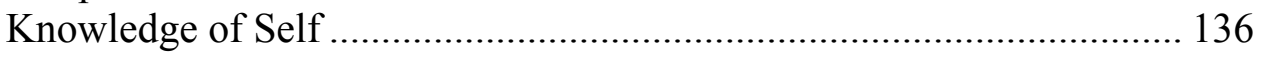

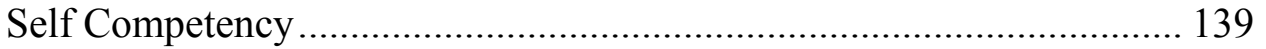

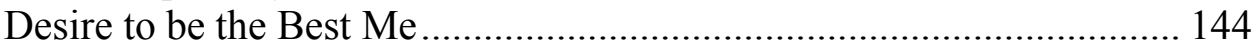

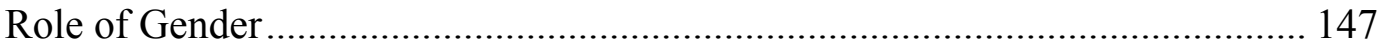

Gender Roles, Expectations and Differences........................................ 149

Strength and Support of Women........................................................ 156

Building on Progress.................................................................... 160

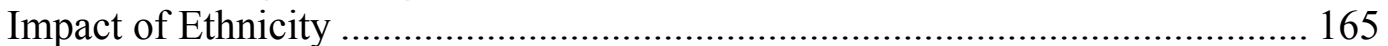

Being a Majority Minority Population.................................................... 168

Using Leadership to Help People of My Ethnicity ................................. 173

Cultural Expectations....................................................................... 175

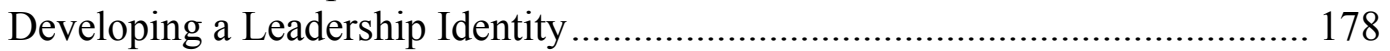

VI. CONCLUSIONS AND RECOMMENDATIONS …......................................... 185

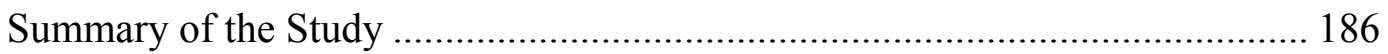

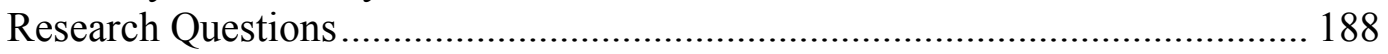

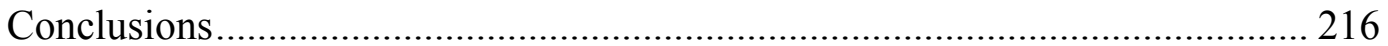




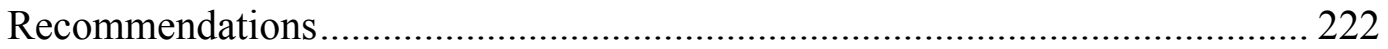

Recommendations for Practice .......................................................... 223

Recommendations for Research ...................................................... 226

Interpretation Parameters ......................................................................... 228

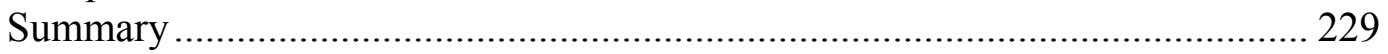

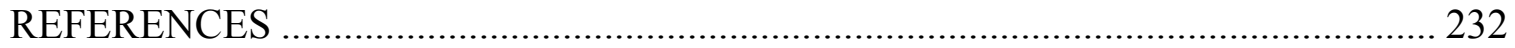

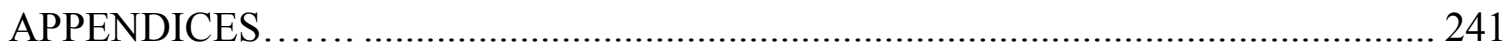

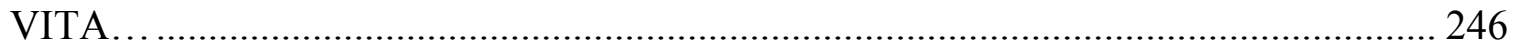




\section{LIST OF FIGURES}

FIGURE

PAGE

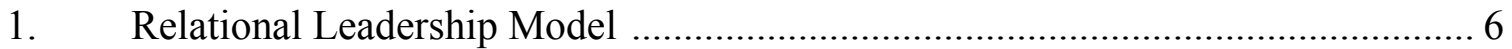

2. Leadership Identity Model ........................................................................... 8

3. Leadership Experience Categories by Participant ........................................... 83

4. Final Coding of Topics and Themes of Influence and Factors Affecting Leadership Identity Development of Hispanic Women Participants.................. 113

5. Developing a Leadership Identity: Illustrating the Cycle ............................... 208 


\section{Chapter I}

Introduction

Leadership is a socially constructed paradigm shaped by the context, values and experiences of a society. Therefore, an examination of leadership should be framed by the theoretical perspectives that influence our current understanding of leadership as well as a historical perspective of what has influenced the current paradigm of leadership. Since it first became a topic of study during the Industrial Revolution, there have been several prevailing models to define the nature of leadership. Despite a plethora of research, scholarly work, and pop cultural self-development books on leadership, key concepts remain elusive.

To begin, there is a lack of consensus on the definition of effective leadership. The concept of leadership and what it means to be a leader has changed dramatically since the early twentieth century when the "great man" theory, which postulated leadership as a set of properties inherent in all great leaders, dominated the landscape. These inherent properties included being male and European American (Hoyt, 2007; Klenke, 1996; McCauley \& Van Velsor, 2004). The more recent paradigm views leadership from a relational perspective, as an ability to influence and inspire others to achieve common goals that often exceed original expectations (Bass, 1990; Klenke, 1996; Kouzes \& Posner, 2002; McCauley \& Van Velsor, 2004; Northouse, 2007). This emerging paradigm views leadership as a process that people engage in together. Important concepts in this leadership paradigm include the belief that leadership involves influence (power), occurs in groups, and attends to the accomplishment of goals (Northouse, 2007). Inherent in this definition is an attention to the processes of 
empowering rather than exerting power over others, encouraging personal development and self-knowledge, and developing and influencing movement toward a common set of goals (Astin \& Leland, 1991).

\section{Background of the Study}

Although the discipline of leadership has evolved over the past 100 years, until the 1980s the majority of research on leadership was conducted on leaders in political, military and corporate settings, which at the highest levels were, and continue to be, dominated by European American men (Astin \& Leland, 1991; Eagly \& Carli, 2004; Hoyt, 2007; Klenke, 1996). These privileged few have defined power, authority and knowledge and have provided the context for how leadership is defined and practiced. Hoyt (2007) cites two reasons that women and people from different ethnicities were excluded from these studies; the dominance of male researchers uninterested in the topic of women and leadership, and an assumption that gender equality exists in our society.

How we define leadership influences how we study and measure it, the symbols and metaphors we apply to it, and the way we practice leadership (Astin \& LeLand, 1991; Klenke, 1996). However, our understanding of the ways gender and ethnicity role expectations have shaped society is changing, and the increase of women and people of different ethnicities in leadership positions has led to scholarly interest in broadening leadership studies, which is beginning to change the way we view, define and study leadership. Interestingly, Pascarella and Terenzini (2005) found that involvement in leadership activities was a significant factor in women entering traditionally "male" fields, such as law which demonstrates that leadership development may be an important 
factor in broadening women's career choice and influence women choosing male dominated fields.

An enhanced knowledge of the ways that students become leaders and the influences that shape their leadership experiences can assist practitioners in developing leadership programs that address gender, multiculturalism and awareness of self as leader. Eagly and Carli (2004) assert that because we live in a patriarchal system in which European American men control the most influential aspects of our organizations and governments, in order to fully consider the effects of gender on leadership we must first acknowledge the profound divide in power and authority that separates women from men. In our society's hierarchical structures, the proportion of women decreases until at the highest level, women are an anomaly and women of different ethnicities even more so. If leadership is gender and ethnicity neutral, why does this discrepancy exist? Although scholars have begun to investigate the influence and effects of gender and ethnicity on leadership, as a body of research it is new.

Because leadership is a socially constructed paradigm shaped by the context, values and experiences in our society, we would be remiss to believe that leadership is gender and ethnicity neutral and that the development of one's leadership identity is not impacted by this context (Astin \& Leland, 1991; Cantor \& Bernay, 1992; Eagly \& Carli, 2004; Klenke, 1996). The context in which we were brought up, our societal views and historical context of gender and ethnicity, and the inherent sexism and racism that exists within our society, undoubtedly effects our views on what it means to be a leader, who merits a leadership role, and who we are as women and men from different ethnic backgrounds. Leadership is therefore collectively constructed. 
Our identity is created in this context. Identity refers to the sense of self that one possesses and can be conceptualized into two constructs; personal identity, which refers to our personal characteristics and social identity, which refers to the roles in which we engage. Identity develops over time and is a process in which individuals discover, more than create, who they are within a social context (Erikson, 1968). Current beliefs on leadership development demonstrate that self-management and social capabilities, both of which develop within the constructs of societal expectations, are important in developing effective leadership skills (McCauley \& Van Velsor, 2004). Therefore, developing an understanding of how women, and particularly women of different ethnicities, develop a leadership identity is critical knowledge in broadening the way we define leadership.

Our understanding of leadership and developing a leadership identity has evolved from a leader focused view to one in which leadership is viewed as a process that people engage in to accomplish goals and create change. From this perspective, leadership is viewed as a complex transformational process that elevates all individuals to levels at which they can become effective leaders. This view necessitates that leadership be studied from a psychosocial perspective, which affords an opportunity to investigate how individuals from diverse backgrounds come to understand themselves as leaders. Merriam (1998) states "the focus on the individual as a way to investigate some aspect of human behavior characterizes the psychological case study" (p. 37). The traditional narrative of leadership is restrictive and male focused. This study challenges the social construction of leadership as male and provides an additional perspective. The orientation of this study is a psychosocial lens. 


\section{Theoretical Framework}

The conceptual framework used in this study is the Relational Leadership model. In the current paradigm it is generally accepted that leadership is a socially constructed paradigm that is exhibited through relationships and context. These two concepts are intertwined as the context is shaped through the relationships we value. The Relational Leadership model places relationships as the focal point of the leadership process (Komives, Lucas, \& McMahon, 2007). In this framework "leadership is purposeful and builds commitment toward positive purposes that are inclusive of people and diverse points of view, empowers those involved, is ethical, and recognizes that all four of these elements are accomplished by being process-oriented" (Komives, Lucas, \& McMahon, p. 74). The model, developed by Komives, Lucas, and McMahon (2007) is comprised of these five primary components; purpose, inclusive, empowering, ethical and processoriented (see Figure 1).

Within the context of this model leadership has purpose when there is a commitment to collaborating towards a common goal that creates positive change and investment in the vision of the organization. Creating this investment requires involving members in the process of vision building (Nanus, 1992). Leadership that is inclusive actively engages a wide perspective of views, approaches, styles and aspects of individuality. This type of leadership requires an understanding of how different groups or individuals may have different perspectives, enhancing the likelihood that differences are respected, and valuing equity and involvement. Komives and colleagues (2007) and Helgeson (1990) describe this concept as developing the talents of all members and creating webs of connections so that the group's goals can be attained. 
Empowering, in the context of relational leadership, refers to activities that promote the self-actualization of members. Understanding power dynamics is an important element to empowered organizations. In empowered organizations positional leaders do not view power as a means of controlling others, but rather are willing to share power and authority and expect members to assume responsibility for group outcomes. Relational leadership focuses on a collaborative approach to power, power with or power alongside members (Kouzes \& Posner, 2002). How people use power and react to the power of others must be examined in relational leadership.

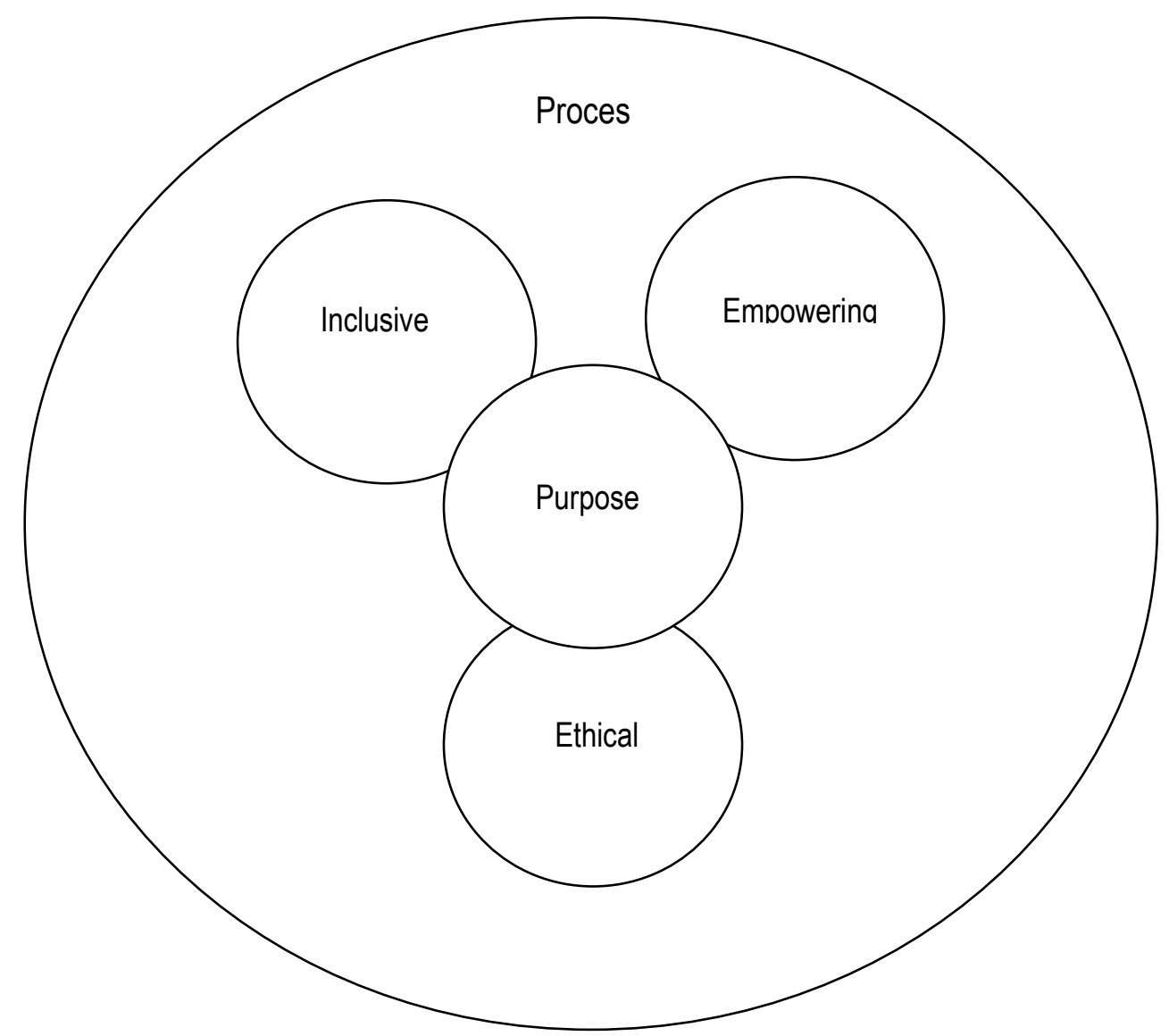

Figure 1. Relational leadership model

Komives, S. R., Lucas, N., \& McMahon, T. R. (2007). Exploring leadership: For college students who want to make a difference $\left(2^{\text {nd }}\right.$ ed.). San Francisco, CA: Jossey-Bass. 
Ethical leadership is emphasized in the Relational Leadership model. This philosophy of leadership is values driven; leaders and members share a commitment to a common purpose and base their actions on the shared values of members and the organization, and a desire to cause real change. The foundation of ethical and moral leadership includes a commitment to high standards of honesty, trustworthiness, authenticity and organizational values.

The final component of the Relational Leadership model is process which refers to the dynamics of how a group works together, how the group becomes a group, remains a group and accomplishes the group's purposes. The key components of process in this context are collaboration, reflection, feedback, civil confrontation, community building, and meaning making (Komives, Lucas, \& McMahon, 2007). The process of Relational Leadership elicits synergy through individuals' interaction with each other to accomplish change.

The Relational Leadership model describes a model of what leadership "looks like" but does not address how one comes to view oneself as a leader and the process that an individual encounters when developing as a leader. The Relational Leadership model set the stage for an emerging model that focuses on developing an identity as a leader, the Leadership Identity Development model (Komives, Owen, Logerbeam,, Mainella, \& Osteen, 2005). The Leadership Identity Development (LID) model, developed from grounded theory, includes six stages of leadership identity, based on social and personal values and a developing awareness that through collaboration change can be accomplished (see Figure 2). 
Figure 2: Leadership Identity Model

Komives, S. R., Owen, J. E., Longerbeam, S., Mainella, F. C., \& Osteen, L. (2006).

\begin{tabular}{|c|c|c|c|c|c|c|c|}
\hline \multirow{2}{*}{ 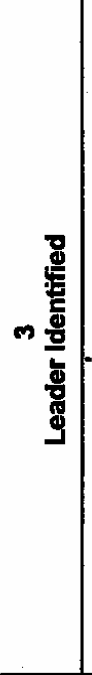 } & 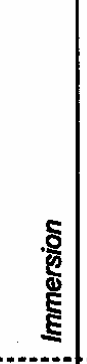 & 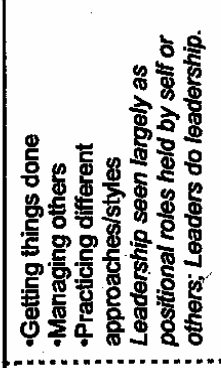 & 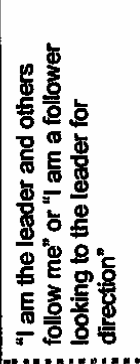 & 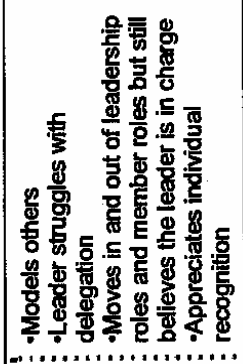 & 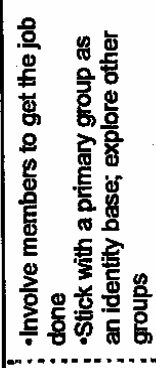 & 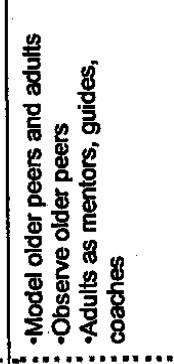 & \multirow{2}{*}{ 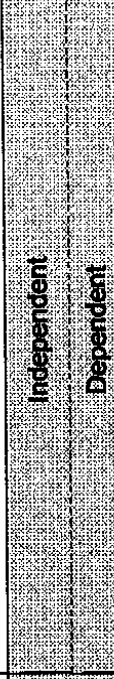 } \\
\hline & 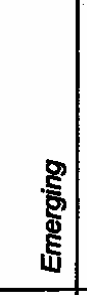 & 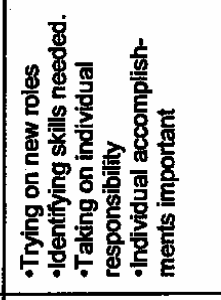 & 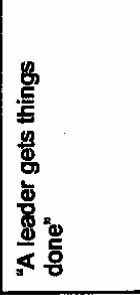 & 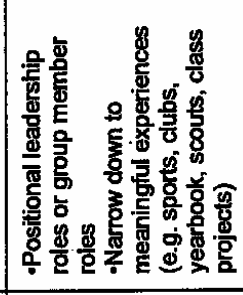 & 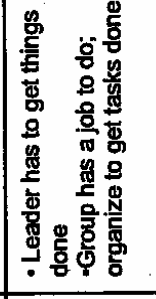 & 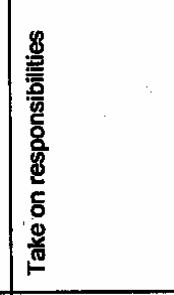 & \\
\hline \multirow{2}{*}{ 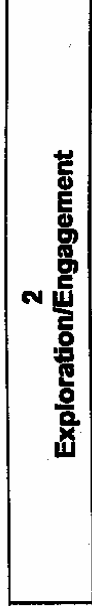 } & 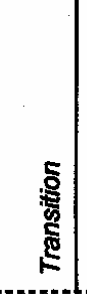 & & 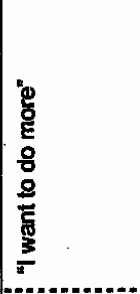 & 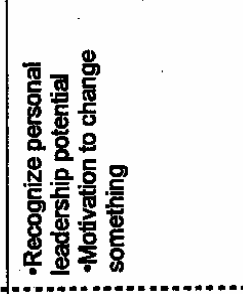 & 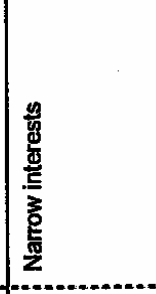 & 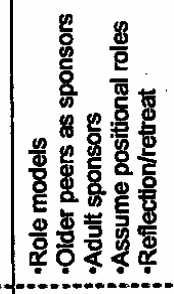 & \\
\hline & & 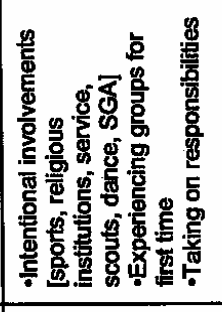 & 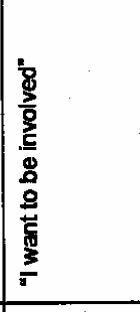 & 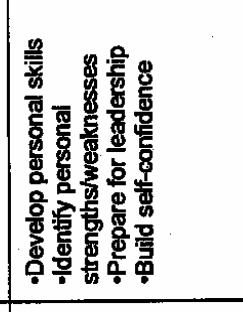 & 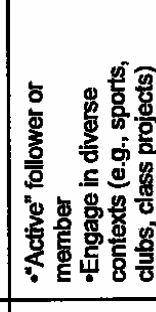 & 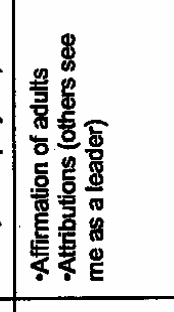 & \\
\hline \multirow{2}{*}{ 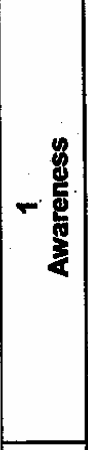 } & 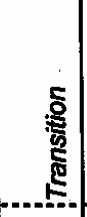 & & 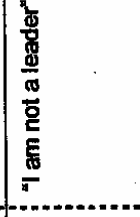 & 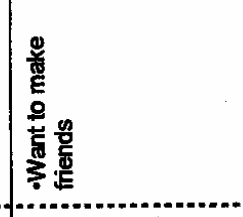 & 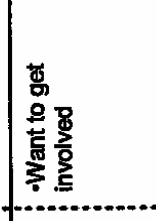 & 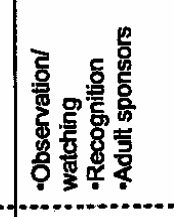 & \\
\hline & & 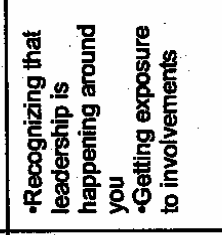 & 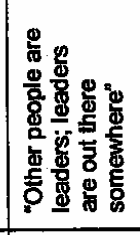 & 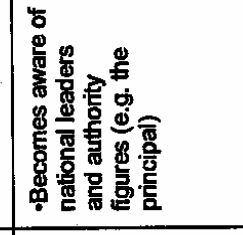 & 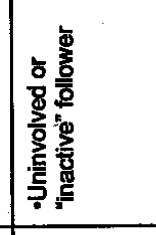 & 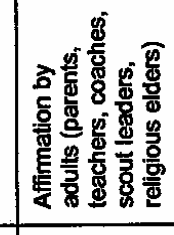 & \\
\hline 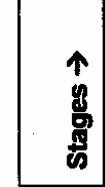 & 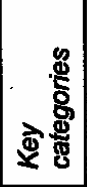 & 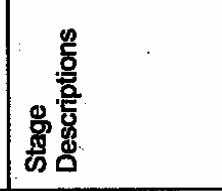 & 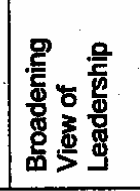 & 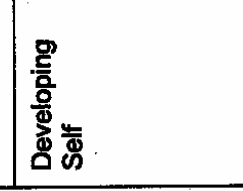 & 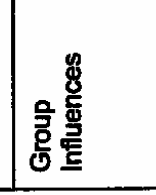 & 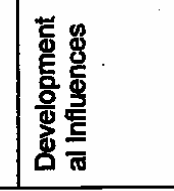 & 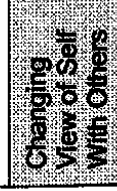 \\
\hline
\end{tabular}


Figure 2: Leadership Identity Model continued

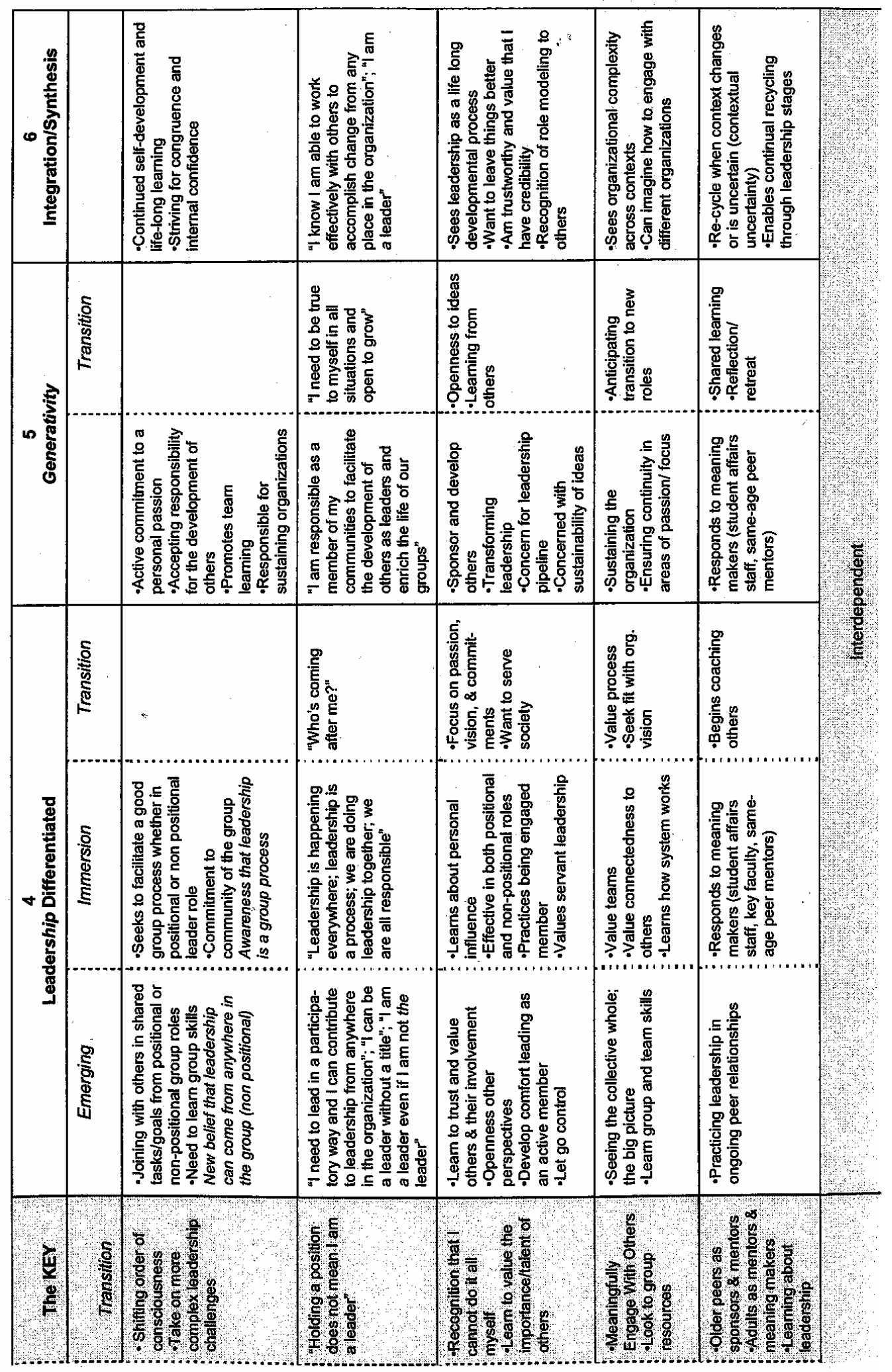




\section{Purpose of the Study}

The purpose of this qualitative case study was to explore and describe the leadership identity development of a select group of women leaders at a Hispanic Serving Institution (HSI) in the southeast.

\section{Research Questions}

Since the conceptual framework underlying this study is the Relational Leadership model and the study sought to understand how a select group of women leaders at an HSI develop a leadership identity, the research questions and interview protocol of the study were derived from Komives et al. (2005) grounded theory study. The exploratory questions that will guide this study are:

1) How do Hispanic women college students at an HSI develop an understanding of leadership?

2) In what ways are Hispanic, women college students leadership identity development similar and different?

3) From their perspectives, what influences contribute to their leadership identity development?

4) How do Hispanic woman college students describe the impact of other aspects of their identity (i.e. gender, ethnicity) on their leadership identity development?

5) Do the ways in which these women describe their leadership identity development align with the process described in the LID model? If so, in what ways are they similar and/or different? 
Currently, there is debate in the literature regarding which term is more appropriate, "Hispanic" or "Latino/a" (Casañas, 2005). Some prefer Latino/a because it is a self-identifying word, from a Latin American country unlike Hispanic, which is the term used by the U.S. government for census and other purposes. Many believe that Latino/a makes more sense and is more politically appropriate, while others believe that in professional settings Hispanic wields more power. For the purpose of this study I have chosen the term Hispanic. First, in my experience, Hispanic is the term more generally used by individuals within this context. Second, Hispanic is the category the institution at which this study was conducted is defined and utilized in collecting demographic information. Third, I knew that during the data collection phase participants would have the opportunity to share the term that they used in describing their heritage. As shared in chapter 4 , each of the participants defined themselves first by their family's country of origin, and secondly as Hispanic. One participant shared that she does not identify with the term Hispanic.

\section{Significance of the Study}

No leader sets out to be a leader. People set out to live their lives, expressing themselves fully. When that expression is of value, they become leaders. So the point is not to become a leader. The point is to become yourself, to use yourself completely - all your skills and energies - in order to make your vision manifest. You must withhold nothing. You must in sum, become the person you started out to be, and to enjoy the process of becoming. (Bennis, p. 104)

Bennis's quote speaks to the core of what it means to be a leader in the context of our society today. Our rapid advancements in technology and increasing globalization have created an interconnected world with new ways of leading, relating, learning and influencing change. Organizations today are becoming more horizontal than hierarchical 
and are increasingly diverse; these characteristics necessitate that today's leaders possess the capacity to deal with complex challenges, to be independent and self-motivated, but also able to work together across boundaries (Van Velsor \& Drath, 2004). Bennis charges that today's leaders should understand differences and cultural expectations that can be incorporated into work environments (Bennis, 2003). In addition, they must have meaningful knowledge of the unique skill set and talents they possess, and be able to articulate a vision for themselves and their groups that meets the goals of their organization (Van Velsor \& Drath, 2004).

This paradigm of leadership requires a deep understanding of self, it requires sharing of power and the ability to empower others, and the development of authentic relationships with diverse others (Astin \& Leland, 1991; Bass, 1990; Bennis, 2003; Kouzes \& Posner, 2002; Van Veslor \& Drath, 2004). Educating individuals who are prepared to succeed within this paradigm of leadership is critical and requires an understanding of differences that exist in leadership styles across diverse individuals. This study contributed to the understanding of how diverse individuals develop as leaders, how they come to understand their self in this process, and what contributes to the development of the skills espoused in this new paradigm of leadership.

One of the main roles of higher education in America is to develop future leaders (Astin \& Astin, 2000; Council for the Advancement of Standards in Higher Education, 1999). This is evidenced in institutional mission statements across the country as well as the proliferation of curricular and co-curricular leadership programs within our institutions of higher education (Cress, Astin, Zimmerman-Oster \& Burkhardt, 2001; Dugan, 2006). In addition, the core mission of student affairs is to develop students 
holistically by connecting curricular and co-curricular initiatives on campus. In fact, the Student Learning Imperative (American College Personnel Association \& National Association of Student Personnel Administrators, 1994) espouses a college educated person as one who has and knows how to apply theoretical knowledge, practical competence, an understanding and appreciation for human differences, and a sense of self within a societal context. In addition, Learning Reconsidered, which states; ... learning, as it has historically been understood, is included in a much larger context that requires a consideration of what students know, who they are, what their values and behavior patterns are, and how they see themselves contributing to and participating in the world in which they live (ACPA \& NASPA, p. 10)

is a decisive document for many institutions.

Institutions of higher education are uniquely positioned to educate tomorrow's leaders and initiate change in the number of women in leadership roles. A report from the National Center for Education Statistics notes that the overall enrollment of women in institutions of higher education increased from $42 \%$ in 1970 to $56 \%$ in 2000 (U.S. Department of Education, 2005). Hispanic enrollment in institutions of higher education increased $237 \%$ between 1984 and 2004, from $5 \%$ of the total undergraduate student body in 1984 to $11 \%$ in 2004 . This increase in Hispanics was comparable to the proportion of their increase in the general United States population (U.S. Department of Education, 2008). Interestingly, approximately $45 \%$ of Hispanic students are enrolled in Hispanic Serving Institutions, or HSIs. Women and Hispanics are transforming the landscape of higher education. In order to respond to these changing demographic and incorporate Hispanic women's specific needs as they develop a leadership identity, institutions of higher education must develop greater understanding of the differences 
that exist within these populations and respond through curricular and co-curricular programs and services.

The purpose of this study was to explore the leadership identity development of Hispanic women college student leaders at an HSI. The context of the setting for this paper was Florida International University (FIU) an HSI in the southeast. In the fall 2007 $62 \%$ of the total undergraduate population enrolled at FIU identified themselves as Hispanic/non-White and 59\% as female. An understanding of these students' leadership styles and the ways they develop their leadership identity will inform practitioners as they create curricular and co-curricular leadership programs.

\section{Definition of Terminology}

Relational leadership. A term used to describe an approach to leadership. This approach is described as a relational process in which people work together to accomplish change or make a difference that will benefit the common good.

Transformational leadership refers to a process whereby an individual engages with others and creates a connection that raises the level of motivation and morality in both the leader and the follower.

The Trait theory of leadership posits that leaders possess certain innate qualities and characteristics possessed by great social, political and military leaders. The trait theory is also referred to as the "great man" theory of leadership.

Situational leadership theory. The premise of situational leadership is that different situations require different kinds of leadership. To be effective a leader must adapt her or his style to the demands of each situation. 
Leadership identity development. The process an individual goes through in developing an understanding of and recognizing self as a leader.

Leadership identity development model. The Leadership Identity Development (LID) model, developed from grounded theory, includes six stages of leadership identity, based on social and personal values and an awareness that through collaboration change can be accomplished (see Figure 2). The model is based on theories of student development and relational leadership (Komives, et al., 2006).

Identity development. Erikson (1968) defined identity as the sense of a continuous self. Therefore, for the purposes of this study, identity development is defined as the process of discovering self.

Ethnicity. There is much debate in the literature on the correct terminology when referring to race and/or ethnicity. For the purpose of this study, the term ethnicity will be used to refer to identification with a segment of a larger society whose members have common origin and share segments of a common culture (Phinney, 1993).

Minority Serving Institution (MSI). Institutions were classified as minorityserving based on either one of two separate criteria: legislation or the percentage of minority student enrollment. Generally, institutions that enroll at least $25 \%$ of a specific minority group are designated as "minority-serving" for that group (U.S. Department of Education, 2005). Congress has passed a number of Acts defining MSIs, for more information on information related to MSIs not discussed in the context of this paper refer to U.S. Department of Education (2005).

Hispanic Serving Institution (HSI). HSIs are defined by the reauthorization of the Higher Education Act as amended in 1992, as those 2- and 4-year colleges and 
universities with $25 \%$ or more total undergraduate Hispanic full-time equivalent (FTE) enrollments.

\section{Overview of the Study}

This study is an exploration of the leadership identity development of Hispanic women college student leaders at an HSI in a large, urban city. As this study sought to understand how these students' realities were constructed the constructivist paradigm of qualitative research, specifically a case study, was used. Data in the form of in depth interviews with 11 Hispanic women college student leaders, two focus groups with 8 women student leaders, and observations of key leadership classes/programs were collected and analyzed in light of previous studies represented in the literature review along with my observations that were unique to this particular case study. This study is organized as follows:

1) Chapter 1 presented the statement of the problem, the purpose of the study, the significance of the study, and the definition of relevant terms. In addition the theoretical perspective of psychosocial development and the framework of relational leadership development were presented and guide the relevance of the materials chosen for the literature review.

2) Chapter 2 presents the related literature to provide an understanding of the nexus of leadership, gender, ethnicity and identity. A historical background of leadership theory and identity development are provided and further delineated by gender, ethnicity and college students.

3) Chapter 3 is an in depth look at the research design and methods for this qualitative study, the reasons for the chosen methods, sources of data, research 
questions, a description of the population, and the selection and location of the sample. The context of the "case," an HSI in Miami, Florida is also discussed.

4) Chapter 4 provides an introduction of the study's participants and an overview of the context of the city of Miami to this study.

5) Chapter 5 provides an analysis of the topics and themes that emerged through the interpretation of data.

6) Chapter 6 describes the implications of themes revealed in the literature and the interviews discussed in this study as well as the conclusions that may be drawn from both. This dissertation concludes with recommendations for further research and actions based upon analysis of this study. 


\section{Chapter II}

\section{Review of Related Literature}

The focus of this literature review is to provide background information on the literature related to the nexus of two broad topics; leadership theory and identity development theory. To provide context to the case study, identity based institutions will also be discussed. Within the topic of leadership the sub-topics of leadership and gender; leadership and college students; leadership, gender and college students; and leadership, ethnicity and college students will be discussed. Within the topic of identity development the sub-topics of identity and gender, identity and ethnicity, and identity and leadership will be discussed. As this study focuses on the leadership identity development of women, with a concentration on Hispanic women college students I have chosen to focus on the topics most relevant to this population; women, and college students and therefore have not delved into the literature related to ethnicity outside of the scope of college students. Through a literature review on these topics, I will connect the ways in which gender and ethnic identity may affect the leadership identity development of a Hispanic woman college student. The implications that may exist for the leadership identity development of students attending a Minority Serving Institution (MSI) will also be considered in this literature review.

\section{Leadership}

As stated earlier, leadership is a socially constructed paradigm; therefore, this examination of leadership must first be framed by the theoretical context that influences our understanding of leadership today. Trait and behavioral theories of leadership prevailed in the industrial era. Leadership was viewed as good management and 
leadership theories described traits and behaviors that worked well and could be applied to production and efficiency (Bennis, 2003). These theories focused on "great man" philosophy, which posited leadership as positional and leaders as exhibiting certain behaviors including power, authority and rational thinking (Northouse, 2007). These theories supported the traditional attitude that certain groups of people (i.e. women and people of different ethnicities) usually lack adequate leadership characteristics, and these theories failed to address how leadership "happens" in real life situations. (Astin \& Leland, 1991; Eagly \& Carli, 2004; Klenke, 1996; Northouse, 2007). As the study of leadership progressed, researchers sought to understand the role of followers in leadership, which gave rise to situational and contingency theories. These theories incorporated the needs of followers, and recognized that situations may call for different kinds of leaders, but the focus remained on the leader in a position of power and influence (Bennis, 2003; Northouse, 2007).

The more recent paradigm of leadership is grounded in human relations and characterized by shared goals (Bass, 1990; Bennis, 2003; Komives, 1998; Kouzes \& Posner, 2002; Northouse, 2007); leadership is considered a process that engages both leaders and members in creating change within themselves, the organization and the community. Within this paradigm, power is shared and individuals are empowered. Most importantly, this new paradigm recognizes that leadership can be "done" by anyone (Northouse, 2007). Individuals, who can work across boundaries with less supervision, create shared understanding, collaborate, and motivate diverse teams of people who have different priorities and values, are sought in this paradigm (Bass, 1990; Bennis, 2003; Van Veslor \& Drath, 2004; Wielkiewicz, 2000). 
Komives (1994) defines this new paradigm "relational leadership" stating that "leadership is a relational process of people working together to accomplish change or to make a difference that will benefit the common good" (p.9). Kouzes and Posner (2002) use the term "empowering leadership" defined as having a focus on relationships that empower people to accomplish a shared vision. Additionally, Northouse (2007) refers to "transformational leadership" as a process "concerned with the emotions, values, ethics ... and motives of people, ... and treating them as full human beings" (p. 175). For more than 20 years organizations have touted a leadership style that is less hierarchical, an empowering and relational paradigm of leadership in which individual needs and voices are connected to the whole. This philosophy of leadership incorporates many of the characteristics inherent in what Gilligan (1982) called "a different voice" and Belenky, Clinchy, Goldberger, and Tarule (1986) termed “women's ways of knowing.” For the purpose of this paper, I will use the term "relational leadership" to refer to the emerging paradigm.

\section{Leadership and Gender}

A review of the literature on gender and leadership confirms that traditional leadership development practices, which focus on hierarchical systems and authority, put women and ethnic groups at a disadvantage (Cantor \& Bernay, 1992; Klenke, 1996; Eagly \& Carli, 2004; Ruderman, 2004). Interestingly, researchers postulate that women should benefit most from the relational paradigm of leadership with its proclivity for stereotypically "feminine" skills and behaviors such as; relationship building, processorientation, connectedness, empowerment, ethic of care and concern, and empowerment (Eagly \& Carli, 2004; Helgesen, 1990; Komives, 1994). 
Statistics do indicate that women exhibit more characteristics from the relational leadership paradigm than men (Eagly, 2007). However, women are underrepresented in leadership roles, especially those that provide substantial authority over people. Even in female-dominated organizations and professions such as nursing and teaching, men ascend to leadership faster than women (Eagly \& Carli, 2004). Catalyst, a leading nonprofit research and advisory organization working globally with businesses and the professions to build inclusive environments and expand opportunities for women, reported that women constitute $14.7 \%$ of Fortune 500 board seats, and, only $3.4 \%$ of these seats are held by women of color (Catalyst, 2007). Currently, a record number of ninety-four women out of five hundred and thirty-five members serve in the $111^{\text {th }}$ Congress; seventy-six women in the House and sixteen women in the Senate, twenty-two are women of color. The seven women who identify as Hispanic are the only Hispanic women to ever serve Congress. In addition, House speaker Pelosi holds the highest position of leadership ever held by a woman in the US Government (U.S. Office of the Clerk, 2009).

Statistics demonstrate the ascension of women into elite leadership roles is gaining momentum (Chao \& Rones, 2007). This data prompts an investigation of the changes that have enabled women to rise into leadership roles they have not traditionally held. Eagly \& Carli (2004) postulate three reasons that these changes may have occurred; (a) a redefinition of what constitutes "appropriate behavior" for women in the last few decades, (b) the leadership paradigm changing to reflect more "relational" styles of leadership, and (c) organizational environments that are changing. To continue the 
progression of women into leadership roles, further investigation of how they develop as leaders and the factors that promote or inhibit this ascension, is necessary.

Studies examining differences in leadership style between men and women posit some interesting findings. For example, in a systematic examination designed to investigate difference in leadership style between men and women, Eagly and Johnson, (1990) conducted a meta-analysis of 162 studies using the average magnitude of effect size to determine differences between men and women on measures of leadership style. Their findings indicate that women exhibit more transformational leadership behaviors and employ a more democratic leadership style; that is grounded in a strong interpersonal approach, incorporating more collaboration and shared decision making. Their research demonstrates that women face a double bind when it comes to leadership. Many of the difficulties and challenges for women outlined in this study relate to the incongruity of the traditional female role and society's traditional view of leader. Although women who exhibited a more relational leadership style were viewed positively as leaders, they also experienced more negative evaluations of their competence as leaders when rated on behavior traditionally related to expectations of a leader (i.e. decision making). This finding was especially true in masculine dominated organizational contexts, where a "masculine" leadership style is preferred. These findings are interesting to this analysis of leadership as they point to incongruence between the female gender role and leadership roles. Possible consequences of this incongruence are less positive attitudes toward female leaders, and an increased difficulty for women to become leaders and to achieve success in leadership roles. These findings indicate the need for further research to expose these implications as well as the need for research in settings outside of 
corporate America, and particularly with college students who are just beginning to experience some of the consequences described.

These findings also provide further evidence that women's ways of leading may be particularly suited for the emerging paradigm of leadership. However, this research also found that although women may be particularly well suited for the relational leadership paradigm, women leaders were evaluated differently than men. Specifically, group members favored men over women when evaluating leaders, even when leadership behaviors were held constant, specifically in male dominated organizations. Women were expected to engage in activities and actions congruent with their culturally defined gender roles which did not include leadership. Eagly and Johnson (1990) also found that women are not as likely to be involved in leadership promotion opportunities, such as mentoring and social events, which contribute to success and progress in leadership roles. This finding should be further unpacked to investigate why particular activities are deemed "promotional opportunities," why women are not included in the pipeline when leadership opportunities arise, and why leadership positions are designed to favor men. The lack of women's ascension to leadership roles was corroborated by further research discussed later in this chapter within the context of women college students (Boatwright \& Egidio, 2000; Ruderman, 2004; Whitt, 1994).

In an effort to compare the leadership experiences of women in the first two decades of the modern women's movement in the U.S and develop a conceptual model of leadership, Astin and Leland (1991) conducted a cross-generational qualitative study comprised of a purposeful sample of seventy-seven women leaders in government and education. Their findings indicate that women's leadership differs from the traditional 
models of leadership in the following ways; utilization of power and influence, conceptualization of leadership as a collective, empowering others to take action in the organization by de-emphasizing hierarchical relationships, emphasizing reciprocity, and emphasizing responsibility toward others.

Implicit in this study is the importance of mentoring the next generation of leaders to help them understand the historical perspectives of leadership and the role of women in this context. Astin and Leland also point out the importance of implementing what we have learned about any uniqueness in women's leadership styles into current practice, and examining current reward structures that may disclude women. Further study examining the process of change and collective action within a leadership context is also necessary. This study warrants further attention as it includes multi-generational perspectives and provides a context of change that occurred in our society within the timeframe that leadership theory was also being examined to include women and other perspectives.

Taken together this literature provides evidence that people expect and prefer that women be relational in their leadership approach and that men be agentic. Because leaders are thought to be more agentic than relational, it is not surprising that stereotypes about leaders resemble stereotypes of men more than women. These cultural stereotypes place women in a double bind as they are expected to follow gender role norms while also displaying expected leadership roles which are still stereotyped as masculine. As a result, men sometimes appear more "natural" in a leadership role, placing women at a disadvantage. Given these cross-pressures, finding an appropriate and effective leadership style could be challenging for women. In addition, finding mentors and role 
models with whom the next generation of women leaders can relate to, may be difficult if women are changing their style to meet society's expectations of what it means to be a leader.

The literature discussed in this section points to the need for further research to explore the ways that leadership identity develops within the constructs of our society, particularly for women and people of different ethnicities. Topics that might be particularly enlightening include; how the formation of a leadership identity progresses, factors that influence this development, the paths of ascension for women, the impact of leadership development programs, and the impact of gender role awareness and ethnicity within leadership programs at the collegiate and career development levels.

\section{Leadership and College Students}

Literature on college student leadership is extensive and provides evidence of a positive correlation between leadership development programs and cognitive, psychosocial and career development (Astin, 1985; Cress et al., 2001; Logue, Hutchens \& Hector, 2005; Pascarella \& Terenzini, 2005; Wielkiewicz, 2000).

Specifically, in order to describe the subjective experience of college students in leadership, Logue, et al. (2005) conducted a grounded theory study that included six students in leadership roles, four female and two male, at a large southeastern university. Each of the participants identified themselves as "White." Logue et al. (2005) identified the "ground" of their study as positive experiences which participants described as enjoyment of their leadership experience including the personal benefits and skill development they received. Within the ground the researchers defined three interrelated themes: people, describing a need to relate to and serve others within their leadership 
experience; action, which referred to achieving goals and getting things done; and organization, an awareness of the personal identity that the organization provided each leader.

These three themes are intertwined with the characteristics of relational leadership development as they make evident the connections between leadership and interpersonal experience with others, and demonstrate the impact of leadership in helping students resolve some of the interpersonal developmental processes that occur in college. Although this study provides an interesting perspective, it is limited by the context of the participants and the institution. Future studies, with additional students from different backgrounds and within a variety of settings may reveal variations that exist in students' leadership experiences.

Cress et al. (2001) used longitudinal data from 875 students at 10 institutions to conduct descriptive and multivariate analyses to assess the impact of students' participation in leadership education programs and found a positive correlation with leadership involvement and self efficacy, civic responsibility, multicultural awareness, skill development, and personal and societal awareness amongst positional and nonpositional leaders. Given the emerging paradigm of leadership, with its proclivity for multicultural understanding and an awareness of the complexity of issues facing our society, leadership programs can have profound impact on students' ability to influence self and others through leadership roles. In addition, an enhanced knowledge of the ways that students become leaders and the influences that shape their leadership experiences can assist practitioners in developing leadership programs that address gender, multiculturalism and awareness of self as leader. 
As this study was quantitative, the authors highlight the need for qualitative studies to further explore the phenomenon of leadership development, particularly amongst students of different backgrounds and experiences. In addition, how these skills translate into life after college and their ability to impact their communities warrants further study.

Using the Leadership Attitudes and Beliefs Scale (LABS-R), an instrument designed to assess leadership and organizational adaptability, Wielkiewicz (2000) conducted a quantitative study to measure how individuals think about leadership processes from two dimensions of leadership; hierarchal and systems thinking scales. Weilkiewicz defines the hierarchal scale as the belief that leaders are those who have assigned positions within an organization and are responsible for its overall direction and success. Whereas the systems thinking dimension posits that organizations exist within a complex global system and that to be successful requires utilization of each member's skill set. The sample consisted of 288 male and 387 female college students representing each class standing, and 16 faculty, staff and graduate students.

Their findings support the need to view leadership in a way that matches the complexities of the modern world stated earlier in this paper, and indicate that leadership development is a powerful tool for student learning and skill development. For example, participants who were more hierarchal in their thinking were frustrated when their organizations were not linear in decision making processes. Activities which challenge students to apply non-linear models of leadership while supporting them to recognize the benefits of this philosophy may allow organizations to be more inclusive of students from a diversity of backgrounds. How these challenges should occur and their impact merits 
further examination. In addition to the need for further testing of their model, the authors suggest additional research related to the effectiveness of students operating within each of the dimensions.

The literature in this section provides an overview of the positive impact that leadership development programs can have on college students' psychosocial development while elucidating the need for further studies related to the ways that students' learn what it means to be a leader. An important direction for future research includes focusing on the experiences of women students and students of different ethnicities. This research could provide additional insight and an expanded knowledge base of what leadership "is" and the ways in which students' begin to view themselves as leaders.

Leadership, gender and college students. Literature related to college students and leadership has also discussed differences between women's and men's leadership involvement and career aspiration, the impact of prescribed gender roles on college students' leadership involvement, differences in leadership style and practice, and the impact leadership involvement may have on college students' overall experience. Astin (1993) reported that women constitute more than half the enrollment in higher education, but remain underrepresented in positions of leadership on co-educational campuses. The importance of peer influence is well documented in the college student development literature (Astin, 1993; Pascarella \& Terenzini, 2005) and may influence the discrepancy between the rates of leadership involvement between men and women. Leonard and Sigal (1989) highlighted that women student leaders work harder to gain respect, fear loss 
of approval if they assert themselves, struggle with not being taken seriously and are intimidated by male competitiveness.

Researchers have suggested other rationales for women students' lesser involvement on college campuses including difference in leadership and relating styles (Dugan \& Komives, 2007), the impact of fewer female role models (Whitt, 1994), gender role expectations (Kezar \& Moriarty, 2000); fear of not being taken seriously as leaders by men (Cantor \& Bernay, 1992) and experience during college (Kinzie, Thomas, Palmer, Umbach \& Kuh, 2007; Whitt, Pascarella, Nesheim, Marth, Pierson, 2003), three of these studies will be discussed later in this paper.

Specifically, the most recent, encompassing, national study on college student leadership is the Multi-Institutional Leadership Study designed to investigate aspects of students' experiences in college that contributed to leadership outcomes (Dugan \& Komives, 2007). This quantitative study of 50,378 college students at 52 institutions of higher education was based on students experiences with the eight constructs defined in the Social Change Model of Leadership. The social change model was designed for college students and advocates for leadership development grounded in social responsibility and change for the common good (HERI,1996). Of primary importance are increasing the individual's level of self-knowledge and capacity to engage others in collaborative work. The Socially Responsible Leadership Scale (SRLS), a 68 item instrument, was used to rate student involvement with the eight different constructs of the Social Change Model of Leadership (change, collaboration, consciousness of self, commitment, congruence, common purpose, controversy with civility, and citizenship). In addition, the authors created a scale for Leadership Efficacy; the Chronbach alpha 
level reported for the scale was .88 . Females $(62 \%, \mathrm{n}=30,960)$ were slightly overrepresented when compared to males $(38 \%, \mathrm{n}=19,183)$ with students from different ethnicities representing $28 \%(n=14,262)$ of the participants.

Of relevance, women reported more skill with socially responsible leadership, scoring higher than men on all of the constructs of the SRLS except "change." Although these statistics were significant, the authors do state a meaningful but small effect size. Interestingly, men reported higher on the "leadership efficacy" construct indicating that although women reported higher competence as leaders, men reported more selfconfidence in their leadership abilities. Multivariate analysis of covariance (MANCOVA) was used to determine differences in the constructs based on ethnicity. Significant positive differences were found in six of the eight constructs (collaboration and common purpose excluded). In addition, Gay/lesbian/bisexual students, first generation college students, African American, Native American, Latino, and multiracial students, and students enrolled in community colleges all scored higher on the construct "change" than their dominant-group peers. The findings reveal ten experiences in college that "matter" in relation to leadership outcomes; pre-college experiences, gender, ethnicity, openness to change, mentoring, being involved on campus, having a position of leadership, and involvement in formal leadership programs.

These findings provide evidence of differences that exist between men and women college students and students from different ethnicities and warrant further study to investigate why these differences may occur.

Dugan (2006) examined leadership style in a random sample of 59 college men and women at a large, public, doctoral-granting institution in the west, using the Socially 
Responsible Leadership Scale (SRLS) as a conceptual framework. The sample was representative of the institutional demographics of this Predominately White Institution (PWI). Dugan used multivariate analysis of covariance (MANCOVA) to test the relationship between sex and the eight constructs of the model and found that women scored significantly higher than their male counterparts on six of the eight constructs; consciousness of self, congruence, commitment, common purpose, citizenship and change. Dugan cites using one institution and small effect sizes as limitations of the study. This research highlights potential differences in leadership style between college men and women. Taken together with Eagly \& Carli's (2003) research that elucidated potential differences in the leadership styles of men and women, these findings provide evidence of the need to examine how individuals develop as leaders and discover a leadership identity.

Given that this study did not examine differences among students from non-white ethnicities, further research on diverse populations is warranted to better understand the impact that ethnic background has on leadership style. In addition, qualitative studies exploring the reasons for any difference attributed to gender and/or ethnicity could add to our understanding of college students and leadership.

Investigating the influence of psychological variables on female college students' aspirations for leadership positions in future careers, Boatwright and Egidio (2003) conducted a quantitative investigation using the Career Aspiration Scale. Their convenience sample included 213 women volunteers at a selective liberal arts, PWI in the Midwest. Their findings indicated that the need for connection, self reported femininity or congruence with prescribed female gender role behavior, and self esteem were all 
positively correlated with leadership aspirations, and that fear of negative evaluation was inversely correlated to leadership aspirations, in college women. This study provides insight into the ways that women engage in leadership and the ways that societal expectations and messages impact female college students' leadership involvement. Interestingly, the authors state a homogenous sample as one of the limitations of the study and as an area for future investigation.

Kolb's (1999) quantitative study of 123 undergraduate students (64 women, 59 men) enrolled in an upper division applied organizational communication course at a large eastern PWI, examined the effect of gender role, attitude toward leadership and self-confidence on leader emergence, which Kolb defined as becoming a positional leader. Reliability coefficients for each of the scales were described as were the procedure for regression analysis. Although no significant differences attributable to biological sex were found in leader emergence, attitude toward leadership was a significant predictor of leader emergence, meaning that individuals (both male and female) with masculine and/or androgynous classifications were more likely to be identified as preferred leaders than leaders with feminine classifications.

These findings have important implications to our understanding the influences that impact leadership development in college students. Given the emergence of relational leadership as the "preferred" way of leading in today's organizations, a further examination of how gender impacts leadership development is warranted. Further research investigating women's preferred and actual style of leadership is necessary to determine whether women college students engage in more "androgynous" behaviors due to expectations of leadership behavior. A finding that Eagly and Johnson (1990) 
concluded in their meta-analysis described earlier. Interestingly, this study used the gender role scale which focuses on stereotypical gender role behaviors and has received much criticism in the literature. One of the reasons this scale is still used is because no other scale addresses gender role implications.

In an attempt to learn more about women student leaders' out-of-class environment, Romano (1996) interviewed 15 women presidents of campus-wide coeducational student organizations on large university campuses. The study was conducted over a five month period and included a purposeful sample of nine European American, three African American, and three Asian American women; one of these women was Jewish and another quadriplegic. This qualitative study provided an understanding of the backgrounds, experiences and peer culture of these women student leaders.

Romano's findings present several implications and key influences concerning women college students' leadership. This study corroborates with Astin \& Leland's finding that strong women influences were important to the participants' leadership development. These findings also support an alignment with the relational and empowering leadership styles presented earlier, collaborative leadership was the preferred style of each of the participants in this study. The impact of peer influence/relationships was of particular importance for the participants in this study. In addition, the participants in this study reported gaining self-confidence and improved communication skills through their experience as leaders thus supporting the implication that leadership is a developmental experience. 
Utilizing the Achieving Style Inventory and the Leadership Practices Inventory Komives (1994) conducted a quantitative pilot study investigating the leadership styles of college women. Participants included 27 women attending a campus-based women student leaders' conference. Pearson correlation coefficients were used to analyze correlations between achieving style and leadership practice and indicated a strong connection between empowering leadership practices and women. The behaviors and values attributed to the inventories that were rated highest for the women in this study included "valuing and empowering others," "contributing to others' success," and "counting on others to accomplish goals". In addition, women self reported their most developed leadership skill as the ability to "enable others to act." Two important criticisms of this quantitative study include the not having a male comparison group, and lack of validation of the participants' leadership behaviors as self assessment techniques were utilized. In addition, further research to investigate the impact of these relational behaviors on leadership and the ways empowering leadership styles are used amongst diverse groups is warranted.

Together, these finding have important implications, first, they provide evidence of the positive correlation between leadership experiences and students cognitive, psychosocial and career development. Second, they corroborate with the general literature on leadership and gender highlighting differences in leadership style and behaviors of college men and women. These studies indicate that women college students prefer to lead from the relational or empowering paradigm. Given this, it is not surprising that the role of mentors and peer influence have a strong role in the leadership experiences of the college women in these studies, nor that gender role expectations 
might influence the leadership experiences of women college students. An investigation of how women college students become leaders and why they are not ascending to leadership roles at the same rate as college men warrants attention. In addition, investigating the impact that women's leadership style and development has on perceived effectiveness, could provide valuable data to address the gap in our understanding of college women's leadership.

Leadership, ethnicity and college students. A few studies have examined the impact of race and/or ethnicity on college student involvement on campus and within student organizations (Arminio et al., 2000; Jones, Castellenos \& Cole, 2002; Kezar \& Moriarty,2000; Guifridda, 2003; Lavant \& Terrell, 1994). As a whole, these studies indicate that the type of student organizations in which the students became involved depended on the students' ethnic background. At PWIs, students from "minority" racial and ethnic groups on campus began their involvement in identity based organizations because it was the place they felt most comfortable, as well as a place where they could connect to other students from their background. In addition, participants in each of these studies indicated a desire to "give back" to their communities as agents of social change. As a whole, this literature indicates that there was not much cross-cultural interaction across ethnic lines on many campuses. Renn and Bilodeau (2007) found that GLBT student leaders' entry point was also through identity based organizations, in their study GLBT student organizations.

Additional research has investigated the ways that ethnicity and/or race impacts college students' leadership. There is much debate in the literature on the correct terminology when referring to race and/or ethnicity. For the purpose of this study, the 
term ethnicity will be used and refers to identification with a segment of a larger society whose members have common origin and share segments of a common culture.

Kezar and Moriarty (2000) utilized the Cooperative Institutional Research Program (CIRP) freshman data from 1987 and 1991 to examine differences in leadership development as it relates to gender and ethnicity. Their sample included 9,731 students at 352 institutions and focused on differences between women and men and African American and European American students. The authors utilized Astin's InputEnvironment-Output (IEO) model of assessing college outcomes as a framework for examining the impact of various college experiences on leadership development. Input includes personal characteristics and qualities individuals bring to college. Environment includes characteristics of a particular institution and outputs refer to the dependent variables being examined. The dependent variables examined in this study included; self-rated entering leadership ability and qualities, communication skills; intellectual and social self-confidence, and ability to influence others. Cross-tabulation and step wise regression analysis were performed on each dependent variable for each population being examined to explore predictors of leadership related qualities.

Their findings suggest that the leadership development process differs among various groups of students and that different strategies should be used in the leadership development of diverse groups of students. Specifically, in relation to gender, both European American and African American men rated themselves higher on leadership ability than European American and African American women. Women were also scored lower than men on each of the leadership related variables, except written communication, at the time of entry to college and again four years later. The rate of 
change on all four constructs between 1987 and 1991 was lower for both groups of women compared to both groups of men. In addition, differences in gender and ethnicity were apparent in the relationship between self-rating on leadership ability and types of curricular and co-curricular involvement. Specifically, participation in a leadership class was a strong predictor of leadership ability for each of the groups except African American men whose strongest predictor was participation in volunteer work and working on class projects.

These findings highlight additional questions such as: Why do men self-rate their leadership ability higher than women? Based upon these findings a better understanding of how leadership is defined by diverse groups of college students, and an enhanced understanding of the factors that influence the development of a leadership identity is justified. The authors suggest further research to explore the ways that the leadership development of students from other ethnic backgrounds might be different.

Arminio et al. (2000) used phenomenological qualitative methodology to investigate the leadership experiences of students from different ethnic backgrounds. Over the course of three years they interviewed, 106 students from two campuses within 35 miles of each other; a mid sized state-supported institution, and a large state-supported research institution. Participants included 22 African American women, 12 African American men, 18 Asian American women, 25 Asian American men, 12 Hispanic women, and 17 Hispanic men of traditional college age (18-21). Snowballing was used to identify the sample. The themes that emerged demonstrated incongruent aspects between these students' leadership experience and traditional notions of leadership and suggested ways that minority students' involvement in leadership experiences may differ 
from European American students experiences. For example; most did not consider themselves a "leader," and disliked the term "leader," felt they were being "watched" by their same ethnicity peers, the administration and European American students, found it difficult to identify a role model within the institution, and articulated a strong ethnic group responsibility for becoming involved. Although these experiences may be common generally for minority students at a PWI, experience in a leadership role may enhance these perspectives as leaders are more "in the spotlight" than the general student population. In addition, women were highlighted as being more relationship oriented in their leadership behaviors. Although the generalizability of this data is limited, it informs our understanding of leadership and provides a rationale for further study.

As women and Hispanics continue to change our college student population demographic, it is increasingly important for institutions of higher education to be better informed about differences in leadership style and development so that our leadership education programs can reflect the diversity of experience, learning and style. In order for this to be accomplished, we must also develop an understanding of how women and students of different ethnicities develop their identities.

\section{Identity Based Institutions}

Some of the literature on leadership and college students examines the impact of women's colleges and minority serving institutions (MSIs). For the purpose of this paper, I highlight the positive aspects of MSIs but recognize that criticisms related to the limitation of single gender/ethnic environments, exist. Research has demonstrated that these environments can be powerful and nurturing to students' learning and provide shelter from the effects of ethnic and gender discrimination (Bridges, Cambridge, Kuh \& 
Leegwater, 2005; Fleming, 1984; Kinzie et al., 2007; Pascarella \& Terenzini, 2005;

Whitt, 1994). Astin (1993) found that women attending women's colleges exhibit greater gains in cognitive and psychosocial development and engage in educationally purposeful activities at a higher frequency and breadth.

For example, Gonzalez (2008) compared the civic development of Cuban American and non-Hispanic White students at an HSI in his qualitative case study. Individual interviews, focus group interviews and observations were conducted over an eight month period. The purposeful sample for in depth interviews included 14 (6 female, 8 male) Cuban Americans, and 15 non-Hispanic Whites (9 female, 6 male), all of whom were second year students. His research found no difference in the civic engagement and development of these two groups. Gonzalez suggests that because of the particularity of the community in which the university resides, "transculturation" has occurred in which non-Hispanic whites have integrated with the dominant Hispanic culture of Miami, through this both groups have adapted to each other and share power within the community. This study was limited in that it is bounded to the experiences of the students in their context.

Using data from the National Survey of Student Engagement (NSSE), Kinzie et al. (2007) conducted an analysis comparing the experiences of women attending women's colleges with those of women attending coeducational institutions from random samples of female first-year and senior students from 26 women's colleges and 264 other four-year institutions. The data was nested, and the researchers intent was to estimate institutional effects, therefore hierarchical linear modeling (HLM) was used to analyze the data. Their analyses indicate that women attending women's institutions exhibit 
greater self reported gains in their academic, intellectual and leadership development. Additionally they found that women's colleges appear to support women's development and understanding of self and others. They posit a less paternalistic culture, the removal of competition with men and traditional gender role expectations, and the presence and involvement of women role models as contributors to these outcomes.

To further demonstrate, the authors reference the fact that graduates of women's colleges constitute more than $20 \%$ of women in congress and comprise $30 \%$ of a Business Week list of rising women stars in corporate America. Three limitations were found in this study; only 26 of 68 women's colleges were included, the instrument used in the study reflects self-reported gains, and ethnicity was not a factor discussed.

In addition, Whitt (1994) in her qualitative research conducted via 200 interviews with students (98), faculty (36), administrators (48) and alumnae (18) at three women's colleges, found the following to positively impact college women's leadership development; a mission focused on the education and development of women, high expectations for achievement, the involvement of female role models, and extensive leadership opportunities.

Fleming's (1984) influential work on Historically Black Colleges and Universities (HBCUs) found that these institutions are more effective in developing the skills in African American students that help them; become responsible citizens, develop high aspirations, and thrive in competition.

Approximately $45 \%$ of Hispanic college students are enrolled in HSIs (Stearns, Watanabe, \& Snyder, 2002), however there are few published studies that focus on the experiences of these students (Bridges et al., 2005), some of which have already been 
discussed. Research on the impact of HSIs commitment to developing Hispanic women student leaders would add to our understanding of the ways leadership programs can develop a diverse group of students who have awareness of the historical context of power relations.

This research provides evidence that MSI's commitment to the education of people from underrepresented groups in our society may provide students more support to assume leadership, reward collective achievements, and move beyond traditional gender role expectations. These findings warrant additional research to further elucidate on the topic.

\section{Exploring Identity}

Identity development theory is one theoretical tool practitioners rely on to understand diverse populations. Identity refers to the sense of self that one possesses and is developed within the context of societal constructs related to ethnicity, gender, culture, social class, sexual orientation, and differing abilities. As students develop these multiple identities, they grapple with the expectations society has of these groups (Erikson, 1968). Development occurs when there is a shift between what an individual thought she "knew" and a new possible "truth." Scholars refer to this phenomenon as cognitive dissonance and the resolution of this conflict as identity development (McEwen, 2003).

Students in marginalized groups have lived in a society with overt and covert messages of discrimination, a lack of power, and perceived unworthiness which underlie their identity development and teach them what it means to be "other" (Cross, 1995; Helms, 1990; Josselson, 1987; Kinzie et al., 2007; Phinney, 1993). 
While Erikson and his followers focused on identity development of European American males, research has challenged the existing developmental theories derived from studying people from traditional orientations of power; White, male, upper middle class. Collectively, this research suggests that the construction and self-perception of identity is not singular in nature but is rather the intersections of ethnicity, gender, culture, social class, sexual orientation, and ability (Chickering \& Reisser, 1993; Helms, 1990; Jones, 1997; Jones \& McEwen, 2000; Phinney, 1990; Torres, 2003; Torres \& Baxter Magolda, 2004). The increase of Hispanics in the United States, and women and Hispanics within our institutions of higher education, coupled with their lack of ascension into leadership roles, demonstrates the importance of preparing college women, and Hispanic women in particular, for leadership roles. In order to be effective in developing and preparing Hispanic college women for leadership roles, we must consider how the formation of identity impacts Hispanic women's sense of self and the possible implications of this on their leadership identity development. Increasing our understanding of Hispanic women's leadership identity development process, specifically whether these two parts of their identity, gender and ethnicity, impact their leadership identity development is critical to support their progression as leaders and insure general identity and leadership theories are inclusive of all.

\section{Identity and Gender}

During the last three decades several studies have investigated the experiences of women's gender identity development (Baxter Magolda, 1992; Belenky et al., 1986; Gilligan, 1982; Josselson, 1987). As a body of knowledge these studies corroborate that women's gender identity develops within the context of a society in which women, as a 
group, have been oppressed, and evolves from an external definition of what it means to be a woman to one that is personally constructed (McEwen, 2003). During this developmental process, events trigger individuals to question traditional gender roles which cause an exploration of what it means to be a woman from the individual's perspective (Jones, 1997; Josselson, 1987; McEwen, 2003).

An overview of the research on women's identity development provides overwhelming evidence that women develop and gain a sense of identity in a context of connections with others and that women's sense of self is organized around building and maintaining relationships (Belenky et al., 1986; Chickering \& Reisser, 1993; Gilligan, 1982; Jones, 1997; Josselson, 1987). One of the first and most influential studies to provide a foundation for our knowledge on the identity formation of women is Gilligan (1982). In three separate qualitative studies exploring women's identity and moral development, Gilligan documented that women's sense of self centers around the understanding of responsibility and relationships, and that women are more likely to preserve relationships than to pursue personal objectives. Participants in Gilligan's college student study included 25 students chosen randomly from a course on moral and political choice. The sample from "the abortion decision" study included 24 women, diverse in age, background and social status, referred through pregnancy counseling, who were interviewed a second time one year later. A third study was conducted to follow up on the theme of "rights and responsibilities" and included 144 participants (72 women, 72 men). Although information about participants is descriptive, Gilligan does not include specific information about data analysis procedures. 
Since Gilligan's prominent work, some research has authenticated her findings. For example, Belenky et al. (1986) explored women's intellectual development through in depth interviews and a case study approach with 135 college students and recent alumnae from nine different academic institutions and human service agencies that support women in parenting. They note selecting a "diverse" sample of women across age, ethnicity and social class. In addition, Belenky et al. (1986) provide a rich description of data collection and analysis methodology allowing easy replication for follow up study. Their findings indicate that women's identity of self and ways of knowing are intertwined. Specifically, women's sense of self as an intellectual being revolves around the need for belonging and confirmation of self as capable of intellectual thought to become engaged and be successful in an intellectual community.

In addition, Josselson's (1987) phenomenological, longitudinal study considered 48 college educated women's identity development over the course of 14 years and found four different identity-status groups. This study included two samples; one dataset was drawn at random from the senior class lists of three institutions: a large coeducational private university, a large, coeducational state university, and a private exclusive women's college yielding a cross-sectional representation of college women in their senior year, interviewed in 1973. The data from twelve women from a large state university who were selected using the same methods and were interviewed two years prior, were also included. Follow up interviews were conducted with 34 of the total sample between 1983 and 1985. Josselson's explanation of data collection and analysis is transparent, making her study easy to replicate in another context. 
Josselson found connection and relationships with others important in these women's development and life choices. Consistent with the findings of Gilligan (1982) and Belenky et al. (1986), Josselson's results indicate that for these participants identity development occurred through the relationships developed with others. These women defined their internal experience of self through their relationships with others. Five themes emerged from her data. The first theme, "separation-individuation," related to distance from home and the struggle to become different yet maintain connection. Although separation-individualization has been described along agentic characteristics as moving toward separateness, for women, the dilemma is about becoming different while maintaining connections. Josselson found that the women in her study sought to reconnect after separating from their parents, to either her primary family (husband/children), career or friendship, and referred to this process as "anchoring," the second theme. Through these relationships the outside world is integrated with the self. Interestingly, all of the women whose anchor was their career had mentors. Relationships for these women were used for inner psychological functioning in a "web of relatedness," the third theme, the confidence the participants had in their ability to take care of themselves emotionally had intense consequences on their identity formation. The fourth theme "openness to growth and change" demonstrates the severe influence that tolerance and uncertainty had on these participants identity formation. The importance of interpersonal relationships in work life in relation to mastery of skills and competency framed the last theme "working and loving."

This study focused on college educated women, tracking their identity development from late adolescence through adulthood and thus provides important 
foundation to studying the ways in which women might develop other aspects of their identity.

In their influential work on college student's identity development, Chickering and Reisser (1993) highlighted differences between men and women college students, stating that women have a greater capacity for tolerance which they noted as important given the skills it provides for dealing with ambiguity, difference, diversity and discrimination. These qualities have also been highlighted as positive to leaders (Kouzes \& Posner, 2002; Northouse, 2007).

These characteristics and experiences of women provide a foundation that positions them to be successful within the relational paradigm of leadership. The ability to relate to others, to exhibit tolerance, to develop relationships with and amongst people, to incorporate diverse individuals with differing experiences and backgrounds, and to form consensus by bringing together these diverse perspectives, are critical to effective, culturally sensitive, and socially responsible leadership. These findings have implications for our understanding of women and leadership and provide a context to help young women develop and enhance awareness of their leadership skills. Even more importantly awareness of power relations and a better understanding of the role societal expectations and messages have played in the process of identity development can inform our understanding of leadership development and enhance the ways in which we facilitate leadership development within our institutions of higher education. In order to be effective in this realm we must first develop an understanding of any implications gender and ethnicity may have on the leadership identity development of women students. The majority of these studies focused on European American women, developing an 
understanding of the gender identity of Hispanic women, and the ways that they develop a leadership identity is important if we are to be effective in developing leadership programs that are inclusive. Therefore, future study examining how Hispanic women college students develop their identity and the experiences that contribute to their leadership identity development are critical.

\section{Identity and Ethnicity}

A growing body of empirical research has investigated students' ethnic identity development (Alvarez, Bliss, \& Vigil, 2001; Cross, 1995; Helms, 1990; Jones, 1997; Phinney, 1993; Torres, 2003; Torres \& Baxter Magolda, 2004). Similar to the literature exploring gender identity, research on ethnic identity suggests that critical experiences prompt exploration into an individual's ethnic identity. An overview of this literature demonstrates identity development is influenced by systems of privilege and inequality. For students from historically oppressed groups, exposure to prejudice prompts them to recognize that identity is socially constructed within a European American dominated context and to reconstruct their social knowledge of what it means to be "other" to one that is more meaningful to their personal experience. Again, identity formation is a result of resolving dissonance between previously held beliefs and new knowledge (Helms, 1990; Jones \& McEwen, 2000).

In discussing the identity formation of Hispanic students, this issue is even more complex as great diversity in geographic region and experiences exists among the Hispanic population. Hispanic is the preferred term used by the U.S. government for census and other purposes and refers to a diversity of peoples including Puerto Rican, Cuban American, Caribbean American and Central and South Americans. Torres (2004) 
states that while Hispanic countries of origin share aspects that link peoples to a common group identity; mainly a history of Spanish colonization, and hence language, and a shared sense of community and dedication to family, differences in immigration patterns and experiences in the U.S delineate unique research findings.

For example, building upon an earlier study by Alvarez, which identified the theme "paradise lost" an integral factor to the identity development of Cuban American college students in Miami, Florida, Alvarez, Bliss and Vigil (2001) interviewed three additional students to explore patterns of differences and commonalities in the constructions of Cuban Americans identity. Their findings indicate that these students had a sense of connection to Cuba and did not feel fully accepted in the U.S. Their internal struggle to feel accepted within the U.S. came from the juxtaposition of how they believed society defined them. Power relations were a strong factor in their ability to be accepted. Although the methodology of the first study was not discussed, for the purpose of this qualitative study the three additional participants were each interviewed for one and a half hours. The limited data in this study suggests that more research needs to be done.

In addition, Torres (2003) conducted a study using grounded theory methodology to investigate the influences on college students' ethnic identity. She used open sampling techniques which yielded 10 Hispanic female and male students in their first year at a highly selective college; these students were interviewed over the course of two years. Torres pointed to the lack of research investigating the diversity of Hispanic students experience as a rationale for her study and commented that as a longitudinal study, it is the first installment on the theory building process. Torres' methodology is well 
documented in her writing and therefore could be replicated in the context of another institution. Her findings yielded two categories that affected the participants ethnic identity development; (a) situating identity, which included home environment/influence, generation in the U.S, and perception of societal status; and (b) influences of change, which included level of cultural dissonance and the change in the relationships the participants were involved. Although these findings are limited to the context of, and participants in this study, the study provides an in depth understanding of the experiences that impacted these students' ethnic identity development and considers the context in which an individual's ethnic identity develops as well as the relationships that impacted these students development and should inform future study.

While the research of Jones (1997) and Jones \& McEwen (2000) precedes the work of Torres, it is presented at the conclusion of this section as it is larger in its multidimensionality and most directly shapes my view in regards to identity development of women and students from different ethnicities in college. To further elucidate, Jones (1997) used grounded theory methodology to investigate the multiple dimensions of identity development and difference among 10 diverse women college students enrolled in a large East Coast university. Purposeful sampling techniques were used to find participants who were diverse by ethnicity, ability, religious background and sexual orientation. Her research uncovered the core, "contextual influences on the construction of identity,” (Jones, p. 379) with 10 key categories defining these influences. The data indicate the interaction of the following categories critical to understanding multiple dimensions of identity; relative prominence of identity in relation to diversity, the multiple ways in which race matters, the interconnection of gender with other 
dimensions, the significance of culture, the influence of family and background experiences, current experiences and situations, values and personal beliefs, career decisions and future planning, and the search for identity. Interestingly, Jones's findings indicate that students who are most privileged in our society understand the systematic influence of privilege and inequality least. Jones's description of her study and methodology is transparent and would be easy to design within the context of other institutions. Her findings suggest further investigation on the complexities of identity development.

Based on Jones's (1997) research, Jones and McEwen (2000) presented a grounded theory model of the multiple dimensions of identity. At the center of this model is a core sense of self with intersecting circles representing the significant factors; ethnicity, sexual orientation and religion, and contextual factors; family background and life experience. Although gender was an identity dimension that each of the women related to, they quickly connected the description of what it meant to be a woman to other dimensions (ethnicity, orientation). Although the overlapping circles suggest the evolving nature of identity and the changing salience of the various multiple identities, it is cumbersome to understand and articulate; further research will assist in developing these concepts, and an enhanced understanding of these concepts could add to our understanding of how these factors affect the identity development of women.

These studies found factors such as family background, peer groups, experiences with prejudice and the importance of connecting with one's history and heritage contributing to women's ethnic identity development. In addition, research demonstrates that the college experience is a significant influence in the development of college 
students (Chickering \& Reisser, 1993; Kuh et al., 1991; Pascarella \& Terenzini, 2005).

Combined, this knowledge indicates a need to incorporate the multiple dimensions of gender and ethnicity into our work with college students. In addition, the studies where ethnicity was a factor, indicate that systems of privilege and inequality were least understood by those who are most privileged in society, indicating a need for developing this awareness in our leadership programs.

\section{Identity and Leadership}

Despite the broad scope of research on leadership theory, behaviors and effective practices, scholarship on the ways that leadership develops, or how a leadership identity develops over time is sparse. To uncover this phenomenon, Komives, Owen, Longerbeam, Mainella and Osteen (2005) used grounded theory methodology and interviewed 13 students who showed evidence of relational leadership practices using a structured "three-interview series" protocol. The results were analyzed using open, axial and selective coding. The data revealed that these students viewed their leadership identity development as a progression from a leader-centric view to a more collaborative, relational process. Six stages of leadership identity development were identified; (a) an "awareness" that leadership is happening around me, (b) "exploring" and "engaging" in leadership, (c) "identifying" what it means to be a leader, (d) "leadership differentiated" in which leadership begins to be viewed as a group effort, (e) "generativity" or taking responsibility for the self and ones personal passions and (f) "integration" or leadership as a lifelong process. The research indicated all essential for each stage; adult role models, peers, meaningful involvement, and reflective learning as impacting students progression as leaders. These influences resonate with themes found in the identity 
formation of women, specifically the importance of relationships in the ways women make meaning of their experiences.

In a follow up article, Komives, Longerbeam, Owen, Mainella and Osteen (2006) further describe the stage based model of leadership identity development (LID). Consistent with other research shared in this paper, Komives et al. (2006) found mentors to be a significant influence as students emerged from one stage to the next in the LID model. This finding was particularly true for the students of different ethnic backgrounds in Komives et al. original study. In addition, Renn and Bilodeau (2006) used the LID model to identify experiences that supported lesbian, gay, bisexual and transgendered students' growth as student leaders. Participants included a purposive sample of 15 LGBT-identified student leaders and activists from three institutions in the Midwest. The authors used open-ended interviews and applied the LID model to the data. Their results indicated that for these participants, involvement in LGBT student activities provided plentiful opportunities for development in each of the model's stages. Limitations to these studies include the use of students who were defined as exhibiting relational leadership behaviors who had formal group involvement. In addition, more research on diverse groups of students is warranted.

\section{Conclusion and Implications}

As demonstrated earlier in this paper, although many researchers have studied leadership, until recently the topic of leadership and women, especially women from different ethnicities, was rarely addressed in empirical research. In addition, our understanding of how these differences relate to the development of identity is still evolving. Research indicates that for women and people from different ethnic 
backgrounds, the development of identity includes reconstructing their social knowledge of self to be more personally situated. How this process occurs in the development of a leadership identity should be explored. As stated earlier, women and Hispanics are changing the demographic of higher education and our society in general. Our patriarchal and European American centered system in which European American men hold the power and exert more influence has impacted how we define leadership, how we study and measure it, the symbols and metaphors we apply to it and the way we practice leadership. Women are underrepresented in leadership roles, especially those that provide substantial authority over people not because of abilities but cultural oppression.

The evidence presented in this chapter demonstrates the impact of leadership programs and involvement on students' cognitive and psychosocial development and the relationship of these programs to educational outcomes such as interpersonal skills, multicultural awareness, civic responsibility and career success. The research presented in this literature review also suggests that the various identities to which one ascribes, ethnic, gender, orientation and ability, lay a foundation for leadership development and that leadership development processes may differ among various groups of students. To understand Hispanic women college students' leadership development, it is important to understand the context in which Hispanic women leaders operate, and the factors and strategies that support or hinder their leadership development. As educators continue to understand this process, we will be better situated to design leadership programs that assist institutions of higher education in achieving their mission: to create a diversity of civically minded leaders who can initiate change. 


\section{Summary}

As evidenced in this review of the literature, research indicates that the college years are a critical period in the personal, social and professional growth of people (Astin, 1985, 1993; Kuh, Schuh, Whitt, Andreas, Lyons, Strange, Krehbiel \& MacKay, 1991; Kinzie et al. 2007; Pascarella \& Terenzini, 2005; Pascarella et al., 1997). Given the increasing accountability on institutions of higher education to prepare college graduates who are prepared for an interconnected world in which they will deal with major economic, societal, and environmental issues; it is important that colleges and universities be intentional in developing leadership programs, based on an understanding of power differentials, that incorporate our diversity across gender and ethnicity, and instill values and skills for effective leadership in a global environment. Preparing individuals who are capable of this kind of complex thinking, leading and relating requires engagement in purposeful curricular and co-curricular leadership experiences which promote self-authorship, understanding across differences, and critical thinking and interpersonal skills.

In order for institutions of higher education to be effective in this realm we must increase our understanding of how different students develop as leaders, the factors that contribute to the progression of their leadership identity and differences that exist in leadership style amongst diverse groups of students. Specifically, there is a gap in the literature addressing the experiences of Hispanic women college students' leadership style and development. An understanding of these students' developmental challenges and experiences will provide rich data to inform practitioners as they create curricular and co-curricular leadership programs. 


\section{Chapter III}

\section{Methods}

This chapter outlines the methods used in this qualitative case study and identifies the theoretical framework that served as its foundation. The role and background of the researcher and the personal foundation from which the motivation of this study came is also described. The research questions and sources of data are explained as well as the selection of participants and a description of the setting. Interview methods are detailed and the treatment of data collection is outlined followed by a discussion of the process that was used to analyze the data.

As previously noted, Relational Leadership represents a more current paradigm in leadership. As one of the main roles of higher education in America is to develop future leaders (Astin \& Astin, 2000; CAS, 1999), research on college student leadership has given rise to a number of models of leadership and/or leadership development that focus on Relational Leadership. The most notable in the scholarship are the Social Change Model of Leadership Development and the Relational Leadership Model (Dugan, 2006). These models offer an approach to leadership that can be used in teaching and developing leaders, but do not address how a leadership identity develops. The Leadership Identity Development (LID) model conceptualizes the process that college students move through as they come to recognize themselves as leaders. The LID developed from grounded theory, and includes six stages of leadership identity, based on social and personal values and an awareness that through collaboration change can be accomplished (see Figure 2). Although Komives and her colleagues developed this model 5 years ago, only one published study, discussed earlier in this document, investigating lesbian, gay, bisexual 
and transgender (LGBT) students' leadership development (Renn \& Bilodeau, 2006), has attempted to explore this model and add to the foundation of literature. Although these studies attempted to include a diverse group of college students, they were conducted at PWIs. As discussed in the literature review, students' experiences at PWIs and MSIs can be markedly different (Astin, 1993; Bridges, Cambridge, Kuh \& Leegwater, 2005;

Fleming, 1984; Kinzie et al., 2007; Pascarella \& Terenzini, 2005; Whitt, 1994). An area that researchers have overlooked regarding college student leadership identity development is the role that gender, ethnicity and enrollment at an HSI might have on students' leadership development.

\section{Research Questions}

The purpose of this study was to investigate this gap and inform educators about the leadership identity development of Hispanic women students at an HSI. Specifically, the exploratory questions that guided this study were:

1) How do Hispanic women college students at an HSI develop an understanding of leadership?

2) In what ways are Hispanic, women college students leadership identity development similar and different?

3) From their perspectives, what influences contribute to their leadership identity development?

4) How do Hispanic woman college students describe the impact of other aspects of their identity (i.e. gender, ethnicity) on their leadership identity development? 
5) Do the ways in which these women describe their leadership identity development align with the process described in the LID model? If so, in what ways are they similar and/or different?

The LID framework and Relational Leadership theory were utilized as a foundation for this study. Specifically, Relational Leadership theory focuses on leadership as a socially constructed paradigm that is exhibited through the relationships we value and the LID model outlines the meaningful experiences and relationships that impact college students as they develop a leadership identity. The intent of this study was to understand the experiences, influences, and relationships that a selected group of Hispanic women students shared as important to their leadership identity development. Therefore the interview protocol focused on discussion of meaningful experiences, relationships and influences. The research questions and interview protocol used in this study were derived from the protocol used in Komives et al. (2005) study. As the LID serves as a framework for the study, it was compared with the data from this study as the final stage in data analysis. The stages and categories of the LID were compared to the data analysis in this study to ascertain any similarities and differences and the findings of this analysis are shared in chapter 6.

Although the LID framework (Komives et al., 2005) was used as a foundation for this study, it was used with three cautions in mind. First, as Merriam (2002) suggests, the purpose of this qualitative case study is to understand processes, describe phenomena, understand differences between stated and implemented policies or theories, and discover unspecified contextual variables. Therefore, I did not assume that this framework would "fit" the experiences of the participants in this study. Second, I recognized the limitations 
of using a stage-based model as a framework as stage based models assume homogeneity of experience and indicate a possible deficit in participants who never achieve the "optimal" end point. Third, many stage based models are developed on primarily the European American population and thus may ignore the results of oppression. This is one of the reasons I believe this study was so important. Given this reality, the model was used as a starting point to frame the study but the data revealed whether comparisons could be made between the participants in this study and the studies from which the LID model developed.

\section{Qualitative Inquiry}

As demonstrated in the literature, the construction and self-perception of identity is not singular in nature and is influenced by such dimensions as gender, ethnicity, culture, social class, sexual orientation and abilities (Jones \& McEwan, 2000; Torres, 2003). This study describes the experiences of women student leaders at an HSI and adds to the growing literature combining the dimensions of gender, ethnicity, and leadership identity development. The constructivist paradigm served as a guide as I listened to understand how these students experienced the multiple dimensions of identity in their leadership identity development. This approach also reminded me to not presume what is most central to these women but to listen for how each participant viewed herself, as a Hispanic woman and student leader.

In order to discover the ways that a selected group of Hispanic women college students at an HSI developed their identity as leaders, this study examined the experiences of 11 Hispanic women student leaders at an HSI in the southeast. Because my goal was to explore Hispanic women's leadership identity development, qualitative 
inquiry was the research approach that provided me with the in depth and rich data required to understand the participants' views. Merriam (2002) provides context for why qualitative research is more appropriate to some research projects by stating that "meaning is socially constructed by individuals in interaction with their world," and that qualitative research provides a context to "learn how individuals experience and interact with their social world, and the meaning it has for them" (Merriam, p. 3).

\section{Case Study Design}

Case studies can be quantitative or qualitative in design (Stake, 1995). Since the purpose of this study was to understand the essence of the lived experience of leadership identity development through the voices of Hispanic women in a particular context, the constructivist approach through a qualitative case study in a bounded setting design was used as the study's methodology, and therefore the study followed case study data collection and analysis procedures or methods (Patton, 1990). According to Stake (1995), a case study is expected to catch the complexity of a single case. The case studied in this research was a selected group of 11 Hispanic women college student leaders at FIU, a 4-year, Hispanic serving, research extensive state university located in Miami, Florida. FIU was chosen because of its status as an HSI and its proximity to the researcher. HSIs are defined by the reauthorization of the Higher Education Act, as amended in 1992, as those 2- and 4-year colleges and universities with $25 \%$ or more total undergraduate Hispanic full-time equivalent (FTE) enrollments.

\section{The Setting}

FIU is a large, urban university with a predominately Hispanic population. In fall 2007 FIU had over 38,000 students enrolled, 59\% of total undergraduates enrolled at FIU 
identified themselves as Hispanic and 56\% identified themselves as female.

Interestingly, only $17 \%$ of the faculty was Hispanic, $50 \%$ of them were women. Also, $25 \%$ of the full time staff self reported as Hispanic, $66 \%$ of them were women. As stated previously in this paper, research has demonstrated that MSIs can be powerful and nurturing to students' learning and provide shelter from the effects of ethnic and gender discrimination that can be prevalent in an individual's construction of identity at a PWI (Astin, 1993; Bridges, Cambridge, Kuh \& Leegwater, 2005; Fleming, 1984; Kinzie et al., 2007; Pascarella \& Terenzini, 2005; Whitt, 1994).

\section{Role of the Researcher}

A unique quality of qualitative research is the role of researcher as the instrument of data collection (Creswell, 1994). In this study I played a critical role in connecting the voices of these students as they shared their leadership identity journey. Together we created the story of how these Hispanic women students, in this context developed a leadership identity; such is the constructivist approach to meaning making. My role as researcher was to seek deep meaning, utilize the voices of my participants to paint a picture, and protect and validate the transfer of knowledge so that it is communicated in a way that increases the likelihood that readers will form an understanding similar to that which I intended. The process of triangulation (Patton, 1990), described later in this chapter, was used to reduce the likelihood of misinterpretation.

\section{Researcher Subjectivity}

One area I had to pay close attention to was researcher subjectivity. My experience in higher education, my educational background, and the choices I have made as a professional influenced my decision to choose this topic of research. In addition, my 
own philosophy, which views leadership as a process in which individuals engage together to create change, influenced my decision to approach this topic. I obtained my master's degree in Higher Education Administration with a focus in Student Affairs in 1995 and during the past 15 years have held a variety of roles as a Student Affairs professional. My perceptions of this topic were influenced by my formal educational preparation and my professional experiences. I have held a variety of positions at FIU during my 10 year tenure. As the director of the Women's Center at FIU, I am responsible for developing programs and services that enhance the personal and educational experiences of our female students and for bringing awareness regarding issues of gender. Many of our programs seek to develop women as leaders in their communities as well as to bring awareness about the impact that gender has on leadership development. In addition I teach WST 4930/5931 Women and Leadership, a course I designed with the intent of developing awareness about the scope of gender and leadership in our society today. I interact with a number of female leaders. I am involved with their lives, their passions, and I am continuously intrigued by their interest in serving their university and their organizations in a leadership capacity.

This is where my interest in studying women student leaders derives and while some may see this involvement as having the potential for bias in data interpretation, I believe that my familiarity with the topic, the context and the student population was an asset as it facilitated the opportunity for me to delve deeply and ask questions that brought out abundant details from participants. Bogdan and Biklen (2007) do caution the researcher about conducting research in one's own "backyard" as participants may have difficulty viewing the researcher as neutral and may thus have a hard time opening up. 
Based upon my experience first in a pilot study as well as with the remaining participants, I believe that my knowledge and understanding of students, the context and student development theory, as well as my reputation as an administrator supported me in developing positive and comfortable rapport with every participant resulting in open communication and confidence in the process. This notion is supported by the constructivist paradigm which views truth as subjectively determined by an individual's social experiences (Merriam, 1998).

However, it was important to me to manage my own subjectivity which I did utilizing the researchers' journal also described later in this chapter. While reflecting in my journal I paid attention to how I reacted when students "tested" me by sharing thoughts to which they thought I might have had a reaction. Indeed, there were times when it was difficult to maintain composure or not respond to the information as an administrator. At the conclusion of one participant's second interview she asked if we could talk about something not related to the interview. I asked her if she would feel more comfortable scheduling a time with me when I was in the office to separate this role from my administrator role, but she declined stating she thought it was better to talk now. I turned off the recorder and we talked, she thanked me after. In response to these potential issues, it was important that my participants not be women student leaders with whom I have an established relationship, which is why my sampling methods did not include women who are involved in Women's Center programming and leadership. Even so, because of my visibility, most of the participants knew of me to some extent. In addition, I am not Hispanic, and students at FIU know me in my role as administrator more than my role as graduate student, therefore the potential existed for 
me to be viewed as an outsider. Although there is debate over the strengths and challenges about a researcher being either an insider or an outsider within a community, I believe that my experience within the context afforded me the ability to utilize the positive aspects of being both an insider and an outsider as I was able to maintain a reasonable degree of objectivity while still developing the rapport and trust necessary to elicit rich data. Utilizing member checking and a peer review process also increased the likelihood that I accurately reflected the voices of my participants.

Although my peer reviewer is also not of Hispanic descent, she has considerable experience with the context of Miami and FIU and is a skilled professional with over 18 years of experience in the field. My peer reviewer also recently attained her EdD, so she is experienced with the process of writing a dissertation and with this knowledge she examined six of the transcripts that did not contain my comments from the data analysis phase and assisted me with editing various components of my dissertation. Because of her combined educational background and experience in the field of student affairs, I found her insight, opinions and feedback helpful to me as I analyzed and interpreted the data. The consistency between our interpretations lends credibility to the findings. Recognizing and setting aside my pre-conceptions or learned feelings about Hispanic women's leadership identity development may be difficult, but utilizing member checking and a peer reviewer helped me to monitor these held values.

\section{Pilot Study}

Prior to the study, I conducted a pilot study as an initial tool to help me develop the individual interview questions, hone my interview skills and search for topics for questioning or topics that might be relevant to Hispanic women students' leadership 
identity development. The pilot study was conducted at FIU in the spring of 2009, before the actual data collection stage began in the summer of 2009. Three participants were identified in the same manner that the actual research participants were chosen (defined in the data collection section). I interviewed each of them following the same protocol described later in this chapter and followed up when necessary. The information ascertained from these participants was included in the actual research and the three participants also engaged in the focus group at the end of the study. The pilot study was limited in scope, but helped to clarify the interview questions and provided the initial areas to address which included: (a) relationships, (b) the impact of being a majority, minority, (c) leadership as an opportunity to develop myself, and (e) making meaning of involvement experiences. Each of these areas was discussed within the literature review. As indicated, each pilot participant was selected based on the same criteria as other study participants. Two semi-structured interviews were completed with each woman to gather data that would be helpful before commencing with the other participants. As anticipated there were several things that occurred during the pilot study that I found helpful to the larger study. For example, in addition to several areas of interest emerging which helped to guide future questions, I found that many of these students did not consider themselves a leader, expressed that although they understand that gender and ethnicity impacted past generations leadership opportunities, they did not "see" or experience this impact with their peers, and when/if they did they expressed that their gender impacted their leadership identity development more than their ethnicity. In addition, the pilot study participants did not initially define their ethnicity as Hispanic, but rather by their country of heritage (i.e., Dominican Republic, Cuban American, etc.). 
This knowledge allowed me to delve further into these topics as questions were reworded, and additional questions were asked with the other participants during the individual and focus group interviews. The pilot participants reflected on their life and involvement experiences, their thoughts and beliefs and were able to articulate what it meant to be a Hispanic woman college student and leader at a Hispanic Serving Institution. This experience helped them tell the story of how they came to develop a leadership identity.

The pilot study helped me refine the line of questions I had developed. I became more confident in my interviewing abilities, more conversational with my participants and in exploring different aspects of their experiences as leaders; I was able to delve more intentionally into the areas of interest that emerged from the pilot study. Therefore I was able to focus on these specific areas as well as the implications of their leadership identity development. The pilot study enabled me to shape the interview questions to explore the complexities and uniqueness of Hispanic women leaders attending an HSI through many lenses, including gender, ethnicity, and psychosocial development.

\section{Data Collection}

\section{Sampling}

This study employed purposeful sampling procedures of intensity sampling to solicit participants who represented the diversity of positional and non-positional leadership roles and thus identified "information-rich cases that manifest the phenomenon

of interest intensely, but not extremely" (Patton, 1990, p. 171). Positional was defined as a student who held a defined position within an organization (i.e., President, Marketing liaison) and non-positional was defined as a student who held membership in an 
organization on campus. For the purpose of this study, organizations were loosely defined to include student government, campus student organizations, student athletes, resident assistants, orientation staff or Peer Advisors, groups affiliated with the institution's leadership programs, and sororities. Three criteria were established for participation; identification as a woman, of Hispanic descent, currently enrolled as a student at the institution, and being involved (i.e., member or position of leadership) with one of the aforementioned groups. Although identifying as Hispanic was a criterion for participation in this study, participants were not asked to identify their specific Hispanic heritage (Cuban, Columbian, Dominican) prior to the first interview as discovering any uniqueness in these students' experiences was part of this study's process. University administrators who advise these leadership areas were asked to identify individuals whom they believed best represented these criteria. The email that was sent to administrators is located in the Appendices (see Appendix A).

\section{Participants}

Research participants consisted of 11 Hispanic women students at FIU who were involved in leadership opportunities at FIU. Johnson and Christensen (2004) recommend $10-15$ participants for studies with in-depth interviews. However, Patton (1990) references the lack of rules for sample size in qualitative inquiry stating that finding a "saturation" point is the goal in this type of design. Therefore, finding the saturation point ultimately determined the number of participants involved. The participants ranged in class standing as some were just completing their first year of college and one would graduate in fall 2009. The students were mostly traditional aged college students between 18 and 23 years old. In selecting the participants, I sought to select a sample 
that represented a diversity of "involvement" categories so that the experiences of students at various stages of involvement with and understanding of leadership were heard (i.e., positional, non-positional, involved for many years, and first time being involved). A target of 5 - 8 positional and 5 - 8 non-positional leaders was determined for the purpose of this study. In addition, participants who represented a diversity of Hispanic backgrounds were desired so that these students' experiences could be revealed, compared and analyzed. Due to the diversity of students from Hispanic origins at FIU, this was easily attained. The profiles of participants, including a description of their ethnicity, are presented Table 1.

Finding an equal number of students who represented the "positional" and "nonpositional" definitions posed some difficulties. As the interviews took place in the summer 2009 each of the participants had been enrolled at FIU for at least two semesters. Upon completion of the pilot study and interviews with the first group of participants, I realized that none of them fit my "non-positional" leader definition. At that time I sent another email to university administrators asking if any could recommend involved students who fit my "non-positional" leader definition, each of them shared the difficulty in this as most of the students they interacted with had begun to engage as "positional" leaders during the spring semester. I then used the snowball sampling technique, asking participants themselves to recommend students who fit this "non-positional" involvement definition. While snowball sampling is considered a form of purposive sampling, it is often useful when trying to find representatives from a population that is hard to identify (Johnson \& Christensen, 2004). A strength of snowball sampling is the shared interests between participants and the person recommended, as it is human nature to associate with 
Table 1

Summary of Participant Demographic Information

\begin{tabular}{|c|c|c|c|c|c|}
\hline Pseudonym & Age & Major & Classification & Country of Birth & $\begin{array}{l}\text { Leadership } \\
\text { Status }\end{array}$ \\
\hline Alissa & 21 & $\begin{array}{l}\text { Human } \\
\text { Resource }\end{array}$ & Senior & Mexico & Experienced \\
\hline Claire & 18 & $\begin{array}{l}\text { Journalism \& } \\
\text { Social Work }\end{array}$ & Sophomore & United States & Intermediate \\
\hline Cynthia & 22 & $\begin{array}{l}\text { Philosophy \& } \\
\text { Psychology }\end{array}$ & Senior & United States & Experienced \\
\hline JLo & 19 & Nursing & Sophomore & United States & Emerging \\
\hline Jennifer & 22 & $\begin{array}{l}\text { Nutrition \& } \\
\text { Psychology }\end{array}$ & Senior & Argentina & Intermediate \\
\hline Lara & 21 & $\begin{array}{l}\text { Health Sciences } \\
\& \text { Political } \\
\text { Science }\end{array}$ & Senior & United States & Experienced \\
\hline Liz & 23 & Public Relations & Junior & United States & Emerging \\
\hline Margaret & 21 & Art Education & Junior & United States & Intermediate \\
\hline $\begin{array}{l}\text { Optimus } \\
\text { Prime }\end{array}$ & 19 & Undeclared & Sophomore & United States & Emerging \\
\hline Ruth & 20 & Accounting & Senior & $\begin{array}{l}\text { Dominican } \\
\text { Republic }\end{array}$ & Experienced \\
\hline Sally & 21 & $\begin{array}{l}\text { Physical } \\
\text { Therapy }\end{array}$ & Senior & United States & Experienced \\
\hline
\end{tabular}


people with whom you share common interests. In this manner I was able to connect with three additional participants. As the interviews progressed and additional participants were selected, it became clear that the majority of students became "positional leaders" during their first or second semester of involvement. Due to encouragement of their peers, opportunities that presented themselves, and the plethora of positional leadership opportunities, these women transitioned from being a "member" to a "positional leader" quickly, a few even had a "position" before being a member, as was the case with two Orientation Peer Advisors. Therefore, only one participant actually fit the pure "non-positional" leader description.

I do not believe that the challenge in recruiting participants biased my sample because it did not prevent me from gaining meaningful information regarding the experience of a "non-positional" leader. As each of these women shared their leadership journey they described their initial experiences as members of organizations prior to taking on designated leadership roles. The experiences these "positional" leaders shared about their membership prior to taking on designated leadership roles resonated with each other and with the one "non-positional" leader I was able to identify. This experience caused me to develop "leadership experience" categories which are shared more thoroughly in Figure 3 in chapter 4.

Once approval from the Institutional Review Board (IRB) was granted in the spring 2009, University administrators were asked to either provide my contact information to the students they recommended or provide the recommended student's information to me, in this way initial contact was made via email with a total of 14 students who were recommended. Through phone conversations I provided an overview 
of the study and the selection criteria to each of the recommended students I was able to contact prior to scheduling our first interview. In this way, contact was made with four students, three of whom agreed to participate in the pilot study. Following the pilot study nine additional students were selected for the study based upon their willingness to participate, agreement that they met the study's criteria, and formal commitment via informed consent (see Appendix B).

Interview Process and Protocol

Before beginning the initial interview I spoke with each participant, sharing the purpose of the research study, issues of confidentiality, and the commitment of time that the study required, I also answered any questions each individual had. If they agreed, the consent form was signed and prior to conducting the interview, I provided each participant with a nominal appreciation, a gift card to a local food vendor. All participants were then asked to provide consent for the interviews to be tape recorded for accuracy, and each granted this permission. I also informed them that they would each receive a copy of their transcriptions for review. This process of member checking provided them an opportunity to read over what was said in both individual interviews and focus group discussions to assist with accuracy. In addition, I asked each participant to inform me if there was anything in the transcription that she did not want to be published in the findings or that was inaccurate. None of the participants requested changes to the original transcripts. Finally, to maintain the highest level of confidentiality and to help establish rapport and trustworthiness between myself and the participant, each woman created a pseudonym for the purposes of the research. 
Individual and focus group interviews were open-ended and semi-structured, with participants being asked a few broad questions and invited to talk freely about their experiences (Merriam \& Associates, 2002). To elicit answers to the research questions, interview questions and probes that would help construct a picture of the implications of gender and ethnicity on a Hispanic college woman's leadership development were initially identified and then adapted based on the pilot study findings. The final list of 12 individual interview and 4 focus group questions are included as Appendix C. Questions focused on key experiences in their leadership experience, their beliefs about leadership, and their experiences related to ethnicity and gender. As previously noted, the interview protocol was derived from the protocol used in Komives's et al. (2005) study. Although the interview questions were derived from the study and were intended to reflect the concepts of Relational Leadership theory and the LID model, the LID model was not shared with participants nor were they asked to situate themselves within the model. There was no intention on the part of the researcher to force participants to answer in any way that deviated from their personal perspectives.

Two types of interviews were conducted in the summer 2009; in-depth individual and focus group. Individual interviews lasting between 1 and $1 \frac{1}{2}$ hours were conducted with each of the participants on two separate occasions and the focus group interviews were each $1 \frac{1}{4}$ hours which meant that each participant spent a total of $3-4 \frac{1}{2}$ hours in interviews. One of the participants was not available for a second interview, or the focus group and two additional students were unable to participate in the focus group interviews. The data from these participants were used even though the participants were unable to follow through on their commitment. 
As stated earlier, the saturation point is most critical in determining the number of interview occasions. Transcribing and analyzing the data between each round of interviews provided an opportunity for themes to begin to emerge and for the data to be understood as well as to determine whether the saturation point had been reached. Following the pilot study I conducted two interview rounds; the first round included three participants for first and second interviews. The second round included three additional participants for first and second interviews, and although with the data of nine participants from the pilot study transcribed and coded I felt I was reaching saturation, I decided to conduct one more round of interviews with three additional participants since I had decided not to use the data from one of the participants. Once this third round was completed, with a total of 12 participants data, 11 of which I decided to use, it was evident that saturation was reached.

In addition, two focus group interviews each with four participants were conducted at the end of the data analysis phase which allowed an opportunity for interaction between participants, for experiences to be confirmed or expanded upon and to further uncover any similarities of experience that existed. The focus group also provided an opportunity for participants to provide feedback on my initial interpretations. Two smaller focus group interviews were utilized as a way to address internal validity through triangulation of data. Comparing the two groups as well as using the groups to respond to the initial themes was used as a form of member checking.

As Morgan (1998) states "the hallmark of focus groups is their explicit use of the group interaction to produce data and insights that would be less accessible without the interaction found in a group" (p. 2). In addition to the group interaction and rich data 
Hatch (2002) also states that focus groups can provide participants with a sense of security and comfort and give participants the opportunity to give direction to the interview. Both Morgan (1998) and Hatch (2002) caution the researcher that the more control the researcher has, the less natural the conversation has the potential of being. In addition, literature on focus groups has also addressed gender and ethnicity. For example, Montell (1999) in writing about the use of focus group interviews as a feminist method states that because "group interviews allow for a more egalitarian and less exploitive dynamic than other methods" (p. 45) they may be especially useful in research with women. Montell (1999) also states that since a constructivist understanding recognizes that issues related to gender are not simply biologically or socially constructed, focus groups provide an excellent methodology to unearth issues related to gender. In addition, Madriz (2003) notes that focus groups are also helpful when working with "invisible groups" such as Latina women. Hatch (2002) suggests that forming a group based upon common points such as age, race, gender, class and socioeconomic status can provide meaningful data about the group. This knowledge provides rational for conducting a focus group when studying Hispanic women college students at an HSI.

To provide continuity focus group questions covered the same topics as the individual interviews with an emphasis on themes that emerged. My intent was to utilize the group to confirm or negate these initial themes and provide feedback on preliminary analysis. The focus group encouraged more open participation as the women found commonality of experiences in their involvement on campus and discussed issues of leadership identity development. In fact, after a few uncomfortable interactions, the 
women actively engaged with each other. I was a little surprised by this outcome as only two of the women had any previous interaction with each other. In both groups participants affirmed each others' experiences, corroborated on their similarities and confirmed my initial analysis of themes.

Observations of Leadership Classes and Programs

According to Patton (1990), triangulation of data sources and analytical perspectives increase the accuracy and credibility of findings in qualitative research. Therefore, in addition, to the interviews, observations of leadership settings were conducted to gain a sense of the ways that leadership was described or promoted in the context of the case. Specifically, I attended three class periods of the Introduction to Leadership course offered as part of the Leadership Certificate. Since my purpose in observing the class was to listen to the ways that the students describe leadership, their underlying assumptions, what was being said, how it is being said, and the language they use (i.e., do their descriptions resonate with the Great Man Theories, Relational Leadership Theory, etc.) I contacted the course instructor, shared my purpose with her and asked her which class periods would be most conducive to this type of observation. She suggested that I attend their final presentations at the end of the semester as the intention of that assignment was a final synthesis of what the students learned about leadership from the class lectures, readings and involvement in their small group service projects. Although the class members consisted of both men and women, 14 of the 27 students enrolled were women and, observing the class provided an opportunity for me to listen for the ways in which gender and ethnicity were discussed within the context of the class. In addition, I observed students during the lunch with women leaders and breakout 
sessions during the Women Who Lead conference, again listening to provide a description of the language being used while discussing leadership and the experiences and influences that they ascribe meaning. Observation of leadership courses, conferences and/or activities was one way that I gained a clearer picture of the research context in which the participants engaged in leadership. The data from these observations helped to confirm that Relational Leadership Theory is the theory taught through leadership programs at FIU.

\section{Researcher's Journal}

During the data collection and analysis phases, I maintained a written journal. The researcher's journal allowed me to note time and place as well as thoughts and insights I had during these experiences. The researcher's journal included a reflection on each interview; descriptions of the participants, their body language and our conversations as well as objects, places and activities were described. The journal was used as an opportunity to reflect and increase my sensitivity and awareness and therefore I recorded mistakes I felt I had made and inadequacies and biases. I felt I was experiencing. The researcher's journal was also used as a method to speculate about what I was learning, and ways to proceed which provided concurrent data collection and analyses. The researcher's journal also helped to establish an audit trail to verify the rigor of fieldwork and confirm data collected (Bogdan \& Biklen, 2007).

\section{Data Analysis}

During the data analysis phase, I decided to remove one participant's data from the dataset, which left a total of 11 participants. Although this woman self-identified as Hispanic, her country of origin is Brazil, whose native language is Portuguese, not 
Spanish and therefore considered South American rather than Hispanic. I struggled with this decision as my criteria clearly stated involvement of students who "self identify" as Hispanic, which she did, but I was concerned that the data from her interviews might be seen as not legitimate by the Hispanic reader. Upon analysis it was clear that this participant's data would not alter, and did confirm, the results.

As qualitative research is a process wherein the researcher derives categories and themes from the data, I actively engaged in the process of discovering categories of meaning that lead to development of themes which lead to identifying areas that need further investigation. The process of engaging in data analysis concurrently with data collection described earlier, supported this engagement, and allowed themes to emerge and be followed up on as the data was being collected. Although the research questions and interview protocol were derived from Komives et al.'s (2005) study, the themes derived from the grounded theory of the LID were not utilized or compared to this data until the last phase of data analysis.

Data analysis began with transcription of the data verbatim by a transcriptionist. The pseudonym created by each participant was used in all interviews and transcriptions to increase the likelihood of anonymity. To enhance the probability that each participant's voice was heard, I listened to each recorded interview twice prior to reading the transcribed interview. After each transcription was completed I coded the transcripts of each participant to designate original location in the transcript as follows: (a) each participant was assigned a number (I1-1 - I1 1-1) for first interviews and (I1-2 - I11-2) for second interviews, (b) in addition, each line on each page of the transcript was numbered. 
In the first phase of analysis I read through each interview transcript and the researcher's journal from the first round of participants as well as observations from classes and the conference, noting general patterns that emerged in response to the interview questions and ways that this supported what students discussed in my class and conference observations. During the second reading of the transcripts from round one I identified words and phrases that signified the most meaning for the participants, as themes begin to emerge, they were clustered into larger semantic units and coded. Each theme was substantiated with rich descriptions using the participants' words (i.e., "voice") based on the verbatim transcripts of the interviews. As the initial themes began to develop, I utilized the research questions to create a list of potential themes and continued to code the data. A phrase/code was designated to each initial theme and written in the left hand column of the transcript beside the quote that the code reflected. After each transcript was coded, quotes related to each theme were removed and placed in an excel sheet that corresponded to the umbrella of each research question and the specific of each theme. These spreadsheets included the quote and a code to identify the participant who expressed the quote. For example I3-2:13:27-32 referred to interview participant number three, second interview, page 13, lines 27-32. During this process I shared my initial list of topics and themes with my peer reviewer who read the first six uncoded transcripts and helped me to verbally process what I was discovering in the analysis phase. She provided great insight and asked me to further define the meaning I was making from my participants' words. Through this process the initial list of topics and themes was refined to better capture the voices of my participants. 
After repeating this process of data analysis for each of the individual interviews, the text of the first round of transcriptions and the researcher's journal were analyzed together and compared to the transcriptions and journal entries from each additional round of interviews as well as notes from the classes and conference I observed. The constant comparative method was utilized for data analysis (Bogdan \& Biklen, 2007). The texts of the transcribed individual interviews were compared to each subsequent interview and analyzed across all individual interviews. In qualitative research, data analysis is simultaneous with data collection. Therefore, this process began shortly after the first interview was conducted and continued until after the data from the group interview were analyzed. This method allowed me to make adjustments, redirect the data collection process and continue to refine the topics and themes (Merriam \& Associates, 2002). Common themes across individual transcripts were outlined and overarching themes identified as the thematic structure developed into topics. Data analysis did not focus exclusively on similarities, but instead sought to identify relationships that connected statements and events within the context as well as contradictions that needed clarification during later interviews. Core categories and themes within them were identified and reworked until saturation of categories was achieved. As described earlier in this chapter, that occurred during the third round of interviews and included the data from 11 participants.

Once saturation was achieved, and no new categories were derived from the analysis, I knew that I had interviewed an appropriate number of women to talk about the essence of their lived experience related to leadership identity development. At this point, I conducted the focus group interviews and continued to compare the focus group 
transcripts with the individual interview transcripts, and journal entries from class and event observations. In the final phase of data analysis I compared the themes and subthemes from this study's data with the results of Komives et al. (2005) grounded theory LID model to ascertain any similarities and/or differences between the six stages and five influencing categories of the LID and the themes and subthemes that emerged from my study. At the conclusion of the data analysis phase, the extent to which research questions were addressed was examined. 


\section{Chapter IV}

\section{Participants and Context}

The purpose of this study was to explore and describe the leadership identity development of a select group of women leaders at a Hispanic Serving Institution (HSI) in the southeast. The purpose of this chapter is to present the data and the themes derived from the cross case analysis. Prior to the findings, the setting of the study is described to provide contextual information. A description of the leadership experience categories, defined by the researcher, into which each participant described herself follows. This is followed by a profile of each participant. A description of the topics and themes that emerged from the data are then presented and discussed at length in this chapter which concludes with a summary.

\section{The Context of Miami}

In addition to the status of FIU as an HSI, the context of the city in which the institution resides is important to the framework of this study. Miami hosts one of the largest Hispanic populations of any city in the U.S. A 2003 Brookings Institute report indicates that $66 \%$ of Miami's 2.3 million population identified themselves as Hispanic or Latino. The report refers to Miami as a "majority-minority city;" a city whose population is more than half Hispanic or non-White. This majority status carries privilege and influences Hispanic individuals' involvement in leadership within the city. Portes and Stepick (1993) begin their ethnography with the statement "Miami is not a microcosm of the American city. It never was" (p. xi). Miami's uniqueness stems from its development by regrouped Cubans who gained political power in the 1980s. Stepick et al. (2003) note that during this time a "reverse acculturation" occurred in which non- 
Hispanic Whites began sharing power with Miami Cubans because of the economic opportunities that existed with Latin America. The result of this "transculturation" is ethnic groups that adapted to each other creating a hybrid of two cultures.

The influential nature of Hispanic culture in Miami is palpable and Miami is one of the most politically organized and powerful Hispanic cities in North America. For example, the first Hispanic woman to serve in the U.S. Congress, Ileana Ros-Lehtinen, resides in Miami (Amer, 2008). In addition, a recent U.S. Census report found more than half (54.9\%) of Miami-Dade businesses are Hispanic owned compared to $17.3 \%$ of the businesses in the state of Florida (U.S. Census, 2006). Interestingly, the same survey found Miami $11^{\text {th }}$ on the list of the 20 fastest growing cities in regards to women owned businesses.

Students at FIU have many curricular and co-curricular leadership opportunities including a leadership certificate compromising 15 credits from an approved list of leadership oriented classes; getting involved in approximately 250 registered clubs and organizations; running for Student Government Association; leadership positions such as Peer Advising or Resident Assistant; and/or participation in numerous leadership programs such as the Academy of Leaders (AOL), the LEAD Team, the Leadership Summit, and the Women Who Lead conference, as well as numerous other programs and services that may not have "leader" in the title, but provide opportunities for leadership development.

In the spring of 2010 , a total of 4,198 students participated in 248 registered student organizations. Sixty two percent of these students identified themselves as female, and $49 \%$ as Cuban, Hispanic, Central American or Latino $(n=93,1,913,15$ and 
43 respectively). The executive, legislative and judicial branches of Student Government Association include 102 students. Fifty nine of these representatives identify themselves Hispanic, of those 20 are men and 39 women.

\section{Leadership Experience}

As the participants shared their leadership journeys, patterns emerged in the ways they described their experiences, their motivation and, what leadership meant to them. Similarities also arose in their definition of a leader and if they considered themselves a leader. The leadership experience of these women helped to provide an understanding of commonalities in their leadership identity development. Where they were in their leadership experience contributed to how they defined leadership, the role they believed a leader should have in group dynamics and goal development, and therefore to where they were in their leadership identity development. From this research three leadership experience categories surfaced; emerging, intermediate and experienced. It was particularly interesting to hear the ways in which the emerging leader's experiences resonated with the ways in which intermediate leaders described the beginnings of their leadership identity development and sequentially the ways that the emerging and intermediate leader's experiences resonated with the ways in which experienced leaders described the journey of their leadership identity development. Figure 3 provides an overview of each leadership experience category, including the participants that were included in each category description. 
Figure 3: Leadership experience categories by participant

\begin{tabular}{|c|c|c|c|c|}
\hline Category & $\begin{array}{c}\text { View of } \\
\text { Leadership }\end{array}$ & Influencers & Skills Gained & Participants \\
\hline $\begin{array}{c}\text { Pre-FIU } \\
\text { Involvement }\end{array}$ & $\begin{array}{l}\text { There is an } \\
\text { adult in charge }\end{array}$ & $\begin{array}{l}\text { - First involvement } \\
\text { experiences usually at } \\
\text { the suggestion of } \\
\text { parent, teacher } \\
\text { Received affirmation } \\
\text { from adults } \bullet \text { Engaged } \\
\text { in groups to form } \\
\text { friendships }\end{array}$ & $\begin{array}{l}\text { - First } \\
\text { responsibilities - } \\
\text { Built self-confidence } \\
\text { - Learned what it } \\
\text { means to be a part } \\
\text { of a team }\end{array}$ & \\
\hline $\begin{array}{l}\text { Emerging } \\
\text { Leaders }\end{array}$ & $\begin{array}{l}\text { - External to } \\
\text { self } \\
\text { Leadership is } \\
\text { positional a } \\
\text { leader is in } \\
\text { charge and } \\
\text { possesses } \\
\text { certain } \\
\text { characteristics }\end{array}$ & $\begin{array}{l}\text { - Seek connection } \\
\text { with role models and } \\
\text { a community of } \\
\text { likeminded people • } \\
\text { Older peers/advisors } \\
\text { recognize skills and } \\
\text { recommend } \\
\text { organizations and } \\
\text { positions }\end{array}$ & $\begin{array}{l}\text { - Begin building } \\
\text { leadership skills } \\
\text { through programs, } \\
\text { activities, } \\
\text { organizations, } \\
\text { trainings }\end{array}$ & $\begin{array}{l}\text { JLo } \\
\text { Liz } \\
\text { Optimus } \\
\text { Prime }\end{array}$ \\
\hline $\begin{array}{c}\text { Intermediate } \\
\text { Leaders }\end{array}$ & $\begin{array}{l}\text { - Moving from } \\
\text { leader centric } \\
\text { view of } \\
\text { leadership to } \\
\text { leadership as a } \\
\text { process }\end{array}$ & $\begin{array}{l}- \text { Team of peers and } \\
\text { mentors } \bullet \text { Leaders } \\
\text { facilitate goal } \\
\text { accomplishment and } \\
\text { shared responsibility } \\
\text { they involve others in } \\
\text { the process }\end{array}$ & $\begin{array}{l}\text { Involved in many } \\
\text { experiences • } \\
\text { Learn about } \\
\text { teamwork/enjoy the } \\
\text { process of working } \\
\text { with others to } \\
\text { achieve goals • } \\
\text { Leadership skills } \\
\text { learned }\end{array}$ & $\begin{array}{l}\text { Claire } \\
\text { Jennifer } \\
\text { Margaret }\end{array}$ \\
\hline $\begin{array}{c}\text { Experienced } \\
\text { Leaders }\end{array}$ & $\begin{array}{l}\text { - I am a leader, } \\
\text { leader is a part } \\
\text { of who I am • } \\
\text { Anybody can } \\
\text { learn to be a } \\
\text { leader } ~ \\
\text { Leadership is a } \\
\text { process in } \\
\text { which we all } \\
\text { achieve goals } \\
\text { and grow }\end{array}$ & $\begin{array}{l}\text { - Activism and service } \\
\text { important, making } \\
\text { the world a better } \\
\text { place } \bullet \text { Involvement } \\
\text { connected to } \\
\text { personal values and } \\
\text { ethics Desire to } \\
\text { empower others • } \\
\text { Desire to leave a } \\
\text { legacy }\end{array}$ & $\begin{array}{l}\text { - Commitment to } \\
\text { cause/organization } \\
\text { and the people who } \\
\text { are involved - } \\
\text { Beginning to mentor } \\
\text { emerging leaders } \\
\text { Confidence in } \\
\text { leadership abilities } \\
\text { - Ability to work } \\
\text { with diverse others } \\
\text { across contexts }\end{array}$ & $\begin{array}{l}\text { Alissa } \\
\text { Cynthia } \\
\text { Lara } \\
\text { Ruth } \\
\text { Sally }\end{array}$ \\
\hline
\end{tabular}




\section{Participants}

Eleven self-identified Hispanic women leaders aged $18-23$ participated in this research study. Four criteria were identified for participation in this study; identification as a woman, of Hispanic descent, currently enrolled as a student at the institution, and being involved with one of the following groups on campus - student athlete, resident assistant, orientation staff, leadership program participant, member of a student organization and/or sorority. These criteria were used to increase the likelihood that each participant had an enhanced understanding of the possible, or perceived, impact her experience at FIU had on her development of a leadership identity. Demographic information about each woman was gathered between the first and second interviews and recorded on a data sheet. Table 1 presented a summary of demographic information and provides a broad view of the participants. A profile, based on self-reported and observational data collected from the interview process, was created for each participant. These profiles, organized by leadership category and alphabetical order of their pseudonyms, provide a back drop from which to understand the findings.

\section{Emerging Leaders}

The emerging leaders' main motivation for involvement was social. They emphasized having fun, connecting with women they wanted to be like and finding a community of likeminded people. While their motivation was mainly social, it was still important for them to be involved in activities with others who cared about making a difference in the lives of others. In this entry point of their involvement at FIU they talked about the peers and the role models, mainly older peers and advisors, who influenced them to get involved. They viewed leadership as leader centered and 
positional and believed a leader should possess certain characteristics. The emerging leaders were involved, but did not describe themselves as leaders. However, once involved they quickly took on more and more leadership roles. Through their involvement experiences at FIU, these women's views of leadership were changing. JLo. JLo was a 19 year old sophomore nursing major. She was proud to share that she is the second person in her family to attend college. JLo's parents had been married for 28 years. Her mother became pregnant at 15 years of age prompting her and her then boyfriend to drop out of high school and get married. JLo has three siblings, a sister who is 9 years older, a 16 year old sister and a brother who is five. She described her younger brother as the heir, or king, sharing that he is the star and with 11 years between him and the youngest girl, he is the miracle. JLo is proud of her ethnic heritage; she is Puerto Rican but shared that with so many interethnic marriages there is quite a bit of diversity in her family now. She considered herself "culturally Hispanic" stating "I don't speak Spanish but we have a lot of Hispanic traditions like food, beliefs, and cultural things." Although she defined herself by her parents' country of origin, Hispanic is a more general term she applies to people from any Latin or South American country, including the Caribbean. "I love everything about being Hispanic and think I'm privileged to come from such a culturally diverse background. I hold that stuff close."

JLo considered her older sister, who recently completed her Master's degree and is a teacher in Tampa, a role model sharing;

She went to college and she got through. She put herself through because my parents can't afford to help us. When it came time for me to go to college, I was kind of like, well I don't really want to do it. I can figure out how to do it on my own. I can go to work and make money and I can make it. But then I see my cousins and stuff, who didn't go to school and they thought they could make it, 
and then I compare them to my older sister who is now just graduating with her masters, and the life she's living compared to the life they're living, they have many struggles, and she doesn't have as many. She's guaranteed a job. She went for elementary education, so she's s a fourth grade teacher in Tampa, and I don't know, I would rather follow her footsteps than someone else's. I didn't want to go to college; I thought I could make my life happen without college, but she motivated me to apply.

JLo expressed that education is now a strong value of hers and will be a family value from here on. Although school always came easy for her, JLo almost did not graduate from high school because she lacked motivation. She viewed the college experience as a way to reinvent herself;

I never really did anything in high school. I had problems, I almost didn't graduate. So when I got accepted into college, it was kind of like a complete turnaround for me. I was going to make my experience; it was a chance to reinvent myself.

She believed that this mindset to reinvent herself came from within, "I pulled it from my big toe." Her motivation for becoming involved stemmed from a desire to create her own experience in college and herself. It also stemmed from a desire to help others, after all she has chosen to pursue a career in a helping field, nursing. JLo's first experience with involvement was as a Peer Advisor during her sophomore year. She expressed a strong desire to become a PA after her orientation experience the summer prior to starting FIU sharing that the PAs had something she knew she wanted to have.

I love to smile and be happy, and they [the Peer Advisors] were always happy and always smiling. They knew what they were doing, and I was just like, I want that too. That looked like something that I could be good at. That's kind of what I was looking for, something I could be good at because I'm not into the SGA, Student Government, and you know, I needed kind of like a transition. And being a Peer Advisor looked like it could be a transition from what I was to what I've become. So when my orientation was over, I went to Vicky's office and said, when do I apply to be a Peer Advisor? 
Liz. Liz was 23 years old and had just completed her junior year at FIU. She had transferred to FIU from a community college in the area and was pursuing her Bachelor's degree in Public Relations. The first to attend college in her family, she was the only participant in the study who did not start college following high school, working full time for 2 years after graduation. She describes this experience as important because it was her choice to attend and the experience made her recognize that college was important to her. Liz chose to attend community college because she knew it was affordable as she could live at home and work part time.

Liz describes her ethnicity as Puerto Rican and Cuban, stating that she feels closer to her matriarchal Puerto Rican heritage because she does not spend much time with the patriarchal Cuban side of her family. She considers Hispanic the overarching term but identifies more specifically with her mother's Puerto Rican ethnicity. When probed she expressed that she now considers herself Puerto Rican and American, sharing that since she was born and raised in the U.S. she feels like she has to keep up with both cultures,

I have to be up to date with the history in both, learn how to communicate and deal with people in both, and it's different, be up to date with music and pop culture of both. When I'm there, they look at me like I'm American; and when I'm, here they look at me like I'm Puerto Rican.

Many of her family members remain in Puerto Rico. She sees the island as a paradise where things move just a bit slower and people are just a bit friendlier, and she visits often. Liz's grandmother came to "the states" with her husband when they were newlyweds, and although she did not speak the language, she left her abusive husband to start a life on her own with her three children just a few years after moving to the states. 
Liz's mother became pregnant at the age of 15 and had to leave high school. She describes the experiences of her mother and grandma as very influential to her life;

My grandma, I love her to death. She's like my other mom, and I know she's been strong throughout her whole life. She raised three kids on her own. She was with a man for 10 years who beat her and finally she got enough courage because, of course my great grandparents were very old school and they don't believe in divorce or that if he's beating you or treating you wrong that you should leave. I don't know how she did it. You know being an immigrant and her English not being that well, but she's really smart and---she overcame all of that, started up her own business and the rest is history. .. My mother was a single mother who got pregnant at 15 , had me at 16 , and I'm her only child up to now. She's always been the biggest influence in my life, and I feel like because she had me at such a young age she had to prove herself not only to the family but to everybody else. So she had to break that pattern of the typical teenage pregnancy. She worked really hard, and she raised me by herself; and she was successful at pretty much anything she put her mind to...

The messages I got from her was "go for what you want, be ambitious, don't listen to anyone. You can do anything you put your heart to." But, she and I have had the toughest relationship growing up. Things that she's instilled in me are what she's trying to control at the same time and it doesn't work. She's already taught me to be one way, yet she tries to hold me back and control me so we've had a tough relationship.

Liz is independent, strong, and focused on her future. She is excited about completing her degree but said that her academic journey had not been easy. Being successful in her academic endeavors was important and this value was instilled at a young age. As a result of good grades she was chosen by her elementary school teacher to be the "patrol" for her class. She attended a single gender middle school which was not comfortable for her because there were so many "mean girls," and she was "forced" by her mother to audition for an arts charter school, which she continued in high school. During high school she competed for the step and swim teams and was selected. Liz described the experience of competing in these sports activities and being on stage as 
challenging her to "step outside of myself" and was integral in developing belief in her self as a strong and determined individual.

After graduation she worked at a national sporting goods store for two years before deciding to attend community college. She pursued her academics with rigor and was invited to join the academic honor society and also became engaged in community service. Upon completion of her Associate's degree, she enrolled in FIU and continued to work part time to pay for school. She shared how hard it was to juggle student activities and work part time. However, she did decide to join an emerging leaders program that year because the name on the advertisement spoke to her. Since becoming involved she felt more connected and more accomplished and planned to continue her involvement.

Optimus Prime. Optimus Prime was a 19 year old sophomore undecided about her major. The youngest of three siblings, with an older brother and sister, Optimus Prime's parents divorced when she was 7 years old. She and her siblings resided with their mother in Palm Beach County, Florida, visiting their father in Broward County, Florida often. Optimus Prime describes herself as living between two worlds; her father's, which has strong Cuban American roots, and her mother's, which she described as European American, stating "these two worlds do not overlap or communicate at all." Optimus Prime moved into her father's home when she started school at FIU two years ago. She expressed that at times she felt a sense of alienation from her father's side of her family because she is not fully Hispanic; “I don’t speak Spanish fluently. Everything I learned, I learned in school, and the culture, the traditions, religion, even food is very different than my life with mom. It's been a big transition." 
This transition from her mother's home to her father's was especially difficult.

She felt that her mother encouraged her to be herself, a woman searching to discover who she is and who she wants to be. Meanwhile she felt her father had clear expectations of what he presumes she will be, a professional who makes a lot of money and is “successful." Optimus Prime's definition of success differs from her father's.

My father is a doctor, but he didn't want to be a doctor, that's not his calling in life. His calling is he wanted to do diplomacy and political things but he became a doctor to make money... I think he put expectations on himself to be able to support his family, that was probably more of a pressure that overrode what he actually wanted to do. And so in turn, I have two siblings, and none of us have gone towards a lucrative profession. None of us want to be lawyers or doctors, or anything that's stereotypically, or what's thought of as being really successful. And he resents that because I think he feels as though he made sacrifices in his life, and he didn't do exactly what he wanted to do. But he did it because he needed to be successful, and he doesn't see being a musician, or artist, or farmer as being successful. So he disapproves of mine, as well as my siblings' decisions as far as education because we might not be making the money you know...

Optimus Prime viewed her older sister as a strong role model and influence in her

life stating that she admires her free-spirit; feminist ideology, liberal political views, success as an environmental scientist, and desire to make an impact in the world. She shared that because of her sister's ideology, and her resentment of the patriarchal views of her father's side of the family, her sister is an outcast within the family. Optimus Prime also described the ways that she "appeased" her paternal side of the family. This included spending as much time as possible with them, taking 5 years of Spanish to help her learn the language, and "doing what's expected" of a good Hispanic woman so that she would not be considered an outsider too.

When asked to describe herself, Optimus Prime expressed that she was growing into herself and becoming a lot like her sister. Passionate about women, holistic practices 
and environmental things, she wanted to get more involved with some of these activities

on campus. She described how being involved in the theater, something she is

passionate, about changed her:

I was always a very, very, very, very, very shy child; very, very shy even through high school. What broke me out of my shell was, in my sophomore year of high school I decided to join drama, do theater because a friend was doing it and I wanted to try it. And then she ended up dropping out the same year I went in so I didn't know anybody anyway, but I did it, and it ended up being really good for me. That definitely kind of got me, definitely made me, I mean I'm not really shy anymore. That opened up a lot of windows for me I guess, opportunities I guess because I was finding myself and ways to express myself and approach people and to be assertive and to make my presence known...There's a special place in my heart for theater people because they were my family.

During her first course at FIU, SLS 1501 "Freshman Experience," Optimus Prime was introduced to an Orientation administrator who was also her instructor for the course and spoke to the class about becoming Peer Advisors. She decided to apply as it would provide an opportunity for her to be in the spotlight with a group of people again and learn more about what FIU had to offer, "after all, if I had to answer all those questions about FIU, I had to know it.” As she concluded her summer as a Peer Advisor, Optimus Prime reflected on her experience; she shared the ways it has changed her:

We're a group of people that outside school, outside of Peer Advising, I wouldn't hang out with them, but because we have the same common experiences as PAs, you can relate and you can have a good time. I definitely love Peer Advising for that. It might be hard work, it might be whatever, so many things, but the people skills that I've learned so far, and the summer's not even over, and it's great. So definitely you have I guess more confidence. I've learned, more tact, how to go about things, responsibility, which I still have a lot to learn, but yeah, responsibility. It's good stuff.

Towards the end of our first interview Optimus Prime shared that she was interviewing with the Theater Department over the weekend and during our second interview she shared that she was accepted as a Theater major. As she pursues her junior year she plans 
to participate in the Alternative Breaks program and get involved with an environmental issues student organization.

\section{Intermediate Leaders}

The intermediate leaders viewed leadership as a process of working together with a team to achieve goals. They recognized that a group could have a positional leader but that members could also have leadership roles. Social connections remained an important part of their involvement experience. However, their focus began to shift. They began to recognize that they could have a positive impact on other people's lives. They wanted to accomplish goals with their peers and influence what was happening at FIU and the larger community. The intermediate leaders in this group became involved in numerous organizations that connected with their personal values. Although some were not sure how they felt about being called a leader, they recognized that they were.

Claire. Claire was an 18 year old sophomore who graduated from high school 1 year early. She is the only child of a single mother and was raised in New York until the age of 10. As an only child who commuted to school, Claire was never really around kids. She grew up around adults which made her "mature faster." When I asked Claire to describe herself she said the following;

I wrote this poem one time. It was my personal statement, and I was like so confused on what to write cause you know it's kinda hard to talk about yourself sometimes. But I came up with the perfect line; "I'm a variety, pick a topic." I feel like that's me. Like, I'm a little bit of everything. I am here, I am there. I like almost anything. I like to try new things. I'm happy to be involved in anything and everything I can. I just love life and all its aspects.

Claire considers herself Hispanic stating that her mother and father were born in Columbia but she was born in America. To her, being Hispanic is about connecting with 
the culture, the food, family, friends, music, and language. This was challenging for her as a child because although she visited Columbia a few times, she grew up in a predominately European American neighborhood in New York and attended private catholic elementary school which she describe as having "a lot of White people." From a cultural standpoint, the experience of moving to Miami was more positive for Claire. She felt that Miami was more accepting of other cultures and that the Hispanic openness and flair permeated the city.

Academics are definitely at the forefront for Claire. Her sense of responsibility for her academics was instilled by her mother who encouraged her to be on the honor roll, attain "perfect attendance" certificates, and participate in academic competitions in elementary school. This stimulated a desire to learn which developed further as she recognized her intellect. However, service and giving to others was always important to her. When Claire was in middle school, her uncle became very ill and was placed in a nursing home. She shared how pivotal this experience was in her life;

I started volunteering there, like just to be around him more because he wasn't in our home anymore. But then I started volunteering there seriously. Not just to be with him, but with all of the elderly people there. And like, for a whole two years I was volunteering there like everyday. It became my home. I really liked helping these people, and I realized that it was a big passion of mine.

For Claire, the nursing home and its residents became her second home, and she learned from their storytelling. It was not until Claire came to Miami and started getting involved in spirit clubs that she recognized how much she enjoyed being involved from a social perspective. She talked about these experiences helping her "develop her own personality," and that she "completely changed" as she started making friends, learning how to speak in public and developed an appreciation for getting involved. 
Claire shared that her heart was always set on coming to FIU and talked about the way that being on a campus that she was comfortable with helped her leave high school, and her friends, a year early. During her first semester, in SLS class, she met her mentor and began to "fall in love with college." She was introduced to an emerging leaders program which planted the seed for her involvement at FIU. It was here where she "finally felt understood for the first time." She stated how the program changed her life;

I guess since I was little, like I tell my mom "I was picked by God to change the world", but like when I was little I didn't know what it was. I just knew. I liked helping people, and then Academy of Leaders gave me, like, the way to do it. And so I think that's what really changed my life, was that it said like "you can do this," and there was no more people thinking that I was crazy, or a dreamer, or whatever. It was people telling me "do it. This is how you can do it," and I think that's what really changed my life.

Involvement for Claire was about making a difference. In the 2 years she had spent at FIU, she became progressively more involved. She served as a member and was on the executive board of various FIU spirit activities, service programs and women's empowerment groups.

Jennifer. Jennifer was a 22 year old senior double majoring in nutrition and psychology. From Argentina, she came to the U.S. three years ago on a student visa when she was recruited by FIU to play tennis. An athlete all her life, Jennifer engaged in many sports, but tennis was her passion. She began playing at five and has competed since she was 13 years old. Her parents were married, and she has a younger brother. She talked about missing home, particularly her family and friends, and the connectedness of Argentinean people. Jennifer was intentional about working hard to attain the opportunity to leave because, as her parents helped her recognize, the opportunities in Argentina were limited. 
I came here because I finished high school, and I started to play professional tennis, and I realized like the economic situation in Argentina was not that good. So my parents showed me reality. I thought that I was right that I just had to play and I would make it. I was really cocky. My father was like, there's no way for us to pay for you to compete so I came to reality and I look forward to come to a university here. And when they told me Miami, I started thinking about hot weather and Latin people and that's why I'm here. Like now it's such a good experience for me. Like, it's over my mind completely. I was this little girl with mom all day, only wanna play tennis, didn't even care about studying.

When I came here I realize I am alone. For my first semester, I didn't study for finals until the last week taking, like, chemistry and those subjects like; you have to study like a fever. The day before my finals! But after that, I learned. You have to study, have to play hard, and learn to balance my life. Like social wise, it was so good. Like right now, I'm not embarrassed or ashamed of anything. I can talk, I socialize. No matter like the background or anything about the other person. Right now is the first year I'm not going home in summer, so I'm staying the whole year.

Jennifer also shared the way the changing economy in Argentina is changing gender role expectations;

Women are like stepping up so much in Argentina too. Maybe because of the economic situation, women have to go outside and start to work and worry about themselves. You can not rely only on your husband or one person to earn money because you're not going to survive. I don't think there's like any conditions for a woman or for a man. I mean I always do whatever I want to do, and I don't care if it's for a guy or a woman, it's going to help me to develop, its okay. I'm just going for it. I think right now, women and men are in the same position. And maybe women more because they are stepping up so much more and are more motivated you know? And men, maybe they are okay that woman are coming up. Maybe they feel they are getting less space, because we are taking some of society away from them; but I don't know...I see women grow a lot.

Jennifer is extremely independent, has great determination, and is motivated by

action. Her father served as a role model for hard work and perseverance. He pushed her to be the best she could be, and she expressed this early in the interview, "my father works so hard, day and night, he does too much and never takes space to relax...he expects the same from me." She emulates this drive within her father and shared "I'm 
learning to build on myself and that's why I think if you have an opportunity you have to take it." Her father taught her how to set and achieve goals. He also taught her three characteristics she admires highly: trust, responsibility and discipline.

Like many of the women in this study, Jennifer describes herself as Hispanic “100\%, as an Argentinean I am nothing else." She proudly shares "Argentineans are the best people in the world." She relates being Argentinean to her language, the friendliness of the people, traditions, ways of greeting each other, and openness. She described the similarities between Miami and home as positive and challenging; "I don't really feel like I am in America, I can't improve my English because we speak so much Spanish, and I have like 50 Argentinean friends!"

For Jennifer, it was especially important to be an integral part of her team. She referred to her teammates as her family away from home. As friends who resided together on campus and helped each other improve their game, study, and enjoy their collegiate experience. Although Jennifer was the team captain last year, she asked the team not to use the title and approached the role as a way to motivate, inspire, and demonstrate commitment through action. It was important to her that they discuss issues and make decisions together. She believed that was what a team captain should do.

Margaret. Margaret was a 21 year old sophomore and Art Education major from New York who moved to Miami in the eighth grade. She described herself as serious and "artsy fartsy." She worked full time while attending school and served as the President of one of the Lesbian, Gay, Bisexual, and Transgender student organizations. At the age of five, Margaret's parents divorced, and she was raised by her single mother. She is the middle child with two sisters who spent weekends together with their father. When 
talking about this experience living with four females during the week and their father on the weekends she relates;

I think my dad was just trying to do his best when he had us for the weekend. He was a mechanic, so the only thing that we would do was fix cars and go camping. Like he would do our hair for us, he would do French braids with a hanger. Like, he was just really trying to do his best that he could. So- but, um, nothing stereotypically girly; and as far as time with my mom, I didn't attach myself to my mom or even, like, connect with my mom until I hit about thirteen when we moved away from my dad, because my dad was my favorite parent for a long time - cause he was the fun one. So anything that would have been normally "girlie" didn't happen, and also my mom just didn't believe in that. She didn't believe that girls were supposed to wear pink and boys were supposed to wear blue. She justshe always raised us with choices.

When she was 13 years old her mother moved her and her sisters to Miami. Margaret was very angry during this period of her life because she did not want to leave her father or New York where she had established herself as a scholar. By moving, she gave up the opportunity to choose between two prestigious academic programs in New York for her freshman year. She was also upset to leave her teachers who she connected with more than her peers. Growing up she spent most of her free time after school with these teachers working on projects and helping them in the classroom.

Upon arrival in Miami, Margaret began to make connections with the teachers at her new school and reestablished herself as a committed student. However, this was a slow process, it took a while for her to find her passion for academics and succeed again in the classroom. She began to "try out" some of the student groups at her new school and was involved briefly with the art club, the GSA (Gay, Straight Alliance), and SGA. Although she did not find the connections she was looking for with her peers, she connected with her teachers and liked the "reward process," such as being Student of the Month, which she received from her interactions with them. She described school as her 
"favorite place to be." When she began her tenure at FIU, she again struggled with grades and finding her place, until she met Grant. They established a friendship and decided to develop a student organization designed to provide lesbian, gay, bisexual and transgender students and allies with a connecting place. It was through this organization that she found her place at FIU as she developed the organization with her friends. Margaret served as the treasurer and then president.

Margaret's mother is Columbian and moved to the U.S when she was 15 years old. Her father, who had recently passed away, was of Puerto Rican descent. She used the term Hispanic to describe her ethnicity stating;

Although to some people it sounds like abandoning your culture, Hispanic is my culture. I know some people describe Latinos versus Hispanics, where Hispanic means it is American assimilated with Latino, but I really don't come from a Latin household. So I definitely associate myself with the term Hispanic.

The experience of moving to Miami from New York was pivotal to Margaret for a number of reasons. She discussed the ways in which Miami culture opened her eyes to the diversity of Spanish speaking groups. "In New York you don't see many Cubans; I had never met White Spanish people." In August, Margaret moved to Chicago to work with an organization that engages $18-23$ year olds in a year of full time service as tutors and mentors to high school youth in disadvantaged areas. Margaret was excited about moving to Chicago and learning from that experience. Although she knew it would be completely different than her current experience, she looked forward to working with the youth of Chicago and meeting new people as she was much more open to new experiences than the 13 year old that moved to Miami 8 years ago. 


\section{Experienced Leaders}

The experienced leaders own the title "leader," it is a part of their identity. The experienced leaders' motivation stems from commitment to a cause. Their view of leadership was about empowering others and coming together to create social change. Relationship preservation remains important as they stem from a common passion and commitment to the cause. Experienced leaders took responsibility for the development of their members and had a commitment to the group's sense of community. It was important to these women that they demonstrate congruence between their actions and ethics.

Alissa. Alissa entered the room with a smile on her face that stretched from ear to ear. She held out her hand and introduced herself. Alissa was a 21 year old senior, majoring in Human Resource Management, who planned to attend graduate school for Sports Administration. Born in Mexico, she moved to the U.S. when she was 10 years old and became a U.S. citizen. Alissa's parents remain married, and she is the youngest of three children, with an older brother and sister. Alissa grew up in the mid-west, and, like many of the women in this study, defined her ethnicity by her country of origin, "Mexican." She stated that using your country of origin as an identifier is easier in Miami, because there is such diversity within the Hispanic population. Alissa also relates to the broader term Hispanic. In describing her rationale for this she stated, "when people ask me where I'm from I'm very proud to say 'I'm from Mexico.' I'm a Hispanic woman....in the mid-west there are not many Hispanics around, so I was used to being comfortable with sharing the Hispanic culture." 
When asked what being involved has meant for her, Alissa enthusiastically shared her love for sports and stated that she played every sport imaginable. Although her older brother was very involved in sports, her mother worried that Alissa would get hurt while engaged in sports. Alissa became a Girl Scout when she was 10 years old to help her meet friends and learn English. She expressed that these experiences helped her develop confidence and socialization skills. She considered herself shy, and remembered this experience as the first time she felt a sense of satisfaction accomplishing goals with others.

Alissa attended private, all girls, Catholic schools and describes her experience as sheltered. Even though she did not agree with her father's decision to enroll her in FIU, she described her orientation as a pivotal experience, "I realized that I am here, and I have to make the best of it. My experience will be what I make it." Since her brother and sister were both members of Greek organizations, she decided to join a sorority. She also became friends with a few Peer Advisors, and these students encouraged her continued involvement. For Alissa, the decision to get involved was based on a desire to continue to develop her self, make friends, follow the experiences of her siblings, and find a community of likeminded people. This is clear from the following statement;

[these opportunities] sounded like things that would be beneficial to me, to meet people and establish relationships with people, other students, faculty and staff. It's always good to build those relationships and to be able to communicate with people, and it opened a lot of doors that I thought would be beneficial.

Similar to the experiences of the other participants, Alissa fully engaged in the leadership experience at FIU. She became a Peer Advisor and Panther Camp Facilitator. She also took on leadership roles in her sorority, became involved in a service 
organization and was inducted into the leadership honor society. Through these experiences, and particularly her relationships with others, she became more involved and developed an understanding of her identity as a leader. In describing this Alissa stated,

I want to leave my mark and influence other people, whether it's just one person, [or many], just knowing that you can affect other people, that you can help them succeed, that you can help them reach their full potential...that's what leadership means to me.

Cynthia. Cynthia was a 21 year old senior, majoring in Philosophy and

Psychology and obtaining a certificate in Law, Ethics and Society. She was

contemplating a third major, mainly because she does not feel as if she is ready to leave FIU, stating "I have more I want to do before I leave," and was unsure if she wanted to attend law school or pursue a Master's in Political Science next. Cynthia attended Catholic co-ed primary and middle schools and had a difficult time adjusting to an all female high school,

I know all female institutions are supposed to empower women, but that was not my experience. The girls in my school were mean - have you ever seen the movie Mean Girls, they were like that, catty and picking on people they saw as not fitting the mold.

She did eventually enjoy her high school experience thanks to the support of a few teachers as well as the influence of what she described as "a more Hispanic community." But it was not until Cynthia arrived at FIU that she finally felt she could be herself; she spoke of this experience as "an opportunity to reinvent myself, or start a new chapter, after all no one here knows me, even the people who did know me then say I am so different now." 
Cynthia grew up in a family with strong women deeply rooted in Cuban

American culture. Her grandmother was a famous novella author in Cuba and her mother a nurse practitioner. Her parents remain married and she has three older sisters. She described herself as a Cuban American but states that she considers herself Hispanic on a "general level." When asked to talk about what ethnicity meant to her she shared;

I've always been very proud of my ethnicity as well as who I am due to the fact that I can look at my people and if you see like they've helped develop Miami and contributed through the Bay of Pigs situation. I like to say I'm Cuban-American because of the fact that I like to know where I've come from and even though that I wasn't born in Cuba, I do know a lot of the culture and I like to be part of it because they've come a long way. I want to go back once you know the whole borders are down and stuff but my parents are very hesitant towards that but my grandmother says I should go. I mean she says that it won't be as glorious as it was when they lived there because they used to have this house which is now a military base and I've seen pictures of it and it's beautiful but they, you know, they've turned a lot of the houses into military bases. There is stuff for the government so it has lost a lot of its novelty.

Cynthia had just finished a psychology paper describing her personality so when I

asked her to describe herself she quickly and confidently responded;

I'm strong-willed, persuasive, demanding of myself and others around me, generous, inquisitive, friendly, silly and witful. So, as far as persuasive, that goes into my communication skills. I'm usually able to talk people into doing what I want them to do in a nice way, not in a manipulative [way]. I don't let myself fail and when I do I feel, it causes me a lot of distress. So I hold others to the same standard. I don't like when people fall short of my expectations because I don't think they're too high that it should be anything that they're not able to meet. I just think that there are common goals and certain things that everyone should strive to do, especially when you're working with somebody else.

Generous...I'm very giving of myself...of my time...I help people with their papers if they need it because I'm a good writer. Since I'm a philosophy major, I'm able to have insight into different topics. I enjoy community service as well, so that's another reason why I'm generous. Inquisitive...throughout my life I've always asked questions. My theology teachers, because I went to catholic school all my life, went crazy because of this. My nickname as a Peer Advisor, because we have nicknames for each other, they just named me a question mark because I'm always asking questions. 
Friendly, I'm very open, people feel like they can talk to me. I'm not closed minded so I'm very perceptive to others. I enjoy having conversations and welcoming people. Silly, I like to play a lot. I don't like a lot of seriousness. I like to introduce sort of laughter into every situation, even the bad ones and that's where I can get myself into trouble. And witful, but sometimes when I use my wit people don't understand it.

Cynthia shared that it was her teachers who really encouraged her to challenge herself and get involved sharing "I think that leadership is something that is born within you but in order to do things you have to be encouraged." She talked about the influence this encouragement had on her as she began a new chapter at FIU. How she began to create her own experience becoming increasingly involved in SGA, an emerging leadership program, starting a service organization and becoming a Peer Advisor. It was interesting to me that although Cynthia recognized that leadership is something you develop and hone over time and through experience, the ideals of the "great man" theory of leadership were still a part of her understanding.

Lara. When Lara walked into the room her confidence and drive walked in alongside her. It was clear that she was constantly on overdrive. Lara was a 21 year old senior, double majoring in Health Science and Political Science, with minors in Chemistry, Economics, Psychology and Health Science Administration. She was also attaining certificates in Leadership and Law, Ethics \& Society. Graduate school is a given in her world. Lara's parents immigrated to the U.S. from Cuba when they were young, her father with his family and her mother as part of the "Pedro Pan" migration of 14,000 Cuban children during the 1960s (Walsh, 2001). Lara was born in Miami, and was very intentional when she described her ethnicity as Cuban-American stating; the struggles that my family has gone through aren't the struggles that I've had to 
face. So, that's why to me, out of respect for my family, and out of respect for my Cuban heritage, I need to hyphenate because I've always had everything. But I am proud of my roots, I give respect..

Although she also defined herself as Hispanic, like many of the women in this study, Lara believed that if she was not in Miami she might connect more with the term Hispanic than Cuban-American, but here in Miami "you really have to narrow it down a bit more, we're all Hispanic." Lara stated that her family is both traditional and nontraditional. She considered her family traditional because Cuban food and radio, as well as lots of loud family members, were a constant in her home. But, she also considered them "non-traditional," because her grandmother obtained a Doctoral degree after getting married, her mother was 41 and her father 55 when she was born, and she is an only child. She attributed her independent nature, strong determination and belief that she can accomplish anything she sets her mind to, to her family history and values.

Lara began her involvement in extracurricular programs in second grade when a teacher encouraged her to enter a poetry contest. She won second place and spent the next year preparing for her eventual "gold medal." Everything in her life since then has been approached with similar determination and self-confidence. Lara believed that individuals play a large role in making their own experience, that she is in charge of her destiny, and that her generation will change the world. Lara attended an all female Catholic academy throughout elementary and high school. She was the driving force in creating a supply drive for a sister town in Ecuador, the impact of this project today is a brand new community with new schools, playgrounds and gardens. A self-defined overachiever she affirms, "I'm a fighter. I overcome stuff." 
Lara takes 18 credits a semester at FIU while maintaining a high level of involvement which included membership in a sorority, two academic honor societies, student conduct board and several social justice and political organizations, as well as being a teaching assistant. She served on the executive board of many of these organizations. Lara is particularly passionate about women's empowerment, when describing her first encounter with the sorority system on campus she stated, "They looked like women who had their act together and to accomplish what I want I knew I needed to be a part of a team with similar values."

Ruth. Ruth, was a 20 year old senior who immigrated to the United States when she was 12 years old. Within the first minute of our interview Ruth described herself as "super and overly involved, have been since I came to FIU." Although she always had a smile and was always happy she was a private person, who loved to learn, to read and to write. An Accounting major, completing a minor in Economics and a certificate in Women's Studies, Ruth was an advocate for women's rights, particularly issues related to domestic violence. She was a strong woman, with solid family and religious values. The depth of her passion for women's issues and empowerment was resilient and guided her involvement in compellingly ways. The struggle she felt between how her culture deals with women, especially violence against women, and her fight for justice and empowerment was moving. Ruth was one of the few women who described themselves solely by their country of origin "I'm Dominican, I'm not Hispanic."

Ruth remembered when her parents sat her and her siblings down to make the family decision about going through the process of immigration. She shared how they decided together that her father would come to the U.S. first to establish a life for them. 
She was 5 years old when he left. She spoke freely of the sacrifices her parents made, including their divorce, her father's marriage to an American to obtain status, and her parent's re-marriage some years later. Although her family was of utmost importance to her, she was conflicted about her feelings for the men in her family and the blatant acceptance of abuse women in the Dominican Republic faced at the hands of their male family members. Ruth recognized early in life that women had very few options in the Dominican Republic. Unless you were independently wealthy, there was no choice but to become a housewife, dependent on a husband for survival. She also understood that this was the main reason her parents were willing to sacrifice to come to the U.S.

From a very young age Ruth's parents instilled the importance of becoming educated through school and personal development opportunities. She started "school" at two and a half years of age and her parents saved to send their children to private schools and music lessons after school. It was clear to Ruth that these things were important because "an idle mind and hands means pregnancy or gang involvement." Ruth is not sure if this desire to learn and to better herself as a person is innate in her, indoctrinated by her parents or her strong religious values, or a combination. Either way, it inspired her to be the best and develop herself through extracurricular activities. Ruth believes that in order to change the world, you have to begin with yourself. She said "I work on myself first because I think it starts here and then everywhere else."

Sacrifice was a term that came up repeatedly for Ruth. It had great meaning and value to her as the sacrifices others made for her set a foundation for her success. This fueled her involvement and contributed greatly to her leadership identity development. She felt a responsibility to do her best and chose to get involved in many programs 
because of her convictions. Like the majority of these women, Ruth found a connection between her values and involvement opportunities at FIU. Her entry points were 2 women's organizations that her sister was already a part of when Ruth arrived at FIU. She served in executive leadership roles for both. Since her arrival 3 years ago she had become involved in numerous service projects, political organizations, and social justice organizations. Particularly those related to women's empowerment.

Sally. Sally was 21 years old at the time of this study; she was on track to graduate in December 2009 and would have spent 5 years at FIU. A Health Science major on the pre-Physical Therapy track, she planned to begin a Doctorate in Physical Therapy in August 2010. The oldest of three, Sally has two younger brothers. As her parents were divorced, she also has a half sister with a half brother on the way through her father's second marriage. She described her experience growing up as full of family, Sunday dinners, holidays, and traditions stating; "I consider all my cousins practically siblings. We are that close." She shared the ways in which her family bond over traditions, games, and especially stories about the "old country." It is through these stories that she has come to understand the values and personality traits that her parents and grandparents possess. It is also through these stories that she understands the struggles they went through, especially both of her grandfathers who were imprisoned in Cuba. Sally placed a lot of meaning and importance on her ethnic heritage and expressed how important it was to her to carry cultural traditions on to her children. Although she remained close with her family, she struggled with the amount of time she had to spend away from them because of school and felt guilty when she could not attend family 
events. She is not sure if her family members understand that she would rather spend time with them than be in the library.

Both of Sally's parents were born in Cuba and while her father immigrated to the U.S. with his parents when he was very young, her mother was 18 when she came to the U.S. Sally believed her mother was more closely connected to her culture because of this;

Growing up I always felt more pressure from my mom to speak Spanish in order to communicate with our [non-English speaking] family. I started pre-K speaking only Spanish. She also thought it would be good for my career.

Sally describes her ethnic background as Hispanic stating that since she was young, nearly everyone she met was Hispanic and that Hispanic was the general term most of the people she knew used. However, as a teenager, she had begun to consider herself American, a U.S. citizen, who associated her cultural background as Hispanic.

Sally attended all female schools until college and shared how that impacted her self-confidence and esteem by stating;

I think that helped me be the person I am today; it helped me focus on my academics. I was able to prove that I can do anything I want. I was successful in academics and a leader in student government from the time I was in elementary school. I listened to my classmates and helped make decisions about things that would affect us all. I engaged in all kinds of activities without being intimidated.

She considered herself an open-minded person and attributes this to her family's background as well as her travels abroad sharing;

Even though I grew up in the bubble of Miami, I feel like I've been exposed to many things and many different cultures. I've traveled abroad and had the opportunity to study abroad, and it's opened my world.

She describes herself as optimistic and excited, competitive and friendly; a good friend who is always willing to lend a helping hand. As a result she has been taken advantage 
of and shared an experience of a friendship that had to end because the "friend" was taking advantage of her and treating her poorly.

Sally's parents encouraged her to get involved in extracurricular activities. The first involvement opportunity she remembers is dancing ballet. She loved it. In elementary school she also ran for student council. She enjoyed helping others through community service, having people look up to her, and the self confidence she gained running for elections and giving speeches. She shared how these activities helped her learn to set goals and prioritize activities. FIU was her backup school. Her first choice was the University of Florida but she did not have the funding to attend and figured she would transfer after a year or two. However, once she started to get involved she realized that she had made a home for herself and strove to "make FIU a better place for everyone." At FIU she was a member of a sorority, a leadership and Greek honor society and was involved in many service organizations, serving in executive leadership positions for two.

\section{Summary}

Although these women were linked by the verity that each identified herself as Hispanic and a leader at the same institution of higher education, the actuality of this experience was richer than these two connecting points. These women shared many things. Each described a desire to give back to a larger community that included FIU, other women, and various issues for which they had become passionate. They shared a desire to become themselves through the experiences they engaged in during college. And, all but Ruth, shared a pride in being Hispanic and female. As each of these women 
shared their stories, the themes began to emerge from their voices. The following is a presentation of those themes. 


\section{Chapter V}

Topics and Themes

The participants' reflections of their experiences revealed the dynamic process of developing a leadership identity. The experiences of these 11 Hispanic women were varied in the ways they came to see themselves as leaders, the ages at which this understanding of leadership and self as leader emerged, and the ways in which these experiences and their context impacted them. However, the way in which they engaged in the process of developing a leadership identity provided a common ground on which to understand their leadership identity development. As I will discuss later in this chapter, their process aligns in many ways with the process described in Komives et al.'s (2006) stage based Leadership Identity Development model.

Data from the first couple of interviews provided an indication of areas I wanted to explore. As explained in chapter 3, the areas that were intentionally addressed included: (a) relationships, (b) the impact of being a majority-minority, (c) leadership as an opportunity to develop myself, and (e) making meaning of involvement experiences. Each of these areas was discussed within the literature review. This data provided a path to guide further question and analysis. Each of these initial areas is represented in the final topics and themes of this study as they continued to emerge as significant patterns in the data. Discussions with my peer reviewer and analysis of the data from this more extensive study caused me to restructure and further develop the themes and topics to the present structure.

The complexity in representing these data lies in the ability to present it in a manner that is easy to understand as identity development formation is a complex process 
and understanding the possible implications of gender and ethnicity on the development of a leadership identity specifically is complicated. Even so, themes connecting these women's leadership identity development emerged from the cross case analysis and, with the assistance of my peer reviewer, I was able to further break down the topics into themes that were most relevant to the experiences of the participants and the focus of this study.

Five topics emerged from this data: (a) Encouraging Relationships which includes the themes my family believes in me, mentors and peers; (b) Meaningful Experiences consists of the themes being a part of something, reflection on experiences, and the ways in which these experiences changed their view of leadership; (c) Self Development which comprises the themes knowledge of self, a desire to become the best me, and self competency; (d) The Role of Gender includes the themes gender roles, expectations and differences, strength and support of women, and building on progress and; (e) Impact of Ethnicity which includes the themes being a majority-minority, using my leadership to help people of my ethnicity, and cultural expectations. The topics and their themes are shared in order of salience to the participants with those the participants shared as having the most salience discussed first. Figure 4 presents the final coding of topics and themes in graphic format.

\section{Encouraging Relationships}

The topic of encouraging relationships is used to describe the meaningful ways in which the significant people in the lives of these participants impacted their development of a leadership identity. These significant relationships included my family believes in me, mentors and peers. The ways in which each of these influences impacted these 


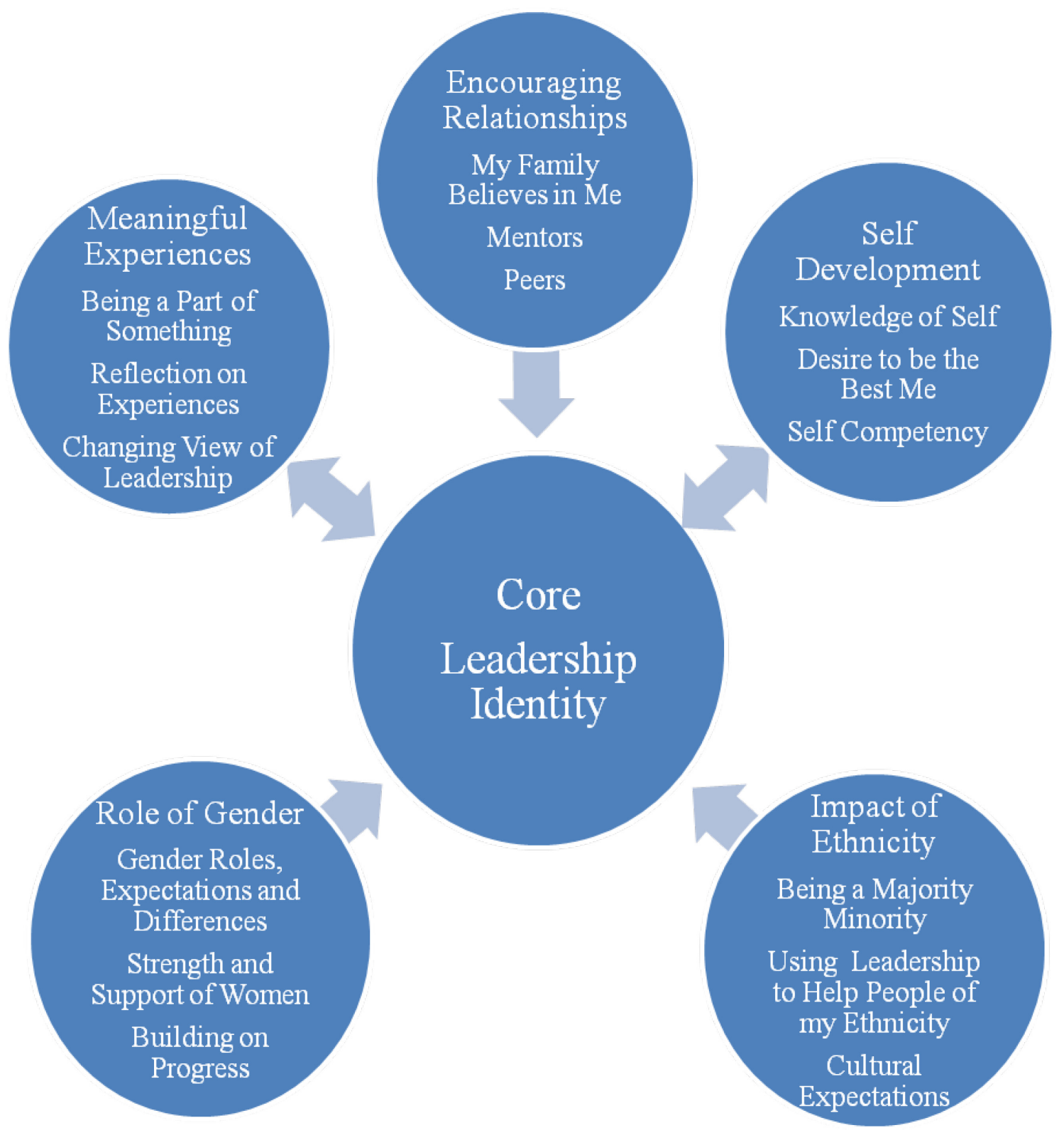

Figure 4. Final coding of topics and themes of influence and factors affecting leadership identity development of Hispanic women participants. 
participants was unique and varied depending on where the participant was in her leadership identity development. Yet, encouraging relationships were salient to all. The people with whom participants had meaningful relationships; family, mentors and peers, were first to encourage the participants' leadership potential. It is not surprising that relationships emerged as a main topic in these women's leadership identity development as research on women's identity development provides overwhelming evidence that women develop and gain a sense of identity in a context of connections with others and that women's sense of self is organized around building and maintaining relationships (Belenky et al., 1986; Chickering \& Reisser, 1993; Gilligan, 1982; Jones, 1997;

Josselson, 1987). Ruth articulated this concept well when she said, "the relationships are what caused you to want to be involved, and also the things that help you get done the things you want to get done."

\section{My Family Believes In Me}

Family members that believed in the participants make up the first theme in the topic encouraging relationships and played a variety of roles in the leadership identity development of these women. Family was their main sense of support in becoming the person they are today, provided the initial push to become involved and develop their sense of self, and provided the foundation of values, ethics and behaviors from which their leadership identity developed. The literature intimates the importance of family in the leadership identity development of women (Komives et al., 2005) as well as the general identity development of Hispanic women (Owles, 2009; Torres, 2003). For these women, family, particularly their mothers, helped them build confidence, and provided support and encouragement as they began their leadership identity journey. The 
message "you have the ability to be and do whatever you want" was explicit in each of their stories and connected to the immigrant perspective that each of their families had. As Alissa stated,

She's [mother] like, "I believe that you can do whatever it is that you want to do." I think that's something that has always stuck with me. Work hard, and sooner or later you'll get what you want. Work hard because at the end, hard work will pay off. Only you can decide what's going to happen.

Their mothers and fathers encouraged the development of an internal locus of control. Although these messages were strong, they conflicted with other unspoken messages about appropriate behavior and decision making for women as illustrated in Alissa's father making the decision for her to stay local and attend FIU. Many of these women are conflicted about the messages they heard from their families regarding gender and their ability to be strong leaders. Although this message "you can do anything you set your mind to" rings true in each of their familial experiences, the expectation to adhere to traditional gender roles is also strong. As Optimus Prime shared "the women in my [on my father's side of the] family take care of the men and treat them like another child...it's very patriarchal." It was clear in her tone and further explanation that Optimus Prime used the term "child" for the men and not "maid" for the women intentionally. She did this to express contempt for patriarchal expectations that men's needs be responded to by women. The separate topics of the role of gender and the impact of ethnicity, and the conflict they create for these women, are delved into later in this chapter.

From an early age the influence of a family that believed in them was profound in helping each woman begin to create the life she wanted through development of self and 
involvement with extra curricular programs, mainly involvement in sports, academic competitions, and service organizations like Girl Scouts of America or church. Through interaction with the people in these programs the participants began to develop a sense of what it means to be a part of a team, to make a difference in the lives of others and to give back to communities of which they were members. Claire, an only child with a single mother feels that she started the process of becoming herself when she began to get involved,

I was in elementary school and I got involved 'cause my mom started getting me involved academically, like always get perfect attendance, always get straight As, honor roll, participate in science "thingies" and competitions; and I was always good at that. She helped me realize I could be good at that and I started like, gaining my own personality.

Their families' immigrant perspective was also evident in many of these women's stories of developing a leader identity. Their leadership stories almost always began with a narrative about the sacrifices that their families endured so that they could have a better life, survival from countries that did not provide opportunities for leadership and education, and the importance of hard work. Ruth, who is one of the few amongst her family who had the opportunity to attend university, and whose life in the Dominican Republic was surrounded by poverty and gangs, was taught the importance of being "busy" outside of school at an early age by her mother,

My sense of being involved outside of school came from her [mother] as well because one of the things she always taught us is that a child who only goes to school and spends the rest of her time with her friends, that's the worst thing you can have, especially in the area we lived...So, every day after school we would go to music school. Yeah, I spent since I was five until I left for the U.S., 6 years or more, going to classical school for music...It was always something to keep us busy with the goal to not fall pregnant at 14 . 


\section{Mentors}

Older adults, teachers, advisors and coaches also contributed intricately to the participants' leadership identity development and emerged as the second theme within the topic encouraging relationships. These adults provided encouragement, challenged them to think critically about their views of leadership, and take on new challenges. Mentors helped them make meaning of their experiences and contributed to developing an environment in which participants felt comfortable learning to communicate their thoughts, relate to their peers, and experience group dynamics. In addition, the women viewed mentors as role models of what a leader "looks like." This information corroborates with studies by Armino et al. (2007) and Komives et al. (2005), both of which indicated mentoring relationships to be especially important for students from non European American backgrounds and Boatwright and Egidio (2003) who noted the importance of mentors in women's aspirations of leadership.

For many of the participants, encouragement from mentors helped them gain a sense of confidence in themselves and challenged them to get involved with leadership opportunities they may not have considered on their own. Lara, whose involvement in leadership activities began in elementary school, articulated this well as she described a particular position her teacher encouraged her to apply for,

I feel like I wouldn't have taken that first step if it wouldn't have been that my teacher approached me. Just because she pointed me out, and it made me feel as though she thinks I have a chance, so possibly I do. Especially because I was so young, I don't really feel like I would have been able to decide on my own whether I was qualified or whether it was just a joke for me to have done it. At that point I had never really heard of the program so I really don't think I would have known about it. And then I feel that, I feel that now it's become a part of my personality and ever since then I go for things. I seek out opportunities to grow as a leader. But at first I don't think I had even established my personality enough. 
Margaret, who until college seemed to connect more with mentors than her peers and thus always had strong role models in adults, communicated the impact that one mentor's recognition of her leadership abilities had as she challenged Margaret to "take her leadership to the next level."

[Advisor] is a great mentor, she's the best ear you can find. If you ever need to talk to her about anything-anything and everything, you can go ahead and throw it on the table and she won't be "mommy like" in her responses; you know, "and you should do this." She is much more of a friend in her responses and she sees the potential in me. The only reason I became a part of the SafeZone committee here at FIU is because [advisor] suggested me, and I was like "wow" that's pretty great that she wanted to put me on a [professional] committee and everything.

Mentors also helped these women understand the complexity of the concept of leadership and recognize that leadership is not just a position, but a process. JLo, an emerging leader, shared that although she does not like to call herself a leader, she understood that others viewed her as a leader because of her position of high visibility. However, the following quote clearly articulates that she was beginning to recognize leadership is not positional;

[advisor] said "have you ever been in a situation where there's a leader but someone else is actually moving the group forward in its process?" and I never thought about it before but it is true...Y You would think that the leader was the one in the position, but in many situations it's someone else taking charge. After [advisor] said it I do pay more attention and I see it.

Participants also expressed the leadership skill they developed from their interactions with mentors. For example, Ruth, who was having difficulty getting members to follow through on a large project that she was overseeing for her organization, sought advice on how to deal with group conflict from a mentor, I reached out to [advisor] and she was amazing. She understands my background because I've talked to her before in terms of how family oriented I am and my story and how close I am to my family and how I see my group members as 
family so it's so hard for me to ask for help... and to hold them accountable if they don't do it themselves. She really supported me in that she would give me advice on how to go about talking to my members.

Similar sentiments were expressed by Claire who described the depth of

experiences her advisor introduced her to as well as the specific skills she learned through

interactions with this advisor,

She [advisor] did everything, I can't lie. She introduced me to these things, she started everything. She taught me about time management, conflict resolution, all these things that form a good leader. She really got me listening and then she introduced me to the Academy of Leaders (AOL), Relay for Life, Dance Marathon, all these other things that I've learned, really just came from her, so I'll always thank her. That's why I'm in her office every day because I feel like every day I can learn something new from her.

Peers

The influence of peers in these participants' leadership identity development emerged as the third theme within the topic encouraging relationships. Numerous participants cited peers as a reason that they joined a particular club or organization. They describe their peers as friends and role models, who encouraged them to become involved, take on various roles, run for leadership positions. Peers also taught them what it means to be a leader, and a follower. Sally, a sorority woman who was involved in numerous leadership experiences, began her FIU experience believing she would transfer after her first year. Therefore she did not seek involvement in the university her first semester.

I never attended any of the summer [sorority] recruitment events because I didn't really care at the time, but once I started I saw friends who told me to do it and that it was great. So I signed up and went through it and fell in love with the philanthropy and community service. And since I've joined the sorority, people who got to really know how I was would tell me things that they thought I would be good for. It ended up being that I was able to develop a different group of people through different organizations. I think initially [the influence] was the 
people in my pledge class who were at the same innocent stage as me and then the older ones kind of adopted us. So I think that was kind of neat that I had some guidance, and they were the ones trying to get me involved, you know, people on the E-Board who saw something in me or potential.

JLo considers herself a new leader and articulates how amazed she was at the

diversity of activities that exist at FIU that her fellow Peer Advisors were involved with,

At one point, all the Peer Advisors from both campuses train together, and [I realized] a lot of them are already involved in things whether it be a fraternity or a sorority. I know some people do Alternative Break and they are like on the EBoard, and some have done Academy of Leaders, the Beacon, and some are part of other organizations... and all these people are doing all these things. They're regular students like me. At first I thought "I'm too young to even do that." I was a freshman when I became a Peer Advisor, and I didn't even think that freshmen could be PAs. But, no matter your status in school, you can still do anything, I saw that they could do it and I was like, hey, I could do it too. If I really want to do something, I could do it.

Peers also served as a model for what they wished to become. Participants

described the actions their peers exhibited that they wished to emulate and the importance of connecting with organizations whose members demonstrated similar values to their

own. Jennifer, a student athlete who serves as a leader for the university athletics association, communicated the importance of her teammates in her leadership identity development,

Sometimes I admire actions. It could be different persons doing different things that you can take and put together...I really admire when people make mega changes in their life. I admire it. I admire when people are honest. When they can tell you in your face how things are because that's difficult, but I expect it. I admire people who help or who don't have enough for themselves, but they are still helping other people, you know? My team, they might have barely enough to live and that's it, and they gave me so much. I feel like they are my family now, and that is leadership.

These participants gained a great deal of understanding about the breadth of leadership from their peers. As evidenced in Sally's earlier quote, peers engaged them in 
the leadership process and challenged them to take on new roles. Cynthia shared a similar sentiment when she shared the following;

Once you get involved in one thing you meet people and you see what they do and it's like, oh I want to do that, and you do it and you meet more people and they're doing something else and you're like, oh I want to do that too. So you start one place and you branch out, and sometimes it's related and sometimes it's not. It's really a lot of fun because you meet a lot of people, but at the same time, you're getting a lot of work done. You're helping the community. You're helping your peers.

Peers helped them learn creative ways to motivate members as Margaret shared "I was doing too much and [peer] suggested that I empower my members by giving them responsibilities...It worked." Peers also helped them process difficult situations with their members. Ruth articulated this in the following;

She [peer] helped me open my eyes to the situation. I couldn't see because I was too close and too upset, but she helped me think it through and think up some good ways to deal with it.

As they progressed in their leadership journey, peers became advocates who helped them contemplate the intricacies of leadership and take their leadership to a higher level. Cynthia, a student who has engaged in numerous structured leadership activities since her arrival at FIU four years ago shared the following about her relationship with a particular peer,

I met a very good friend of mine [as an SGA intern] who is the founding president of another organization. We stayed connected throughout the past 4 years. We took classes together, and we encouraged each other's leadership. We support each other in sort of professionally developing each other's members as well as our own. Whenever I have a problem with my organizations, we bounce ideas off each other; how to deal with those situations. Within my group, my peers have helped me a lot because they see something in me, and they want to make sure that I go as far as I can. They value a lot of my opinions. 
Encouraging relationships influenced the participants' leadership identity development uniquely at each stage in their process. However, it was clear that the encouraging relationships they had were salient to all in this process. Parents and family members carried the most influence early in their involvement experience while peers and mentors were more influential to this process while at FIU.

\section{Meaningful Experiences}

The topic meaningful experiences is used to describe the impact that participation in activities, programs and organizations had on the participants' leadership identity development. These participants engaged in programs and activities that helped them feel a sense of connection, process what it means to be a leader and practice leadership skills. Thus, these experiences became meaningful to them in their development of a leadership identity. Research indicates that involvement in meaningful experiences can have a profound effect on students' leadership development (Astin \& Astin, 2000; Dugan, 2006; Kuh et al., 1991). This was evidenced throughout these women's stories as they shared how involvement in key experiences helped them engage in group processes, "try out" leadership styles, build upon this foundation and develop an understanding of what leadership meant to them. In listening to the voices of these students, it is clear that the meaningful experiences in which they participated provided the environmental context in which their leadership identity developed. The meaningful experiences described by these women emerged in three themes; being a part of something, reflection on experiences, and the ways in which these experiences changed their view of leadership. 
As described earlier in this chapter, a large percentage of students involved at this institution are Hispanic women. In listening to their voices it is clear that this environmental factor impacts their engagement in these meaningful experiences, specifically in their feeling of connectedness. While I touch upon these implications in this section, they will be presented in greater detail within the topics of the role of gender and the impact of ethnicity.

The participants in this study chose to become involved for many reasons, both intrinsic and extrinsic. For many, their first experience derived when they were young and a parent or teacher encouraged them to participate in a particular activity and for others it was a desire to belong to something. But each had a "first experience" that began her leadership journey. During these first experiences each participant connected to a sense of involvement in extracurricular activities that prompted her to continue to seek involvement. As one participant shared "I felt like I belonged, and once I started getting involved, I wanted more, and more.” These experiences served as a training ground for them to develop an understanding of what it means to be a leader and for their leadership identity to evolve. Optimus Prime shared "I started to see what I was capable of, how my skills fit into the team and what I could contribute." These experiences also helped each woman develop a better understanding of who she is, and to clarify her beliefs and value system as well as her interests.

Through these experiences each developed important skills. They learned from peers and experienced different value systems, life experiences, and perspectives. Involvement in these experiences, and the people they developed relationships with through these experiences, broadened their understanding of leadership. They developed 
a broader perspective of what it means to be a leader. Participation in these experiences gave them words to talk about their new knowledge, and helped them to create a leadership identity.

\section{Being a Part of Something}

The desire to be a part of something played a significant role in the leadership identity development of these women and is discussed here as the first theme under the topic meaningful experiences. For many, their rationale for getting involved stemmed from a yearning to make friends, find a community of like-minded people and have a positive impact on others in the process. Boatwright and Egidio (2003) found correlations between women's connectedness needs and aspirations of leadership and hypothesized that because women develop their identities within the context of connections with others and the changing paradigm of leadership theory, younger women may find congruence between developing connections and leadership roles. Therefore it is not surprising that these women articulated a desire to experience connections with others through meaningful leadership experiences. As Claire stated,

I always felt like I was at a different place than my [high school] friends; but here [in AOL] everybody was motivated to make a difference, I finally felt that I was connected with these people and I was like, "Finally!"

Early in this process they sought involvement in groups with likeminded individuals whom they could connect with via participation in team sports, theater, sororities, and leadership roles on campus and within service organizations. Their motivation was to find a social connection with other likeminded people and a place where they could become involved. It is through these groups that they began to take on leadership roles and become invested in developing as leaders. Later, as evidenced in 
Claire's statement above, their motivation to be involved focused on accomplishing meaningful goals that had a positive impact on the lives of others, particularly underserved populations including children from low socio-economic backgrounds, gay, lesbian, bisexual and transgendered individuals, and women who have experienced domestic violence. Their motivation for these causes was personal, a group they belonged to, an understanding that they now had privilege thanks to their parents' struggles and thus had a responsibility to "pay it forward," or a desire to right wrongs they had witnessed in their communities. As Margaret shared,

Well, I am a part of the GLBT community so I felt that I needed to help other students like me who are having issues. Whether it be with their family or, like, socially, maybe they need more friends they can connect with or something like that...so, those are my main reasons.

This ethic of care, of wanting to help and support other people, was evident in each of the participant's stories.

Lara's involvement experiences focused on community service, and her passion to be a part of something that will continue to positively impact others was evident as she discussed a community clean up project in Ecuador of which she was a part;

It's so amazing to see something that started so miniscule, just doing a drive, ends up being something that every single year, different schools will go and will be something even better and greater. They've built a playground; they've been able to really establish a home for these kids. When we first saw pictures, where they were living was a sewer, it was literally a dump for sewage for the better parts of Ecuador, and now it's a city that even tourists are looking into because they don't just want to go and visit and sight see, they want to be able to kind of leave a mark.

Formal group leadership experiences were of particular meaning to these women's leadership identity development, particularly the ones that connected theoretical learning with service projects. Formal group leadership experiences connected them to a 
community of peers working towards similar goals. They provided a context to intentionally discuss what being a leader means to them as individuals, and as a group, and provided a chance to "try out" the skills and tactics they learned. The opportunity to "see" leadership in action, through group dynamics and to gain an understanding of the diverse viewpoints of peers, were meaningful in these women's leadership identity development. Liz was involved in a few team activities including theater, step and an honor society prior to coming to FIU but felt that she really began to understand what it means to be a leader and a part of something through her involvement in the Academy of Leaders (AOL). She viewed this experience as significant in her leadership identity development.

AOL pretty much confirmed in my head, like my perspective of being a leader, that everyone should be involved, not just one person. So I think the main thing that I got out of it was that it is a team effort and it's not just one person. We all had different views, different backgrounds and different things to contribute. It was a lot of fun, and I developed relationships with people. I learned more about being a leader. I was a part of something.

We had a retreat in Labelle, Florida for a full weekend, and we had a blast. It was so weird because I've never experienced something like that before where you're with a big group of people you don't know and two days later you feel like you've known them forever. We had a blast; we learned a lot about each other on that trip. We studied, and we had a lot of activities that even helped us to get to know ourselves better. We even had a challenge course in the middle of the woods, and it was really cool. Then we had meetings once every two weeks where we talk about how to be an effective leader, how to delegate tasks instead of demanding, and they took us through different steps, to help us understand how it applies. They gave us the information and afterwards they would have us apply it in different challenges or activities.

Then they would bring us back in and give us a different step and more information and have us apply it again. I think that's a good way. Experience and seeing how it works in group dynamics helped us learn about other people, what they think, who they are. And then we applied it to our service project, working together, as leaders, each giving our part, to accomplish that goal. It was awesome! 
The Academy of Leaders was meaningful for both Liz and Claire as it provided a connecting point, something to be a part of with like minded individuals as well as a structured environment to learn about leadership while contributing positively to the lives of others as each AOL class chooses a service project to engage in as a group. Of particular importance, they came to believe that leadership is learned and that anyone can develop leadership skills.

Although their understanding of what is means to be a part of a team was different for each group of leaders, it is intimately connected to the theme of belonging. Each of the women described the experience of learning to be a part of a team as critical to her leadership identity development. Ruth's sister, a feminist and women's rights activist, came to FIU the year before Ruth and encouraged her to become involved in both the Women's Studies Student Association and the Vagina Monologues production. Ruth shared what jumping into these leadership activities, with little leadership experience, taught her about teamwork. The following quote illustrates her understanding that leadership is not about doing it all, but about engaging others in the process.

When I came in as secretary of the Women's Studies Student Association, I was put in charge of the Vagina Monologues, which was ok, I will do it, that's what I came in for, to be the director. I was supposed to have a producer, but she failed at what she did, so it was up to me to take that on as well. And, at the time I hadn't had any leadership experience that would help me with that. I'd had experience with the play and whatnot, but not to the extent where I would have to take over, where I knew how to bring everyone together. It was my first major, major leadership role. Everything depended on me, or at least I thought it did...I had just turned 18 at the time, and I didn't know. I didn't know how to go about calling for sponsors and asking other people to give me something, and I didn't want to ask for help from other members of the organization because they had their own responsibilities. So I basically talked to my sister. My sister didn't know either because she didn't have that experience either, but she was helping me out. It came to a point were I was burning out because it was so much 
responsibility...finally I asked for help from my members and my sorority sisters, the cast members and my family, and from that experience I learned that you have to ask for help. You have to involve others and trust others, you have to build a team.

This premise of not wanting to ask for help, or hold other's accountable to their responsibilities, permeated these women's experiences and is a concept that will be examined thoroughly under the topic role of gender. It is through experiences similar to Ruth's that each of these women came to recognize that leadership is not about doing it all yourself, it is about engaging others in the process and empowering them.

By listening to the stories of the participants, it became clear that there were certain common experiences that held particular meaning for their leadership identity development while at FIU. Two structured programs, the Academy of Leaders and Alternative Break, were identified by the majority of participants as having a significant impact. Two of the participants expressed a desire to run for leadership positions in the Student Government Association (SGA). However, both expressed disappointment as they realized that at FIU, if you are not involved in a fraternity or sorority and have the support of the Greek community, it was nearly impossible to be considered a viable candidate. Cynthia articulated this feeling in the following;

When I was at orientation I made my decision that I wanted to go through the SGA route and I became an SGA intern my freshman year. I then decided to run for lower division rep, but I didn't have a sorority to back me up and they kind of run SGA. So I didn't have my people, and I couldn't get enough votes. A lot of bad things happened in that election and I decided to go another route in my involvement.

Although not explored in depth, I found it interesting that Cynthia, as well as two other participants who were not involved in SGA and/or sororities, described the outsider 
experience of this. This would be an important topic for future studies or for administrative policy.

\section{Reflection on Experiences}

Intentional opportunities to reflect upon their experiences also contributed intricately to the participants' leadership identity development and emerged as the second theme within the topic meaningful experiences. The types of reflective activities depended on their leadership experience. Early on, it was during intimate conversations with family members. Later, reflective activities included assignments in leadership courses or training activities as well as conversations with peers and mentors as a way to process group experiences that were particularly good or difficult. Sometimes these occurred in groups after training experiences. The reflection exercises provided an opportunity to assess their self, understand others, and make meaning of their various experiences. Margaret commented on the intentionality these reflections had on her cognitive learning about leadership.

We actually had assignments. We had to read stuff and read up on leadership theory, and then we discussed it in class. We would all share, and we had such different experiences to relate to the readings. Those are things I wouldn't have done in another organization, and it made me think about what leadership really is.

Regardless of whether it was participating in an assignment for class or for a structured program, processing group, leadership and team experiences, reflection was important in these women's leadership identity development.

Optimus Prime, an emerging leader who described herself as shy was not the first to share her opinion in a group or get involved in the activity at hand, unless she was 
prompted. Optimus Prime shared how important these reflective exercises were to her

understanding of leadership and for herself as an emerging leader.

Having a chance to talk about it after is just as important, for example take the team builder exercises. We've done a lot of them. I mean, basically they are just difficult tasks for a group of people to accomplish because of conflicting personalities. There have been times where it's just very frustrating. People get snippy with each other and they start getting, you know [cat sound ] and you just sit back and go, here we go. That's how people work together. It's the trial and error. It's the frustration and then once the task is accomplished, then it's like whoo, a release. Then it's like okay, it wasn't that bad, we worked it out. You know, I'm sorry, I said this or I'm sorry I said that. But in the heat of things... yeah. That teaches us how to work with people and the discussion after helps us understand how it all happens, the role we all play in it and how others think.

JLo had just finished her first year at FIU and was learning the role that civil

conflict played in team development. Like many of the women in this study she found the process of expressing herself in a group reflective experience important to her team's cohesion and to her leadership identity development. She shared the following,

At the end of every day, we [the Peer Advisors] would do group up, and there's been a couple times when personalities have clashed and ideas clashed but we've never made it into a full blown ordeal. Later on at our group meeting we talk about our highs and lows, and we process group stuff. At one of these meetings, my teammate said that one of his lows was when I corrected him in the middle of our presentation. He felt I should have pulled him to the side and told him, but I felt that he should have pulled me to the side instead of saying it in front of everybody during the group up. In situations like that, when someone is hurt we give them space, but we always group up; and then we kind of come together as a whole. And we kind of see what we're doing, what we've learned. Like sometimes we're not including everybody in the group so we stop and see what we're doing wrong and then we fix it.

The more experienced women leaders in this study also used reflection within their groups as a way to help group members understand the responsibility they have for group development. They used reflection as a way to help their members see that understanding a diverse group of people's needs and motives and sacrificing for and 
supporting the overall group need, is important in developing effective organizations.

Claire expressed how she first recognized the power of using reflection for this purpose when she served as a co-site leader for Alternative Breaks, a program where college students plan community service projects for an entire year and use their break periods to engage in the project.

One girl woke up in the morning super grumpy because some people are not morning people, and another girl tried to say hi to her, but the other girl didn't answer because she's one of those people who doesn't like to be bothered in the morning. So they started arguing. There was this big miscommunication because the group was dividing. Half the group wanted to go to church and the other half wanted to go sight see, and it was back and forth fighting and they thought the other half of the group was getting together to form their own alliance. It was weird; it was like a reality TV show for the first 3 days. My co-site leader helped me because I was overwhelmed with emotion, like I didn't know what to do so he was the mature one. He sat with me and he was like, "Ok, we have to do something." and I was like we can do the reflection and he helped me facilitate it. And we got them talking in a respectful way, with rules, so that worked really nicely.

\section{Changing View of Leadership}

The ways in which participation in these meaningful experiences broadened their understanding of leadership was significant in the leadership identity development of these women and thus emerged as the third theme within the topic meaningful experiences. As they participated in these experiences and reflected upon them, their view of what it means to be a leader and what leadership is, changed. This changing view of leadership impacted the way they chose to lead, the skills they called upon, and their philosophy of leadership. A pattern became evident in the leadership philosophy these women followed. In their early experiences they understood leadership from the "Great Man" perspective; a leader centered theoretical approach which views leaders as possessing particular characteristics that are often "masculine" in nature. Within this 
approach, a successful leader must possess particular characteristics such as decision making and delegation skills and must have a charismatic personality. In this framework leaders are responsible for making things happen; delegating tasks to followers, and making followers follow through on tasks (Northouse, 2007). Jennifer articulated these participants' early understanding of leadership well when she said, "Yeah, I wanted to be the boss; I was dreaming of being the director of everything, I thought that's what leadership was." In contrast, many of the participants shared that they did not want to "be a leader" initially because they did not want to have to "boss people around."

Interestingly, although these women understood that their gender and ethnicity had an effect on their leadership, at this point in their leadership identity development they did not view their gender as a deterrent to being a leader. While they recognized that they did not want to be a leader in this framework of leadership, they did not yet recognize how "masculine" the characteristics were. As they entered into leadership roles they quickly took on the view that "anyone can be a leader," as they believed that a person's gender, race, or ethnicity did not impact their ability to "learn leadership." As JLo said, "It doesn't matter if you are a man, a woman, Black, White, or purple, anyone can be a leader." They sought to almost diminish the role of leader so that they would not put themselves at a "higher" level or be seen as "better than" their peers. The influence of gender will be presented more fully in the topic role of gender.

Their philosophy of leadership changed as they engaged in meaningful experiences. The "Great Man" approach to leadership diminished as they became much more team focused. They began to describe leadership as more of a process in which everyone contributes and recognized that anyone can be a leader as there is no list of 
qualities one must possess, but rather skills that anyone can develop. Their perspective broadened, and they began to understand that incorporating the motivation, goals and needs of all participants in decision making created a synergy that supported an investment in the accomplishment of goals. Margaret was just beginning to take on this view and shared the following awareness moment;

Before I thought I had to make things happen, I was solo as the leader and that was it. Now I'm more receptive, I really want to hear what you have to say, you probably have a better idea or maybe we can make some sort of synthesis go on.

Cynthia also talked about the progression in her understanding of leadership as she immersed herself in leadership experiences at FIU;

Well, in the beginning I would just take charge, I was too much of a chief. I really like took control of the situation because we didn't have anybody planning it so I just started telling people what to do, and that didn't go so well...But now, I understand that you have to get your members involved. So, this financial crisis conference we planned, I came up with the idea but I got other people behind me, supporting me, other organizations even. They asked me what I needed help with, and we talked and split the costs and everything; it took a lot of communication. It took a lot of being on top of everything. I think that if you are going to get things done you have to be able to communicate and take ideas from other people, incorporate their ideas...I learned that [from these experiences].

Cynthia's description is common for the women in this study. Involvement on sport teams, in the theater and as members of organizations helped these women understand the importance of contributing to group processes and goals and supporting group members. Serving in leadership roles helped them understand the value of developing group dynamics, supporting team development and taking the time to engage others in a vision. Lara is one of the most experienced leaders in this study. She has engaged in a multitude of FIU's leadership development programs that espouse team and consensus building, shared goal development and servant leadership. Lara's understanding of leadership truly 
resonates with the philosophy espoused in FIU's leadership development programs,

which was evident in the following reflection;

I feel like those, those different opportunities each one has contributed in one way or another to my leadership style, and to the way that I have evolved as a leader. If it's taking me a little bit more out of my shell. Or, giving me a problem and helping me find a solution. Or even if it's been being a part of a committee, because I feel like you don't always have to be the one driving the car in order to be the individual that makes a difference. I feel like even being a part of a committee has helped me. I've been able to see how other individuals take on responsibilities. I feel like when you're a part of a committee, there are always so many struggles... When you're a part of it you're able to kind of oversee what everyone else does. I feel like I've learned more by being a part of a group as opposed to always just having to be the leader.

As their view of leadership changed so did their comfort owning the term leader.

All of the emerging leaders and many of the intermediate leaders in this study were not comfortable being referred to as a leader. Although they recognized that they possessed many of the qualities and skills that they use to define leaders, they were uncomfortable "being put in the spotlight like that," or "being put on a pedestal." They do not want to be differentiated from other members of their group; they do not want to stand out. However, they are honored that others see them as a leader. This finding corroborates with research conducted by Arminio et. al (2000), which also found that students of color in leadership positions were uncomfortable standing out as different than their peers who were not in a position of leadership. It also corroborates Whitt's (1994) and Boatwright \& Egidio’s (2003) research on women student leaders which found women student leaders to be uncomfortable with the title leader. However, each of the experienced leaders owned the title leader, using it as a descriptor of themselves within the first 5 minutes of our interview. As Ruth shared "I'm a senior, FIU student who is a very, very, involved leader on campus." While this ability "take on" the title of leader contradicts 
what the literature demonstrates, my sense is that this is due to their new definition, which is more reflective of the relational models of leadership.

\section{Self-Development}

The third topic, self-development, focuses on those factors related to personal growth and development that contributed to the leadership identity development of the participants in the study. Self-development includes three themes; knowledge of self, a desire to become the best me, and self competency. These themes focus specifically on the ways the participants described their upbringing and values, their growing awareness of who they were as individuals, the skills and characteristics they developed along the way, and the personal and professional characteristics they desired to attain, as influential to their leadership identity development. Of particular interest was the importance of interpersonal skill development as it related most closely to developing a leadership identity.

Self development is defined by Webster (2005) as "efforts toward self-fulfillment, either through formal study programs or on one's own." This section addresses the ways in which their involvement in leadership and their leadership journey helped them find

self fulfillment. For these participants, involvement in leadership activities contributed to a growing sense of self. An awareness of who they were motivated them to take on leadership experiences more closely aligned to their values and thus contributed to their understanding of self as leaders. As evidenced in the literature on college student development a positive correlation exists between involvement in leadership development programs and cognitive, psychosocial and career development (Astin, 1985; Cress et al., 2001; Logue, Hutchens \& Hector, 2005; Pascarella \& Terenzini, 2005; 
Wielkiewicz, 2000). Therefore, it is not surprising that the participants in this study shared the ways in which they believed their development of self contributed to their leadership identity. However, what is of particular interest is the way in which these women describe the intentionality of their involvement. As a group, these participants describe an inner desire to enhance themselves, and recognize the leadership experience as a conduit to becoming their ideal "me." Self-development relates to the personal growth these women sought out and experienced and the ways in which their knowledge of who they were, their desire to develop their personal and professional qualities and become the best "me" they could, and their desire to develop others, particularly other women, had on the participants' leadership identity development.

\section{Knowledge of Self}

The theme knowledge of self is used to describe the awareness the participants had of themselves, their unique qualities and personality traits, and the ways in which this sense of awareness was enhanced through their leadership journey and which accordingly contributed to their leadership identity development. Each of the participants shared the understanding that in order to be effective in their various leadership roles they first had to develop their knowledge of self. Awareness of their interpersonal skills and the way they related to others was something that each of the women discussed. It was clear that they understood that effective leadership involves social skills at some level. For all, this was articulated through awareness that in order to be effective as a leader they must have good interpersonal skills. Some of the participants described this as a need to "break out of their shell," but for many of the participants, it was awareness that they were natural social beings. 
As these women described the ways in which their knowledge of self impacted their leadership journey and the way their leadership journey impacted their knowledge of self, it became evident that these experiences had a reciprocal effect that helped them develop a multifaceted knowledge of who they were as leaders. Alissa expressed the sentiments of many of these women when she discussed the impact that her leadership experiences had in developing her knowledge of who she was as well as the leader she had become;

I love being involved. It's fun to try different things, meet different people, work with different organizations, and like I said, grow as a person. All of these experiences change you completely - you learn so much about yourself and others that it's really interesting to see how being in different environments and situations, how it effects you as a woman. I evolved from a little quiet girl that moved to the United States from Mexico knowing no English, not one word of English, to being able to play soccer on the soccer field with them or going to our Girl Scout meetings and going camping and doing all of our little community service events. It was very interesting. I broke out of my shell with that. I was always really quiet when I was younger, but I think after that, I had no other choice. I had to: A. learn English and B. make friends. So I think that was the best way for me to do so. Now I just do so much and love what I've helped create at FIU and the people I influence with my leadership... You have to try things, you have to change. You have to be willing to accept things as they come, and definitely being involved helped. Meeting different people in different organizations and just getting involved. Having different positions, you learn to work with people, you open yourself up. Going to your meetings or your events definitely helped a lot.

Early in their leadership experience participants' knowledge of who they were was based upon qualities identified as talents by others, particularly family, mentors and peers. Significant others in their lives recognized that they were smart or had good interpersonal skills or simply wanted them to develop their potential, and these talents were then encouraged and developed. Early on it was difficult for these women to articulate who they were; their characteristics, skills and values, outside of how they 
related to the important people in their lives. Their sense of identity was closely connected with those with whom they had close relationships. For example, Lara shared how a teacher in second grade recognized her sociability and asked her to become involved in a project, "I've never been a shy kid, I was always very friendly, and they recognized that and asked me to be group leader and such." These early experiences set a foundation, an understanding that I matter, that others recognize me and that I do have skills.

As they developed a sense of independence in college and experienced involvement activities that helped them find their voices and articulate what was important to them, they enhanced their knowledge of self and were able to identify parts of their personality that were unique talents to them as well as areas that they wanted to develop or as Claire shared "I started like, gaining my own personality." While peers remained an important influence, they began to separate a sense of "who others think I should be" with "who I really am." Liz, who went through a period being what she would label "a follower," experienced an epiphany as she entered college.

You know, once you enter high school you go through a whole identity-not identity crisis, but it's hard to understand who you are. I think a lot of high school students have a hard time with that. When I entered high school, I wanted to be a part of the group, and everyone wants to do things that they shouldn't do together. After a year or two of being in high school, I realized I didn't care what anyone else was doing. I could make my own decisions. I really started rebelling sophomore year. That was around the time I started saying I don't care about any one of you. I'm doing what I want. Well I knew before I came to the university that one of the biggest, most important things was to get involved, not just getting my grades but meeting people and becoming a part of different organizations and so forth, to accomplish what I wanted for me, what I already had planned.

As these participants recognized themselves as leaders, as the term "leader" was incorporated into this sense of self, it became a part of their identity, and they were able 
to recognize how to use their unique characteristics within a leadership capacity. Their leadership identity grew from their participation in leadership. Cynthia shared what many of the experienced leaders articulated; that her knowledge of self, her awareness of who she was and the talents she possessed now comes from within, but is based on a foundation which others helped her understand and build upon. Like most of the experienced leaders, Cynthia had adapted this understanding of her talents and characteristics into her identity as a leader. She recognized that her unique talents made her the leader she is today;

As a leader you have to know yourself and fit yourself into your roles and your members needs. You have to find the things that move you and the other people who are moved by that. But you also have to recognize how you work with others. I'm a very strong willed individual, and if I don't pay attention I start to "run the show." However, I am empathetic in the way that I can easily put myself in other people's situations, and I use that in my decisions. I want to know what they are thinking, to include them, and I've learned to utilize my strengths and work on my challenges, to find others who can balance me. I know me now, better than ever; I am hard working, persuasive, demanding of myself and others around me, generous, inquisitive, friendly, silly and witful.

\section{Self Competency}

The theme self competency relates to the belief each of these participants established in their abilities and the ways in which this belief contributed to their leadership identity development. In sharing their stories it was clear that particular interpersonal skills - communication, the ability to get along with diverse others, consensus and general relationship building, as well as organizational skills - running meetings, prioritization, and task accomplishment, were important to their development of a leader identity. It was important that they have the opportunity to practice these skills and "do leadership." They developed self competency as they engaged in these 
skills and explored different styles in utilizing these skills to determine which worked best for them. It is through these experiences that they began to understand that leadership skills can be learned which was important to their development of a leader identity.

Early in their leadership experiences the participants identified interpersonal and task related skills that they believed were important for leaders to possess. They expressed ideas consistent with situational, trait or style leadership theories. Although the emerging leaders recognized these characteristics in others, they did not yet feel confident that these characteristics were developed in themselves. The emerging leaders were not yet sure that they could claim these skills and the title, possibly because of the modesty women are expected to exhibit, or because their definition of leadership was still closely aligned with the "great man" theories where leaders "tell others what to do." The intermediate leaders acknowledged that they were developing these characteristics within themselves and the experienced leaders had incorporated these characteristics into their knowledge of self and aspired to develop them in others. Each of these women shared the ways in which the skills and confidence she developed through her involvement experiences contributed to her belief in herself as a leader and thus her leadership identity.

Sally expressed this awareness of recognizing her talents, working on the things that challenged her and recognizing that leadership does not always mean taking the lead when she stated the following;

At one point my GPA had gone down and I don't think it's because of the organizations I joined. I think it's because within those organizations I gave $100 \%$ to everything that I was involved in and school came last because I was so 
into like getting things and thinking I had to do it all. And I just came to a point where I was really miserable and this isn't me. It got to a point where I had to tell myself that I can't do it all, and I always find myself in those situations. I had to make adjustments and still be a part of everything but step down on certain projects and take a backseat. It's helped me mature and focus on my major more and realize what my major has to offer. I've learned how much I can tolerate or handle and that I don't have to be so active. Other people can do it too, and it's not sitting on my shoulders. I've matured in that sense because now I see that other people can do a job just fine instead of me having to do it and that it's important to involve others.

At the core of developing self competency for these women was the shared sense that they mattered to someone, mainly their families and teachers, this positive selfconcept developed in adolescence, contributed to their sense of who they were, and gave them the confidence to engage in involvement activities. They later found this sense of mattering in their involvement communities where they continued to be encouraged to develop their skills through various projects and leadership roles. This links to the encouraging relationships topic described earlier as relationships continued to be influential in their process. Margaret, who had just been accepted to City Year, a program which engages students ages $17-23$ in a year of full-time service tutoring and mentoring in school systems across the country, was experiencing a period of self-doubt and shared "so, I interviewed and they accepted me and I said 'okay, if you believe I can do this, then I guess I can'.” This external locus of control, the recognition that others "believe in me," was important to their development of self competency and eventually an internal locus of control.

As they continued to be involved they received positive feedback, challenged themselves to continue their involvement experiences, and connected their involvement experiences to their value system. These experiences contributed to the development of 
self competency and an internal locus of control. They began to recognize how these experiences developed them as individuals and taught them skills that they believed would help them be more successful. As these women engaged in leadership activities they enhanced who they were as people, their skill set, and their sense of self competency. Optimus Prime, who described herself as very shy and the theater as an experience that helped her "break out of her shell," also describes the ways in which her interpersonal skills progressed through her involvement as a Peer Advisor during orientation for incoming students;

That's the best part of peer advising, since I still have difficulties interacting with people. I have a hard time approaching people first. But as a Peer Advisor I have to ask people if they have questions or things. I have a hard time having that connection. So, what it's teaching me is to be more personable. Also how to deal with [people] in a PC kind of way, especially with parents. It's a good skill to learn, how to be a diplomat in these kind of things. So that's an awesome thing to learn, just how to work with people in all different situations. That's one of the best things [about being a PA]. I guess I have more confidence. I've learned more tact in how to go about things. I've learned responsibility...

As mentioned in the theme knowledge of self each of the women shared an awareness of how her interpersonal skills affected her leadership development. However, as indicated in Optimus Prime's comment, their involvement in leadership experiences also provided opportunities for them to develop competence in interpersonal skills. Each of the participants shared the ways in which her involvement experiences taught her more effective ways to communicate, especially with people who were different. They developed an appreciation for diverse perspectives and valued different points of view and experiences. The women all talked about the impact that working with others who were different than them or feeling different than others themselves, had on their development of self competency and their leadership. For the women who felt different 
and were in some ways marginalized from the norm, their self competency connected with creating opportunities for marginalized individuals to connect and be included in leadership opportunities. Others began to value what "difference" could bring to their organizations and shared a commitment to involving individuals who might be marginalized.

This sense of self competency was different depending where the women were in their development. Early in their leadership experiences self competency linked to the skills they needed to develop as they learned to work with other people. For the intermediate leaders who were beginning to take on positional leadership roles, self competency connected to goal and task accomplishment skills. The experienced leaders recognized that to be effective with their groups they had to develop their team skills, they spoke about delegating, about trusting others and sharing decision making. As their competency in these areas developed they shared the importance of facilitating a team process and building relationships amongst diverse individuals with different needs and reasons for being involved.

As these experienced women developed a greater sense of self competency they began to recognize that the next step in their self development process was to help develop the next group of women leaders. They had developed a maturity in their leadership and viewed themselves ready to serve as mentors to the less experienced members of their organizations. This came in part from a desire to phase out of their roles as graduation approached as they did not want their leaving to affect what the group would be able to accomplish in the future. 
Early in their involvement experiences at FIU each of these women connected with a vision of someone she wished to emulate, something she saw in another and recognized that she wished to become. While these women also spoke of men who served as role models, each specifically spoke of an older woman student whom they looked up to early in their leadership experience. They developed relationships with these women who mentored them as they developed a leadership identity. As their leadership identity intertwined with other aspects of their identity they recognized that the next step for them was to "pay it forward" to the next generation of leaders on campus. While they commented specifically on mentoring younger women students, those in mixed gender groups expressed a desire to encourage all students interested in leadership. Alissa talked about her experience as a Panther Camp facilitator and how important it was for her to develop her group members' talents and skills;

I encouraged them and shared with them ways they could get involved and become leaders, and they did, they got involved in organizations and sororities and some became Peer Advisors. So it was kind of like, I helped them realize that they have the potential to get involved and be a leader at FIU just like how I did.

\section{Desire to be the Best Me}

The theme desire to be the best me relates to the ways in which the participants' motivation to engage in experiences that they viewed as advantageous to helping them be successful people, impacted the way in which they developed a leadership identity. Early in their lives, the belief that the decisions they made now and the activities they chose to be involved in would impact the people they would become and the success they would experience was embedded within each of these women. Although for many, some of their major decisions, for example to attend FIU because it is close to home, were made 
for them by their parents, they incorporated the message that they were responsible for making their experience and that their years in college were building blocks to the adults they would become. Lara articulated an understanding, shared by each of the participants, that she had the ability to build herself into the woman and the leader she wished to become, when she shared the following;

I feel like these are the peak years that we're developing as students or as daughters, or as girlfriends, as wives. Whatever it is that we are I feel like these are the peak years. These to me are the play dough years; these are the years that we're molding ourselves...And I thought, oh my god, this sorority, you know they all looked so poised, they all looked so put together, they all looked like women that were tomorrow's leaders. That's the first image that I got from them. And it's not so much that I wanted to be them and I wanted to have that kind of mentality, I just wanted to, I always wanted to do that. I felt like I, in order to accomplish certain things, I'm going to need to be a part of something bigger than me.

These women recognized that their collegiate experience provided them with a unique opportunity to engage in activities that would support them in developing into the person they wished to become and they were not going to let this opportunity lapse without taking full advantage. To them, developing to their full potential and being a leader involved risks. It was difficult for them to understand why some of their peers would let these experiences pass without taking advantage. They believed that this motivation was within themselves, was just a part of who they are, but also acknowledged that the support of family, teachers and older peers, a connection with the leadership values espoused through FIU, and involvement in extracurricular experiences encouraged their desire to develop themselves to their fullest potential. Jennifer expressed this belief when she shared the following;

I think I was always involved in everything like I was always thinking about ways to improve further than this and some days it was too much but since I'm young, 
I'm trying to build on myself. That's why I think if you have an opportunity you have to take it...I cannot see a possibility coming and I'm not taking it because that's the worst. I mean if it's not working you can return to the normal thing that you were used to. I think I am that kind of person, I cannot see things for what is happening and stay here and watch it. No, if there is as problem, I need to act. I need to be proactive, to anticipate, for me it's real easy, but that's what leaders do. I think some people see there's a risk so they don't do it, because this could happen, but I'm the person who knows I'm going to learn. If anything I'll fail, something may happen, but I'm going to learn. So I'm always saying, "yea it might be risky but it's okay." Life is too short to sit down.

The participants desire to become their best self also related to their motivation to empower others, especially other women; they identified this as critical to their leadership identity. They believed that they were not being the best "me" they could become if they were not attaining their full potential as leaders and that they could not attain their full potential as leaders if they were not supporting the development of others along the way, particularly younger women and girls. This desire to "pay it forward" emerged later in their leadership development. As they began to "own" the term leader, became more confident in their own skills, and more mature individuals, they started to think about those who would lead when they were gone. As one of the participants shared;

I feel like I have learned so much through my involvement and I am becoming who I am supposed to become. It makes me want to do more and more because when I graduate, these are the things that will help me become my best. I would have never thought about becoming [career choice] without the involvement I've had and what I've learned about myself. You know, each experience has opened new doors and gave me a new perspective, a new understanding of me, and I feel like I want to give that back to others to, you know, the girls who now look up to me.

Interestingly, while these women spoke passionately about the ways their leadership experiences were helping them become the women they wished to be, few connected these experiences to their future careers. While they articulated that employers were 
looking for graduates with leadership experience, they compartmentalized leadership and did not connect leadership to a career role. Further exploration of the meaning of this would be interesting for future study.

\section{Role of Gender}

The role that gender played in these women's leadership identity development was shared to some degree in each of the previous topics. However, as the participants shared their stories it became clear that their gender had a profound impact on their leadership identity development; therefore the role of gender emerged from their voices as the fourth topic. Although it was difficult to separate the ways that these participants gender and their ethnicity influenced their development of a leadership identity, through in depth questioning, probing and follow up in the focus group interviews, a pattern emerged indicating that each of these aspects of their identities as individuals had influenced their identities as leaders.

The fourth topic, role of gender, is used to describe the ways in which the participants' understanding of what it means to be a woman impacted their development of a leadership identity. The findings in this section focus on the ways that the messages they internalized about gender taught them what it meant to be a woman leader and the ways that gender roles, gender expectations and gender differences influenced their involvement, the choices they made as leaders and thus their leadership identity development. This section describes several themes that create an understanding of the implications that being a woman had on these participants' leadership identity formation. While gender is discussed as an independent topic, it is important to note that it was impossible for these participants to separate being Hispanic and being a woman as those 
identities were indivisible for them. I have chosen to separate them in order to provide some clarity on the meaningful and complex ways that their gender and their ethnicity influenced their development of a leader identity. The themes within this topic include; gender roles, expectations and differences, strength and support of other women, and building on progress.

A growing body of literature has examined the impact of gender on leadership style, performance, aspirations and ascension to leadership roles (Boatwright \& Egidio, 2003; Eagly \& Johnson, 1990; Kolb, 1999). This literature demonstrates that women are underrepresented in leadership roles, even in female dominated organizations and professions. This research further references that although some differences in style were found amongst men and women leaders, more impacting is the finding that women are negatively evaluated when they do not engage in activities and actions congruent with their culturally defined gender roles, which did not include leadership (Eagly \& Johnson, 1990).

Although, I was unable to find research specifically investigating the ways that messages related to gender influence women college students' development of a leadership identity, Owles's (2009) found that Hispanic women college students struggle with the expectations placed upon them in the home and their desire to develop their leadership potential via involvement on campus. In addition, Komives et al. (2006) found that the influence of gender had an impact on the leadership identity development of the women in their grounded theory study. Specifically, their participants were aware of differences in expectations and opportunities related to gender in leadership settings. In addition, a few developmental theorists have examined factors that influence women's 
identity development (Gilligan, 1982; Josselson, 1987). This research provides a

foundation of understanding the implications of gender and identity on a Hispanic woman's leadership identity development. As the role of gender emerged as a major topic in this study, it is comprehensible that the context in which their gender identity and their leadership identity developed impacted their perspective on leadership, as well as the leadership choices and opportunities for these women.

\section{Gender Roles, Expectations and Differences}

The influence of gender role expectations and differences in these expectations for men and women is the first theme in the topic role of gender. Each of the women in this study described the ways in which her understanding of what it means to be a woman and a woman of Hispanic descent impacted her leadership identity development. While their parents reinforced that they could be anything they wished to be, it was still clear to the participants that they could be anything they wished to be as long as they were also a "good Hispanic woman." The term "good Hispanic woman" was described as "putting family first," "letting the man make decisions and have the voice," "being responsible for the domestic responsibilities in the home even if you have a career," and "getting married and popping out babies right away." These women shared the differences in the chores and curfews between girls/women and boys/men in their households. It was clear to them that if they were going to be independent and make plans for their lives they would still be expected to take care of their families' needs.

Messages regarding these expectations were most directly imparted to them through their family members. The participants whose parents remained married described the role that their parents played in the home as influential. Their fathers were 
the patriarch of the family and had the most vocal voice, directly expressing what is expected of them as Hispanic daughters. Older family members, grandparents, great aunts and uncles, also expressed this direct message. Mothers played an important role as well, while most worked full time they also took on the domestic responsibilities of the family. While the participants were aware that their mothers would never question the authority of their fathers, they also knew that they wanted more for their daughters. Mothers relayed subversive messages about independence and "doing better than me," that these women integrated. Their mother's message was often conflicted; reinforcing traditional gender role expectations for daughters in public, but imparting the importance of independence and the message "don't do as I did," in private. It was clear that their moms had "given up" a lot to raise a family. One participant shared,

My parents came here to the U.S because my dad got a job. Then my mom found a job, but my dad worked a lot of hours and she had to take care of us and the home. That's what a good Hispanic woman does.

Interestingly the behavioral messages of mothers aligned with traditional role expectations, but it was the direct verbal messages they received from their mothers in private that most contributed to these women's sense of independence. Each of the women whose parents remain married, Alissa, Cynthia, JLo, Jennifer, Lara, Ruth and Sally spoke of the dichotomy in the messages their mother verbally shared with them compared to the role they played in the household. Alissa, recognizing that her mother did not have the same choices as she did, shared the following statement;

My mom didn't graduate from college; my mom just got married to my dad. And then they moved to the United States because my dad was pursuing his Masters and his Doctorate. And my mom has always told me, she's like, "I don't care who it is, I don't care if it's the President of the United States, if he tells you that you can't do something, don't listen to him. You can always do whatever you 
want to do and do whatever makes you happy." Maybe it's not necessarily from being Mexican, but just a woman. She's always been very, do whatever you want to do, don't let anybody stop you, not your friends, not even your family, not your boyfriend, not anybody. She's like, "I believe that you can do whatever it is that you want to do."

Alissa's mother encouraged her daughter to discover herself, identify and begin to pursue her dreams and make decisions for herself before finding a significant other, so that she will know when she has met someone who would also support her choices and dreams. Although the messages were seldom explicit, they were integrated into these women's understanding of the role gender played in their leadership identity development. They share differences in the way that boys/men were treated in their families, and the ways in which girls/women were expected to behave as meaningful in their experience. Many spoke of being trained to be mothers and housewives, to cook, clean and take care of the men in their families and believed that they should do all this while pursuing their leadership and career aspirations. JLo verbalized eloquently what each of the women expressed;

"When are you going to get married? When are you going to have kids?" Like my older sister just got married, and they're already waiting for her to have kids. And she's like, "I'm not ready yet." And sometimes I feel like my family are like baby making machines; someone's always pregnant. And the whole traditional, you cook and you clean, that's a woman's role. That's very part of the older side of my family, my grandmother and my mother. But the newer generation, we're not really as much into the whole the woman has to cook and clean...My grandmother is the type, you have to serve the man, but it's kind of diminished as the years have gone by. But they're still like, you should get married and have kids. Education is good, but you have to have someone to keep the family name going... So now he [father] has this little boy, he's the star. I don't even know how to explain it, they're so happy that they have a boy to carry on the name. I don't know, he's cute...He really is like the star almost because they're looking at him to carry the name on and they kind of even put less expectations on him too. They're more lenient. When I was growing up it was kind of like, "Don't do that, I'm going to tell your dad." And I'd shiver in my boots. I'd be scared, like, "No don't tell him." But now it's like, if you tell my little brother, "Don't do that, I'm 
going to tell Dad." He's kind of like, "Ha-ha, yeah right." I'm like, "oh my God, are you serious?" They put a lot less expectations on him. And he knows that too, and he's only five.

This message that boys are more important than girls was articulated by two other participants.

At the same time, each of these women talked about the messages of independence and self autonomy they received behind closed doors, mostly from their mothers who shared that they desired more for their daughters. Their message was "Do as I say, not as I do," for while they could clearly see that their mothers subscribed in action to these prescribed expectations of women, they had their ways of "getting what they wanted" from their patriarchal husbands. These stories were shared by nearly all the women, except Lara, who recognized that her family was very different than the other Hispanic families she knew.

Participants raised by single mothers received the direct message that it was important to be independent, but this often conflicted with other family members and gender expectations within their community. For Claire, Liz, Margaret and Optimus Prime who were raised mostly by their single mothers, these messages were overt and related to relying upon yourself, not a man, to gain and accomplish what you want out of life. They were told, and believed that they could "have it all." This meant have a successful career, a life partner, children and take care of family responsibilities. They described a life partner who would share household and family responsibilities, contributing in ways that men have not traditionally contributed. Even those from single mother households believe that they will find a supportive partner because men today are "different." 
The internal struggle to incorporate these scripts into their future plans was most prevalent with the participants whose identity was intimately connected to their Hispanic roots: Alissa, Claire, Jennifer, JLo, Liz, Ruth and Sally. Each of these women portrays the struggle they all felt to follow these scripts while continuing to develop their leadership identity. However, Lara, one of the participants who most strongly connects to her Cuban American heritage, described her experience as an anomaly. Although she understood that her experience was not "typical Cuban family," she grew up in an environment where she was challenged to step outside the box. Her grandmother earned her doctorate and had a career, and her parents became parents very late in life. However, she describes how completely different this is for the other Hispanic women in her sorority.

Of particular interest was the belief that the men in their lives, particularly their future partners for those who were heterosexual and desired to form life partnerships with men some day, would be less patriarchal than what they viewed as traditional in their culture. This concept was of particular interest to me as even though it was clear to these women that the men in their lives, their brothers, friends, boyfriends, were for the most part exempt from household chores, and grew up with these same gender role expectations, they articulated a belief that these men would behave differently when they became colleagues, supervisors, fathers and husbands. Contrary to virtually all the evidence they provided to the contrary, these women were able to hold this illusion. They saw these experiences and leadership as completely separate and believe that these men's experiences with gender role expectations will not affect their belief in what women can, or should do. 
These participants are not yet making the connection between the gender role expectations that their male colleagues have been raised with may affect their interactions in leadership roles. They share a leadership perspective that is gender neutral. They do understand the inequality that currently exists in our society between men and women, particularly women of different ethnicities in leadership positions. However they believe the disparity we see in society today is due to the discrimination that exists in their parents' generation and that their generation thinks differently. Therefore they believe they will not experience such blatant discrimination when they compete with men for the same leadership positions. While they understand that racism and gender discrimination still exist, they believe that their generation will bring us that much closer to parity. Jennifer articulated this sentiment, expressed in some form by each of the women, in the following quote which also alludes to a recognition that there is still a "fight" going on for this parity.

I think it's [our leadership abilities], personality more than gender and initiative [that controls our leadership destiny], and personality and everything is shaped by our society and our influences, you know? For me, Hispanic people have a more difficult way to get stuff, that's from my experience. When I came here [to the U.S.], everything was so easy for me. I couldn't believe there's a world like this. When things are difficult, you have to learn to keep going all the time. And for a woman too, women have to come up against men, because men are in everything so that's what it's like being in leadership now, too, we have to fight for our place. Whether you are a leader or not, depends more personality. I saw men that are not leaders at all, and I saw many women that are leaders. It's more personality than ethnicity and gender, if you are able to get there. Well our society rules do affect that..we [women] have to fight harder. So when you come outside and see things are going to be difficult because of the rules that society made, you start putting yourself down and then never keep going, you know? Like, here, in college, we don't have those barriers we are more equal, you know?

These women are involved in organizations in which the majority of leaders are Hispanic women, and they do not believe that men and women lead differently. 
However, when they shared specific leadership experiences it was clear to them that some differences do exist, and when they were asked to elaborate on contradictions in the ways in which they view leadership as gender and ethnicity neutral with their personal experiences, they began to articulate the inherent ways in which scripts related to gender impacted their leadership experience and thus their development of a leadership identity. Cynthia expressed this understanding well when she stated;

... the way guys and girls take on roles is very different. Girls always have their little agendas and their task lists and boys are a little more, "I got it, it's all up here, it's all in my head," and it seems they're a little more relaxed than the girls. I certainly think you can see a change and a difference between them.

Those who had co-chaired leadership experiences with a man often expressed frustration at what they felt was unequal distribution of the work. They felt that they were expected to take the brunt of the administrative details and follow up activities like phone calls, emails, creating agendas etc. They also felt that they were the ones expected to mediate group conflict and that the men involved did not understand the importance of developing group dynamics as part of the leadership experience. Claire expressed this sentiment when she shared;

It definitely changes [when guys are involved] because even though there are girls who aren't emotional as well, most girls are emotional. We're emotion-based. We think with our hearts; it's the truth. And guys are different; they do everything different. Even if they have the same personality, they're still gonna do it differently because they're guys. They're set up different, their brains and how they function, so it is a little different with guys ... They're not - they don't really think with their hearts. They're more thinkers than feelers. Like if it goes to personalities nine times out of ten you'll find a thinker. That's hard because you'll make decisions based on your heart and how you feel about the situation, but guys are more objective. They think if I do it this way for this person then I have to do it the same way for everybody else; so that's a big difference ... I feel like my leadership never really changes, [I am emotional, I sometimes make decisions based on subjective things] like I'm gonna be [myself]. But it does give more 
leeway to let them do it their way and back off a little so I don't always have it my way.

This feeling of letting the needs of others come first was prevalent amongst the participants. Each of the women in this study shared examples of the ways she put the needs of others first, whether it was to avoid conflict, because she saw their needs as not as important, or because someone in her group, or family needed her. Sally expressed this sentiment in the following statement;

I've noticed, um, I care more about helping other people and getting things accomplished for other people than I do about myself, and my own work, and my own school work, because if I have to put something on hold to get something accomplished that other people are going to get affected by it, I-I take care of that first and that's not- it's good

The majority of the participants expressed the desire to keep harmony within their groups and to take on others' responsibilities when they did not follow through, often not taking care of their own priorities. For these women, learning that they can't do it all, to hold other members accountable and to stand up for their needs, were issues each of them struggled with as they developed their identity as a leader. Women's self sacrifice is a strong traditional gender role that remains ingrained in these women's experience.

\section{Strength and Support of Women}

The strength and support of women is the second theme in the topic gender. The participants in this study described women's strength and support as integral and positive forces in their leadership identity development. As mentioned in the topic encouraging relationships, the relationships they developed with family members, mentors and peers were significant to these participants' leadership identity development. While men also played a positive role, the strength and support of women was noteworthy and thus 
became a separate theme within the role of gender. It is important to note that within the context of their involvement few men serve as advisors, in addition many of the participants' leadership experiences were in all female environments (sororities, Women's Studies organization) and that even "mixed" gender organizations at this institution tend to be dominated by female leaders.

In addition, all but one participant described the strength of women only communities as integral and positive to their leadership identity development. Both Romano (1996) and Whitt (1994) found strong women role models and all women's environments to have a positive impact in their research. To begin, the influence of strong Hispanic women family members were described at length in each of the women's interviews. They spoke about the ways that strong female role models taught them to stand up for themselves, believe in themselves and have faith in their intellect and abilities. The value of hard work, the importance of perseverance and the common thread of sacrifice were prevalent in all of these women's family figures. Four of the women, Claire, Liz, Margaret and Optimus Prime were raised in divorced families and spent the majority of their time with their mothers. These women describe their mothers' role as head of house as providing leadership and the ones who gave them a foundation of what it meant to be a leader. The strength they possessed, and their ability to move the family forward in the progression of needs and goals, was a motivating factor for these women. Optimus Prime shared;

The fact that my mother raised the three of us as a single parent, went through college at the same time, earned her Bachelor's while raising us and while dealing with medical issues too, the woman used to not sleep!... and still was there and still picked me up from school and still did these things and went to meetings and then graduated from college and got a job... That's leadership to me, and she's 
just a great mom. She's wonderful, I love her very much. So, she's my number one role model and leader, and she's smart too. I hope I grow up to look like her too.

As the women shared their stories and spoke about who they are as Hispanic women leaders it became clear that the ways in which these women defined themselves as Hispanic women and the characteristics that they brought to their involvement experiences, impacted their leadership identity development. This was clear when Jennifer shared, "we are all a big family and I want all of us Hispanic women to have this knowledge and take advantage of these opportunities." As they engaged in their leadership identity development journey and increased their self awareness, their understanding of what it meant to them to be a Hispanic woman in a leadership role was enhanced and impacted their leadership and involvement choices and thus their leadership identity. Like the majority of the participants, Claire began to see the importance of developing networks amongst women, and to support other women as they develop their leadership. She shared; "I definitely grew, like, more connection with women and wanting to help out women, and wanting to be more around women because I felt more at home with them."

In addition to a growing awareness that women should help each other grow, part of their leadership identity development process involved engaging in issues related to gender and ethnicity. They developed a desire to increase awareness of issues related to gender and ethnicity in others and to rectify injustices they saw related to gender and ethnicity. Lara, who expressed pride in her Cuban heritage and the strength of women, articulated this sentiment well when she stated;

I just feel that we can't stay stagnant. I feel as though if we would have stayed 
stagnant years ago then we would not have had a right to vote ... you wouldn't be getting your doctorate, I wouldn't be wanting to pursue law school. I feel that certain things just, we need to move bigger and better. I don't think it always needs to be a drastic change, I think that small changes [can have an impact] but we need to keep on it and make each other aware.

For the most part, they shared the ways in which they felt at home with and supported by other women. While Liz experienced incidents with "mean girls," each of the other participants described a sisterhood that Ruth related to the relationship between the female characters in "The Secret Life of Bees," strong women who supported the true essence of each other's being while challenging each other to be the best they could be. Interestingly, Alissa, Cynthia, Lara and Sally all attended single gender primary and secondary school systems. Lara talked about her experience in an all girls school expressing;

It felt so comfortable, everyone was so just welcoming and I felt like I was at home. I knew how important I was and I knew how motivating and how great of an experience it was to have that close knit bond with these women that share my morals, share my ideals, they share my vision.

In addition, many of the participants chose to become involved in all women's organizations through women's athletic teams or becoming a lifetime membership in a sorority. They describe these organizations as having an impact on their understanding of leadership because they were empowering to women and emulated the values of sisterhood, service to your community, personal and professional growth. They were drawn to these organizations, particularly the sororities, because of the strength and apparent leadership of the members and because they believed participation would help them develop the skills they needed to be successful leaders in their lives and communities. 
The participants in this study experienced women leading in a variety of capacities, family, work, school and the organizations of which they were a part. These interactions with other women leaders helped them to develop confidence in their abilities, taught them that they were leaders and that women can be in charge. Lara talked about her own awareness of this concept and her desire for those who did not see women as capable leaders to understand that women can lead in the following statement;

I want all women to stand up and go together, I want us to rule the world, but not, we don't have to diminish any man, but I just feel like I want to be at that same level so badly, that I'm always quick to assume that role. And at least in our culture, for any Cuban man, you'll see that they're very, very, very, very macho, and I can't stand that, I can't stand that...And I feel like for me, that's always been a big, a big thing, a big frustration that I have had, I guess with my culture.

\section{Building on Progress}

The third theme in the topic gender relates to the awareness these women have that the rights and leadership opportunities they have as women exist because of the women and men before them who fought for women's rights, and the understanding they have that in order to progress, they must help to bring awareness about issues related to gender to their peers by serving as role models and seeking to rectify injustices. This sentiment was clearly expressed in Lara's previous statement. As discussed in the topics meaningful experiences and self development, many of the women in this study chose to involve themselves in activities that raised awareness about injustices related to women. Ruth shared how her experience lobbying with a student group in Tallahassee encouraged her activist leadership identity;

I go for things that I have a personal take on, like with my activism with [major and student groups] because in my culture I was raised to be less than what I can be. I can be more than just a housewife; I can be a housewife, but I can be more. For example, I'm pro-choice, very much, because pro-life to me it has become so 
fanatical, and I've seen it at the clinics. It's your right to choose. How can you prevent me from having control over my own body?

It took me a while to get to that conclusion, actually. Once I heard of the issue, I had been around women who had had abortions, a whole mess of abortions actually. In the DR. It's not legal in any way, shape, or form. Not even if the life of the mother is in danger medically, it's hush, hush. You don't go to the doctor for that, not even after you've had it and you have some type of complication. You would get in very serious trouble. So I've heard all types of ways to have an abortion and these are from friends and cousins and girls that I know. I've seen it, but I had never given it any thought to how wrong or how right it should be... until now, and this [awareness] has gotten me involved in different activities and I got to know so many women leaders, I've even lobbied in Tallahassee for women's rights.

Coming over here, I didn't put a label to what my issues were, what my wrongs were, until I finished high school, and my senior year I ended up calling myself a feminist for the first time, and then coming to college, I mean, I knew I had that label over me, but I didn't know what I was going to do about it until I started seeing the different organizations here on campus, building relationships through my sorority and my sisters who felt the same way and who were very strong feminists, and they introduced me to the leadership positions that developed that quality in me and that gave me the confidence, gave me all of that, and tested me in so many ways, because I had to work with so many women.

The connection to something personal, breast cancer awareness, domestic violence, GLBT issues, and awareness raising issues that helped move women's issues forward, were important in the way these women developed a leadership identity. Working together, towards causes which they were passionate about and with others who shared these values, helped them gain insight into the leader they espoused to be.

The women in this study also talked about differences that existed between the generations in their families, how women's roles are changing and the ways in which women entering the workforce and entering a variety of leadership roles has changed the image of what it means to be a leader. Those who were first or second generation immigrants also spoke of differences that existed between the U.S and the countries they, 
or their parents, came from within these topics. Sally talked about her experience as an intern with Representative Ileana Ross-Leithenen, the first Hispanic female to serve in the United States Congress;

Actually when I was in middle school I did a couple years of an internship with Representative Ileana Ross-Leithenen even though she was hardly ever in the Miami office but she's so cool and so down to earth and she's Hispanic and we talked in the office in Spanish all the time. At the same time she holds this position that's great and she does have a lot of decision making to do for the whole country and it's nice that I got that exposure while I was young and able to realize that I'm not limited by anything and that I can definitely go all the way.

However, they also understand that, for the most part, women in our society still have the added responsibility of family. The following statement made by Liz resonates with most of the women in the study;

As each generation passes, which it is true, women are coming into play and being more in the leadership role, but the woman has two jobs, not only does she have to go out and work a man's job but she comes home and she has another job too. It's a lot of pressure and a lot of responsibility. It's hard. Life is hard. It's twice as hard for a woman.

Although Liz, and many of the participants in the study spoke of this second shift for women, they were torn between feeling like it was still their responsibility and wanting to challenge it. As Cynthia said;

I want to be a mom, I can't wait to be a mom, but I don't know how it will feel if I am working late and unable to go home to my family. I think I will still feel like I need to have supper ready and spend time with the kids and all that, even though I don't think it's right.

As these women talked about the progression of women in our society they talked about power dynamics and the ways in which our patriarchal society exhibits power over women. As college students they saw themselves isolated from some of the power controls. However, they felt that gender role expectations and the glass ceiling in some 
ways creates an environment in which women feel they that they have to exhibit more agentic behaviors to be successful and must compete with other women to get the one slot "reserved for the female." While they challenge this concept, they do believe that is exists. Jennifer shared the impact she believes this has on women leaders;

We grow in a society where men are still in power, so women have to shut up and do the stuff that's expected and we don't have confidence because we don't know if what we want to do is going to be accepted. And that's why sometimes the women who are leaders, they come to the same decisions as men, and everybody is like, oh looks like the woman is wearing pants. And what I do hate about women and leadership is that once you are in that position, the subject of labels arises, and if you're the aggressive woman leader then you are a...bitch, or you're a feminazi. There are so many labels. And obstacles, they represent obstacles in so many ways because if you're not strong, and you got there, they question how you got there, you're not the aggressive woman, then you're a what? Everyone thinks they can roll over you. But the guy, he's just being a boss.

This "double bind" sentiment is prevalent in research related to women and leadership. For example, Eagly and Johnson (1990) in their meta-analysis of 162 studies on gender and leadership found that women who exhibited a more relational style of leadership were more positively viewed as leaders but also experienced more negative evaluations of their competence as leaders when rated on behavior traditionally related to expectations of a leader (i.e., decision making). Many of the difficulties and challenges for women outlined in this study related to the incongruity of the traditional female role and society's traditional view of leader.

The participants in this study believed it was important for them to support other women and continue to educate others about the impact of this power dynamic, they also strongly believe that because this awareness and education exists, it will be significantly different as they engage in leadership roles and positions after graduation. It is important to note that many of these participants were involved in organizations that promote 
feminist values; the Women's Studies Student Association, Pan Hellenic Women's Empowerment Week Committee and the Vagina Monologues are three examples of the feminist activities in which these women engaged. While they represent the typical Hispanic woman leader on FIU's campus in many ways, through their activities with feminist organizations, in women only communities, in Women's Studies classes, and discussions with advisors and each other, they have begun to explore their feminist values. They recognize that the feminist movement supported the development of women leaders and set a foundation for them. But they also share the ways in which women continue to be stereotyped and discriminated against if they break out of gender role expectations, as well as the negativity associated with the word "feminist." However, as young Hispanic women leaders they also continue to feel pressure to succumb to traditional expectations. Optimus Prime articulated this sentiment, shared by a few of the women throughout their interviews and then specifically by all of the women in the focus group interview, in the following statement;

I feel as though yeah, we've come a long way as women since, you know, I guess in the modern era, but I feel like we have so much more to go. And it's like, people can't choose between when they want to be a feminist and when they don't want to be a feminist. That was a feminist in air quotes, by the way. Because listen, you said that you'd labeled yourself as a feminist, but why is that such a bad thing? Why does it have a negative connotation, right? What's a feminist? It's the radical notion that women are equal, right?

During the focus group interviews I shared statistics about women's ascension into leadership roles currently in our society with the participants. I also shared with them their common belief that it will be different for their generation. I asked them if my supposition was indicative of their sentiments. They shared why they believed this to be true and as they did I asked them if this was congruent with some of the data. As the 
participants delved deeper into their leadership experiences, contemplated my questions, and built upon each others thoughts, they articulated a disconnect in their belief that leadership is gender and ethnicity neutral. They went deeper into the differences in the way the men and women in their groups "do" leadership and began to have those "ah ha" moments connecting the ways in which gender role expectations encourage these differences. As shared in the quotes above, they also began to recognize the discrimination that women in leadership roles face.

\section{Impact of Ethnicity}

The fifth topic, impact of ethnicity, reflects the ways these women describe their ethnicity as influential to their leadership identity development. Throughout their interviews the participants shared how their experiences being Hispanic impacted the ways they evolved a leadership identity. However, through their narratives the influence of ethnic status within the Miami Dade community also emerged. While all of the participants described a sense of privilege in being a Hispanic leader at FIU, the impact of ethnicity was most prominent for the non-Cuban participants. A few of the participants expressed a disparity between Cubans in Miami and other Hispanic groups. This disparity was stated in subtle and not so subtle ways, as when Sally stated "Cubans have a lot of power in Miami compared to other Hispanic groups," and when Claire shared "everyone just assumes you are Cuban first." Compared to other U.S. immigrants in the later half of the $20^{\text {th }}$ century, the U.S. government bestowed upon Cubans numerous rights, including retraining and recertification, scholarships, permanent residence status, and business loans. These privileges that exists amongst Hispanics in the broader Miami community, assisted Cuban Americans in attaining unparalleled 
success compared to other enclaves that immigrated during this same time period and supported them in attaining political control of city government and public school system (Stepick et al., 2003). This attainment of power helped to create some divisiveness amongst groups that could be heard in the students' voices.

As the participants shared their stories it was clear that their ethnicity influenced their development of a leadership identity in specific ways. Three themes evolved within this topic; being a majority-minority population, using leadership to help people of my ethnicity, and cultural expectations.

A few studies have examined the impact of race and/or ethnicity on college student involvement on campus and within student organizations (Arminio et al., 2000; Guifridda, 2003; Jones, Castellenos \& Cole, 2002; Kezar \& Moriarty,2000; Lavant \& Terrell, 1994). As a whole, these studies indicate that the type of student organizations in which the students were involved depended on the students' ethnic background. At PWIs, students from "minority" racial and ethnic groups on campus began their involvement in identity based organizations because it was the place they felt most comfortable, as well as a place where they could connect to other students from their background. In addition, participants in each of these studies indicated a desire to "give back" to their communities as agents of social change. Renn and Bilodeau (2007) found that GLBT student leaders' entry point was also through identity based organizations, in their study GLBT student organizations. In addition, Komives et. al (2005) found race to have an impact on the leadership identity development of the students in their study. However, for the students in this study, this was not the case. While organizations 
specifically connected to Hispanic and women's identity do exist on the campus, the students in this study became involved through a myriad of involvement opportunities.

One of the opening questions I asked in the interviews with my participants was a request for them to describe their ethnicity. Each of the women responded with their, or their family's country of origin, "I'm Mexican," "Puerto Rican," “Cuban American," was their strong, first response. This pride in being able to connect to their specific country of origin, while including their American experience, was prevalent amongst all of the women; each spoke about this position being specific to Miami. Because there are so many people of Hispanic descent in Miami, connecting to their specific country of origin as natural for them. Still, except for Ruth, each of the women connected with the general term Hispanic and shared that it is a part of how she defined herself. In addition, those who were raised outside of the Miami-Dade and Broward County vicinity, in different parts of the U.S., shared that since there were so few people of their background in the area they grew up, the general term "Hispanic" was what they chose to describe their ethnicity during those years. Claire expressed this sentiment of what it means to be Hispanic that was shared by each of the participants;

I would say I'm Hispanic, I mean my mom and my father were both born in Columbia, I was born in New York though, but my background is Hispanic. I wish I was little more in touch with my Hispanic side, whereas my mother always talks to me in Spanish, but I always reply in English. I guess because I grew up here in America, but like I love my Hispanic culture; the food, my family, my friends. When we go visit Columbia it's just, I like it. So, I would say I am Hispanic. [Being Hispanic means] the culture, the way of life, the music, and we speak Spanish. All that stuff and dancing, what! Merengue, Salsa, Reggaeton, all those! Uhhh ..., I love music.

These cultural connections, the importance of family, food, music, dancing, language, talking loud and with your hands, and "silly" traditions, such as waking up with a café 
con leche and father listening to radio Mambi, a local Spanish only radio station, for Lara, were shared by each of the women as they described what being Hispanic means to them and provide the foundation on which their leadership identity development was created. Cultural connections, like those just stated, are evident throughout the literature on Hispanics (Alvarez, Bliss, \& Vigil, 2001; Gonzalez, 2008; Owles, 2009).

Although the role that gender had on their leadership identity development was discussed as a separate topic within this chapter, because of its significance to this study, it is also important to share its relation to the influence of ethnicity within this topic. Ethnicity and gender were described as indivisible parts of who these women were and the ways in which their leadership identity emerged, and therefore it is difficult to separate them as topics of discussion. Being a Hispanic woman, a woman, and Hispanic were intertwined in these women's leadership identity. Interestingly, the influence of gender seems to trump ethnicity as a pivotal factor in these women's experience. Given the strength of the Hispanic influence in Miami this is not surprising. As they shared what it means to be a Hispanic woman it was evident that they felt more discriminated against as a woman than as a Hispanic. Optimus Prime articulated this awareness of how being female affected her opportunities more than her ethnicity when she stated, "I see how my background affects my leadership in groups or whatnot but I think the question is more being a woman in that position more than a Hispanic woman."

\section{Being a Majority-Minority Population}

The first theme being a majority- minority population is used to describe the ways in which these participants' majority status as Hispanics impacted their leadership identity development. As indicated in the setting description, FIU resides in a unique 
environment, the city of Miami. A 2005 census report states that demographically Hispanics comprise $61 \%$ of the Miami-Dade county population (U.S. Census Bureau, 2005). FIU is a Hispanic serving institution as by definition more than $25 \%$ of its First Time Enrolled (FTE) identify as Hispanic, but unlike HSCU's, women's colleges, or tribal colleges this demographic exists because of the demographic of the surrounding community. Like the majority of HSIs in the U.S. its enrollment reflects the racial and ethnic demographics of the county in which it resides. Unlike other racial and ethnic minorities, as the majority population in the county, Hispanics demonstrate political and economic power in what Stepick (2003) describes as a reverse acculturation in which non-Hispanic Whites and Hispanics share power. It is not surprising that this majority status would have an impact on the leadership identity development of women students at an HSI. As noted in the literature review, Gonzalez (2008) found that ethnic enclaves did not exist in the civic engagement of Cuban American and non-Hispanic Whites at FIU. Although identity specific organizations existed at the institutions, Hispanic and White students engaged fully in the major organizations on campus. In addition, Bridges et. al (2005) demonstrated that the environment of an MSI can be powerful and nurturing to students' learning and provide shelter from the effects of ethnic and gender discrimination.

Each of the women in this study talked about the experience being a member of this population had on their leadership identity development. They recognized that Hispanic students were involved in every club and organization, served in every leadership role on campus, were on the executive boards, and were the ones making decisions through SGA the political voice of students on campus. In addition, most of 
them had mentors and advisors at the university who were Hispanic. Sally shared that "being in Miami, I've grown up in a bubble, everyone that I run into is Hispanic, just like me." These women are not aware of the subtle and not so subtle effects of discrimination that exist as they experience Hispanics having some power within their communities and their networks are predominately Hispanic. Ruth shared the ways this impacted her desire to become involved at FIU;

When I came [to FIU] I didn't know much about SGA, until today I don't know much about SGA, I don't really care for politics. But I used to see women who are clearly Hispanic in positions of power, or positions, whatever. And when my own sister used to tell me, "I'm secretary of my club, and we do this and we've done that." And I was like, oh, ok, and you have more of an accent than I do, so I should get involved. To me it was a place of inspiration, and kind of like a sign that, just go ahead, others have, you're not going to be the first one or the last one to go in and serve and still have an accent and all that.

In addition, they share the impact that being at a diverse institution, where

Hispanics are a majority has influenced their involvement. They talked about the ways that having the opportunity to interact with and build relationships with diverse others, especially students from different countries, influenced the leader they were becomming. They also shared that they appreciated being able to share and celebrate the diversity of Hispanic culture whether it be Cuban, Dominican, Columbian, Nicaraguan etc. Cynthia expressed this sentiment as she reflected upon the diversity of her involvement experiences;

At FIU, everybody pretty much has an international background but I do find that it's easier to relate to because there are a lot of Hispanics in the university so it's kind of like, if you're not Hispanic, it's like oh, really where are you from? There is so much interest. So I feel that as opposed to other places we have such diversity of culture. Nobody really cares because everybody is different. We have a really great understanding of individuality on this campus among the people who are involved. I have rarely heard of somebody being discriminated against because everybody who comes here, even if they don't start off open, they end up 
being friends with people they normally wouldn't have because they were different.

Although they recognize on a cursory level the impact being the majorityminority population had, each of the women had a difficult time articulating the ways in which this majority status impacted their involvement. Margaret shared this lack of awareness;

I don't know because I've never been anywhere else. I've always been in majority Hispanic cultures - not cultures - but like communities and circles. You know what's funny? You don't even realize it. To us it's normal, but we're classified as a Hispanic university but I don't necessarily see it that way. I mean I guess I see it because we are everywhere and so that's the influence, but it's not like we talk about it like, 'Oh I go to a Hispanic Serving Institution'.”

Lara also had a difficult time expressing the impact that her ethnicity had on her involvement as a leader and shared;

Here in Miami, Cuban-Americans are everywhere. So, I kind of feel as though, maybe something that I take for granted, as being just, that's just a part of my leadership style, maybe if I lived somewhere else maybe I would think, oh that? that's definitely a part of my culture and that makes a difference in who I am and how I lead.

Similar to research regarding White students at PWIs (Rankin \& Reason, 2005), Hispanic students at this institution hold privilege. While there are Hispanic student organizations (Puerto Rico Statehood Student Association, Lambda Theta Alpha Sorority, Free Cuba Foundation, Society of Hispanic Professional Engineers) Hispanic student involvement permeates every aspect of student involvement on campus. From their stories it was clear that they understood that "they are everywhere" but were not quite aware of the intricacies and intensity of this privilege. Because they saw other Hispanic students at the university involved in leadership roles, it made it okay for them to become involved in leadership opportunities. And because the majority of students in 
the organizations with them were Hispanic, they didn't feel like "the outsider" for being Hispanic. This feeling of inclusivity can be compared to the experience of White students at PWIs who often do not recognize the privilege they have on campus and within student organizations. Rothenberg (2005) refers to this as "white privilege" stating that the power of Whiteness is that it gives certain people an advantage without ever acknowledging that this is the case.

However, those who have lived or engaged in leadership experiences outside of south Florida share a very different perspective as indicated by Ruth when she traveled to Georgia for her sorority and to Chicago to participate in an Alternative Break program;

Now this year I've taken the time and the opportunities given to me to travel to other parts of the US and see the subtle differences and the not so subtle ones. I've been to Georgia, I've been twice this year already, for some events for my sorority and some other organizations. And one of the trips that I went to we went to a rather small town and it didn't shock me, it was just kind of, "ok, wow." That I was labeled as, because of my skin color, I was either mixed or Black and was discriminated against. That just doesn't exist where I've been and where I come from. We're all Black, what the hell are you going to discriminate about? And then I went to Chicago and I love the city, I love it. And I saw that I really stood out, my group, not just me, my group, because it was just so foreign to us how the whole culture, Miami is a whole different world compared to the rest of it all.

In addition, the influence of cultural status also emerged, while the Cuban participants articulated an insider perspective, as when Lara shared "well even our President [of FIU] is Cuban." Although the participants shared the meaningful ways that different Hispanic groups interacted with and shared leadership together, participants who were from ethnic backgrounds considered lower in the ethnic status in Miami described how this impacted their leadership identity. For example, Ruth, aware of the 
stereotypes that exist regarding Dominicans, felt a need to prove her leadership

capabilities in her organizations, she shared;

people in my organizations expected me to be very happy-go-lucky and very wild, I guess. They expected me to kind of live up to those things. I think it was a surprise for them as well to find out that I'm a strong leader, I'm not their typical Dominican, as they call it. I'm not thinking about beer, Presidente, all the time. When I used to speak to them in Spanish and all that, they expect me to speak in more of a vernacular that we use that's very, very ghetto, very street, very uneducated, slang, using a lot of bad words and whatnot, and when I didn't they [other Dominicans] would just look at me like, who do you think you are?

Through these quotes, the women in this study shared the ethnic stratification that exists at FIU. Alissa, a Mexican by descent, shared that she is mistaken for Cuban all the time and that when she shares that she is Mexican, people are always surprised "they assume I'm Cuban, because I hang out with mostly Cubans and I am very light, they don't know what a 'Mexican' looks like."

\section{Using My Leadership to Help People of My Ethnicity}

Many of the participants' involvement as leaders connected to their ethnicity and their desire to utilize their capabilities as leaders to help those from similar ethnic backgrounds. For example, Cynthia and her business fraternity helped to tutor children in an elementary school within a predominately Cuban neighborhood and Lara and her classmates who traveled to Lindo, Equador to help build communities in an impoverished neighborhood. Lara shared the ways in which being Cuban-American directly influenced her involvement as a leader;

I don't know if it's so much my leadership style or my personality or just how I've evolved as just an individual but I want to make a positive impact in my culture and, but I know that there are certain things that as a Cuban-American I won't stand for. Like individuals talking about a problem in a country, I feel like if you live in a good spot, or if you're in a good place now, you shouldn't be taking advantage of another country's misery. So, whenever I hear someone 
talking about... plastic surgery or implants or things of that sort women will say "I'm going to Cuba because I'm going to get it done for \$100." And they'll come back and they're set. But what they don't understand is that they're really helping that country's misery because they're boosting that economy and the only one that they're helping is the President, and the President doesn't help the people of the country.

The influence of ethnicity and a connection to the problems inherent in their countries of origin, impacted many of the projects in which these women engaged and influenced how they evolved a leadership identity, this desire to support the struggles of their people was strong for many of the participants. Jennifer shared her desire to develop her leadership skills and help to create change in her home country of Argentina in the following statement;

I spend a lot of time with other Argentineans and I try to help all of them, especially women, recognize what they have here and make the most of it, you know get involved and be a leader. Everybody says that Argentineans think they are the best people or the best in South America and I think it's because we are really different like, our way to speak, our language it's really different. Like people, like Latin people don't understand our Spanish sometimes. And we're too accelerated to talk and to think and all the time. But, I don't know, I love my country. I mean it's in a really sad state and I wish it were in my possibility to stay, and to help the progress I can do there, with my experience here but what I am learning here will help my country when I return. When I go back I am going to help young Argentinean girls realize their leadership potential.

This sense of connection to their ethnicity also connected them to a community of

Hispanic women within the university and instilled in them a desire to help and mentor young Hispanic women. They recognize that in order for them and for other Hispanic women to be successful, they must help create a pipeline of educated leaders. Claire articulated this well when she shared;

I think sometimes when you get out into the real world it's about connections. Sadly that's how the world is. You can have all the knowledge in the world but you need connections. Just like it's our responsibility to mentor the freshmen Hispanic women that are coming in this year, help them get involved, it's just as 
important for us to find Hispanic women who can help us develop our leadership. That's why it's statistically more White men - they have more connections. In the real world yes you need to have skills, yes you need to be a team player and have things under your belt but it's also who you know. Sometimes you'll know a lot more than somebody else but they'll know a person in high places and they'll get up there. That's how society is. That's why now it's important that leadership studies emphasize differences in who gets leadership positions based on race.

What Claire articulated in her statement is similar to the voices of most of the participants, Hispanic women leaders need to stick together and help each other out. It is through the building of networks and involvement with each other that Hispanic women will progress.

\section{Cultural Expectations}

The third theme within this topic is cultural expectations and relates to the impact that cultural expectations had on their ability to be involved as leaders as well as the role the lack of understanding their families had regarding their involvement played in their leadership identity development. Much of the literature states that while there is great support from their families for Hispanic women to attend university, they are expected to stay at home and have a significant amount of familial responsibility while in college (Nicholas, Stepick \& Stepick, 2008). According to Black et al. (1992) the cultural influence of the male machismo ethic was one of the most difficult barriers for Hispanic women leaders to overcome. The pressures of cultural expectations were strong for these women and although not directly apparent to them, were expressed as influences in their leadership identity development. The cultural expectations placed upon these women first by their families as well as within the larger Hispanic community, had a strong influence on their leadership identity development as they described the ways in which they struggled to be full time students, engage in extracurricular activities, and balance 
the demands placed upon them in the home, but also as they described their interactions in leadership roles that included men. Alissa, who wanted to attend university outside of Miami like her older brother and sister, shared the struggle she faced in balancing her familial expectations with her involvement at FIU.

I find that sometimes it's harder for us Hispanic people to get involved here at FIU. Maybe not harder, but I guess in our culture, or in the Hispanic culture parents just want their children to go to school, maybe work, and then be with the family, just come home. I also think that's why a lot of students stay living at home, it's the Hispanic tradition, don't go away too far for college, stay with the family and then after you graduate, even staying in Miami area. So I think that it's a little harder to get those people involved and to get more leaders because of the customs and the traditions of the Hispanic culture.

Many of the women in this study shared the ways that their parents struggled to understand why they were on campus so late and the amount of time spent with clubs, friends and activities. Their parents questioned why they enjoy being involved which made it difficult for them to connect with their families about their passion for leadership, a large part of who they had become. Optimus Prime expressed how difficult it was for her to share this aspect of herself with her family because as a feminist she feels a difference in values between her family and herself.

I appease them. Because I don't, I guess I would say that I make an effort to understand them, like I try to understand that they don't see the world as I see it and that they have their own values and traditions and things and I respect that because I love most, I love a lot of the aspects of our culture. Also, I don't, I mean I know there are subjects that you just don't talk about and...And it's not that I'm afraid to bring them up and share my opinion on them, but they just don't really ever come up, and if they do I would but, I'm not going to bring them up. So they don't know about all this involvement stuff that I do. I also appease them by being around more and that says a lot in the Hispanic families, and if you're not around it's like you don't love us.

The participants face a number of contradictions in their leadership identity development when it comes to their ethnicity. While they are passionate about issues 
related to underserved populations, partly because of their ethnic heritage and recognition of the privileges that they have, they struggle with the bind they feel between being a "good Hispanic woman" and developing their full potential as leaders. They feel their parent's disapproval when they choose to attend an activity instead of helping with a family event. They see the questioning in their eyes when they demonstrate strength of character, especially around or "over" a man. Optimus Prime shared the ways her sister was in part ostracized from the Hispanic side of the family because of her choices;

for example, my sister who just graduated, she's the first to graduate on that side, from the honors college, she's got a great job, she's doing great things as far as environmental work and feminist activities, but she's still looked as, she's kind of the black sheep on my father's side of the family, for many reasons, because I don't think she fits the mold as far as what it means to be a good Hispanic woman in the family, kind of thing.

Since this term was used frequently by the participants, I asked them to share what it meant to be a "good Hispanic woman." Ruth shared what this meant in her family, "It means being a good housewife. I've been trained to be a housewife, so has my sister, you have to take care of your family first, involvement in leadership doesn't fit into that picture." Ruth's description of a "good Hispanic woman" paralleled each of the participant's descriptions. Each of the women struggled in her own way to ascertain what it meant to create a leadership identity and maintain her status as a "good Hispanic woman." Sally described this desire to develop herself as a leader while maintaining this identity as a good Hispanic woman, she felt a sense of pride and ownership in proving herself and her capabilities and shared;

I think being Hispanic, there are certain things that have pushed me because I have seen in the past certain limitations that have been set and it's about going beyond that and proving that its not okay and that there could be so much more 
done. I think it's cool that we can achieve so much yet still be traditional and keep our women instincts.

\section{Developing a Leadership Identity}

Each participant came to FIU with a foundation of what leadership means based upon early experiences with group involvement such as sports, service organizations, theater, class and extracurricular experiences. Through these experiences they developed a preliminary understanding what it means to be a part of a team, took on responsibilities, developed personal skills and self confidence in their abilities and received affirmation from adults who were important influences in their lives. Their initial motivation to become involved was to develop relationships with others, for the ESL (English as a Second Language) participants an additional motivation was to enhance their English.

The intersection of their identities as Hispanic women had a profound influence on the ways in which these women developed as leaders. The messages they heard regarding cultural and gender role expectations were conflicted with an understanding that each generation has a responsibility to progress and can make different choices than the generation before.

While the following is in no way intended to represent a stage based model of leadership, it was clear that these women progressed through similar processes as they took on a leadership identity. The role of relationships in this progression was also clear, as was their desire to use the Relational Leadership approach. All of the women sought to develop "good" leadership skills and be a "good leader." And, while their leadership experiences prompted them to utilize different skills and approaches, each of the women in this study could be identified as "good leaders," individuals who wanted to create 
change that would benefit all and who worked with team members to accomplish the goals of the organization.

Upon their arrival at FIU, the women in this study were introduced to a particular philosophy of leadership, one grounded in the relational leadership model which espoused leader as participant. While Owles' (2009) study found the HSI non-influential in the identity development of Cuban women students, each of the women in this study shared the way in which she connected with the philosophy of leadership shared during orientation and through various programs, specifically the Center for Leadership and Service, the Office of Sorority and Fraternity Life and Panther Camp. Optimus Prime articulates how prevalent the message of leadership was to these women;

I didn't really give any thought to this whole leadership thing, the word and what it means to be a leader until I got involved in college because that's when I thought they just throw that word out there all the time. You have to be a leader, leader, leader. Leadership summits, conferences, it was just ad nausea leadership. But that's when I kind of realized...I don't know...I guess I already work well with people already and I mean I did learn things at these retreats for sure because it's always good to learn how to work with all kinds of people and how to do that. I guess I'd already been doing it for a while in some way and then just...I had a word for it.

For the emerging leaders, their motivation for involvement continued to be social but with an emphasis on connecting with women they wanted to be like and finding a community of likeminded people, people who wanted to make a difference. In this entry point of their involvement at FIU they talk about the peers and the role models, mainly older peers and advisors, who influenced them to get involved. At this point they viewed leadership as a position and a leader as the person responsible for setting the agenda, making decisions and telling others what to do. They were involved, but did not describe themselves as leaders. As JLo articulated; 
I thought a leader was someone who was like, "Hey you gotta do this and this." Now, they call me a student leader, but from my old definition, I wouldn't have thought that's a leader. Now I just see myself as a fellow student who has learned different techniques of what to do in certain situations. We know how to take charge but we know how to back off, so a leader also knows how to follow. I think that's important.

As JLo intimated, through their involvement experiences at FIU, these women's view of leadership was changing. Liz was an emerging leader whose was struggling with whether leadership is about being in a role in which you "tell" others what to do. For her and many of the emerging leaders, the term leader carries a negative connotation. While she expressed a desire to take on more leadership roles and possibly a leadership position, she was struggling with what that would mean in her relationship with her peers in the organization she is involved with;

My preference is to be involved as a leader but not necessarily have to make decisions or to lead the group. I think there has always got to be someone who can stand up and say this is what we are going to do. The problem becomes who is going to do that? Most people who do that are just a little too aggressive. I think it's a tricky situation and it all depends on how you come across...you can't come across as too aggressive. People don't like that... You have to ask people what they want. If I don't see anyone getting things started, then I will be the one. Most of the time, I start by asking what do you guys think we should do? If they don't have an answer, then I'll start... asking for suggestions, nobody really has anything to say. So as soon as I start making suggestions, everyone jumps in. It's different with every group but most of the time, that's how it has been.

For most of these women, what FIU's involvement opportunities espoused as leadership connected with what they wished to develop into and be a part of (Peer Advisors, Sorority women, the LEAD team, a poster about the Academy of Leaders). For others, it was a desire to create a place where they belonged (Stonewall, the GLBT student organization). And for all, it was a desire to make friends, have fun, make a difference, and make the most of their college experience. As they became more 
involved they quickly took on positional leadership roles and many involved themselves in numerous organizations at the encouragement of their peers and mentors. These intermediate leaders were honored that other's "saw something in me," and wanted to please the role models that they admired. One participant said "involvement became a drug for me and I needed more."

For the intermediate leaders in this study, social connections remain an important part of their involvement experience, but additional motivations arise; recognizing that they can have a positive impact on other people's lives, working toward accomplishing goals with their peers, building relationships, understanding others through perspective taking, and influencing what is happening at FIU and the larger community. Although Sally was an experienced leader, in sharing her journey she spoke about a particular experience she had as an intermediate leader that helped her understand the importance of learning to work with others when things do not go your way;

So I learned how to deal with things like when I lost an election at one point and how I would still have to work with the person just in a different position. I learned how to get along with people because if you can't get along and be on the same page then you won't get very far with what you're trying to accomplish. You're better off with a group that just likes each other and can get work done.

The intermediate leaders in this group were likely to get involved in many organizations that connected with their personal values, "trying on" different leadership opportunities, developing skills, learning about their strengths and challenges as leaders, and engaging in leadership experiences with their peers. Through these experiences and by continuing to develop through progressively more challenging leadership experiences, they developed a different understanding of what leadership was and what being a leader entailed. They developed a leader identity that "fit" them. Like many of these women, 
Claire dabbled in many organizations and leadership roles; she epitomized the extremely involved student at FIU.

After my experience with AOL, I joined Lead Team so I can teach people what I learned. And then $\mathrm{aB}$, and then this year, actually, I'm starting Relay for Life this summer- I did it my first year here, at UP. I did Relay for Life cause some of my friends from AOL did it, so I joined their team and just experienced it like that. Now I am going to be a BBC [Biscayne Bay Campus] Liaison so I am really excited about that; to get people to go, cause I feel UP [University Park] sometimes has really good events but BBC, like if they know about, they don't have the motivation to go and they should because, events like Dance Marathon, are like awesome things that I can, at least, get three or four teams from here to go to Relay for Life.

Although some are not sure how they feel about being called a leader, they recognize that they are because they work with other leaders to achieve goals, create change, and make things happen. At this point in their leadership identity development they see a bigger picture of what can be accomplished. Their leadership ideology was congruent with the relational leadership model as they believed that engaging people in the process of decision making generates investment in common goals. This was described by Ruth in her experience with the Vagina Monologues earlier in this chapter. They understood that you do not have to be in a position of leadership to lead and believed that anyone within the group can lead. Cynthia expressed this sentiment well for all the participants when she stated;

There are certain people that earn their position by hard work and slowly but surely it's recognized. Then there are other people, the minute they start talking they have the attention of the group. A person who is too dictating makes it hard for the members because it's hard to accept that that's it. You get tired of listening to the same person and then you notice that they are not doing their job. I think that somebody who has power has to be able to not only tell you what to do but do it next to you. Do it while you're doing it at the same time. Not only does that show that they have power but that they're still an equal and also it gets a lot more done. I can't stand when leaders just say, 'you guys can stuff these name tags while we go and do this,' which is just like sitting around and talking about an 
idea. Like we can stuff while we talk, you know, be more participatory.

It is the experienced leaders who actively own the title "leader," it has become a part of their identity and how most introduced themselves within the first few minutes of our time together. For the experienced leaders, their motivation is about being actively engaged in the vision, a cause that they are committed to, because they have developed close connections with others who have similar passions, a focus on relationship preservation remains. As they have developed themselves as a leader through various experiences, they now feel that it is their responsibility to develop the members in their organizations and build a commitment to the group's sense of community. They exhibit a sense of astuteness in their leadership and have progressed to the point in their own development as leaders that they are ready to help develop the next group of leaders. Ruth articulated this well when she described the way in which her aB (Alternative Break) group connected after months of planning and team building as they prepared for their "homelessness" service learning trip to Chicago;

As a group leader it was my responsibility to get the members connected, to build a sense of cohesion and to develop them so that they were ready for the trip. When there's that cohesive unit in the team, when you see the results of what you're doing, we just looked around the room and it was kind of like, yeah, it was just that type of shared thought, even though the group itself was very [different]. The dynamics of the group was amazing even though we were so different from each other. It's a feeling, for us, and in that term because we knew we were even closer to the date, closer to our goal, and we were getting closer to each other... In the end all of them wanted to apply to be a site leader, and that's what it's all about.

Because their leadership involvement and the way they lead is connected to their values and personal ethics these women believed that they have to begin by leading within their own life and find congruence between their actions and ethics. They 
believed that developing and empowering the next generation of leaders at FIU, as was done for them, was important for them as leaders. Lara spoke about the way that she developed and empowered the members of her sorority;

I just feel like if you're a leader, for instance, I'm now President of my sorority and I feel like as President of my sorority, I'm going to be probably the last one at every event helping to clean up. If your task is fundraising, I'm not going to be stepping all over your toes going, "Ok, so what are we doing? I need to know every single detail." No. I don't want you to feel like you're working on your own, so I'm going to be there to help you set up, I'm going to be contacting you along the way just to see if you need any help, and I for sure will be there with you to break down completely because just because I'm the President doesn't mean that I can't get my hands dirty and work with you too. I think that some of the best leaders actually work with their group. I feel like some of the biggest leaders make their most impact because they're one with everyone else as opposed to having that difference.

All five of the experienced leaders hoped to leave their legacy at FIU, to create a better experience for those who will come after them, and that in the process they have made FIU a better place. Alissa spoke specifically about leaving her legacy at FIU;

it's about leaving a mark and influencing other people. It could be just one person, but just knowing that you can affect other people, that you can help other people succeed. That you can help other people reach their full potential. I hope that at least one person in five years remembers the name, Alissa. Oh, she was my educator for my new member period, or she was my Peer Advisor, she impacted my experience here at FIU, or even if it's just the smallest little thing, I hope that when I graduate, I made a difference in someone's life, or helped FIU be a better place.

For the most part, the experienced leaders are preparing to leave FIU and their organizations. Interestingly all plan to attend graduate school after graduation and all know that they will continue to be engaged in causes for which they have developed a passion, in turn making the world a better place. They recognize that they will continue to learn through their experiences and hope that others will continue to learn from them as well. 


\section{Chapter VI}

Conclusions and Recommendations

How do Hispanic women college students at an HSI develop a leadership identity? This chapter addresses this overarching question, summarizes the major findings from the study, draws conclusions from the study's findings and provides recommendations for practice and research. Chapter 6 includes four sections. Section One summarizes the study's purpose, methods and findings. Section Two encapsulates responses to the initial research questions used to guide this study. The third section outlines the researcher's conclusions based on the data collected. Based on data from participants, the fourth section delineates recommendations for higher education administrators working with leadership development programs as well as suggestions for further research.

\section{Summary of the Study}

As evidenced in institutional mission statements across the country and the upsurge of curricular and co-curricular leadership programs within higher education, the emphasis on institutions of higher education to develop our future leaders continues to flourish (Astin \& Astin, 2000; Cress, Astin, Zimmerman-Oster \& Burkhardt, 2001). Research indicates that much of our understanding of leadership theory is based on patriarchal systems and although researchers have begun to examine the implications of gender, race and ethnicity on various aspects of leadership, research exploring the impact of gender and ethnicity or race on the leadership identity development of college students remains diminutive. The impetus for this study was a belief that higher education administrators and faculty should be aware of the implications these individuals ascribe 
to their leadership identity development in order to effectively develop and implement leadership programs that educate participants about the impact of gender, race and ethnicity on leadership and help to close the leadership gap. An enhanced knowledge of the ways that students become leaders and the influences that shape their leadership experiences can assist practitioners in developing leadership programs that address gender, multiculturalism and awareness of self as leader.

This study explored and described the leadership identity development of a select group of women student leaders at Florida International University, a Hispanic Serving Institution in the southeast. The study applied a psychosocial approach using Relational Leadership theory, specifically the Leadership Identity Development model, as a guiding framework. Eleven participants of sophomore, junior or senior standing that were identified as involved in leadership activities were chosen. Purposive and snowball techniques were employed with the assistance of university administrators who worked with various leadership programs and student organizations which yielded participants with diverse perspectives, experiences and involvement. Utilizing a three interview process, two semi-structured individual and participation in one of two focus group interviews, each participant shared her experiences as an involved Hispanic woman who was in the process of becoming a leader, or currently identified herself as a student leader.

The data from the interviews were transcribed, coded and analyzed to understand the experiences of the participants and the cross-case comparison method was utilized in developing themes. The following triangulation methods were utilized to increase trustworthiness of analysis. First, member checking was utilized to provide an 
opportunity for confirmation, disagreement and clarification. Participants were asked to read their transcripts, and emerging themes from the data were discussed with participants during the focus groups. Second, a peer reviewer was utilized to offer feedback during data analysis. Third, multiple sources of data collection were utilized, including two individual and two focus group interviews and informal observations. Fourth, researcher reflexivity, or the process of reflecting critically on the self as researcher was utilized. Finally, an audit trail, including a reflective researcher journal describing how decisions were made throughout the inquiry, was used for data management. Five major topics emerged from the data analysis: (a) encouraging relationships, (b) meaningful experiences, (c) self development, (d) the role of gender, and (e) impact of ethnicity.

Encouraging relationships described the meaningful ways in which the significant people in the lives of these participants impacted their development of a leadership identity. The people with whom the participants had encouraging relationships included family, mentors and peers. They were first to encourage the participants' leadership potential and involvement. These significant relationships included the themes (a) my family believes in me, (b) mentors and, (c) peers.

Meaningful experiences were also integral to these participants development of leadership identities and illustrated the impact that participation in activities, programs and organizations had on the participants' leadership identity development. These meaningful experiences included three themes; (a) being a part of something, (b) reflection on experiences and, (c) the ways in which these experiences changed their view of leadership. 
The impact of personal growth and development also emerged as an important contributor to the leadership identity development of the participants in the study. The topic self development includes three themes; (a) knowledge of self, (b) a desire to become the best me and, (c) self competency. Of particular interest was the importance of interpersonal skill development as it related most closely to developing a leadership identity.

The fourth major topic, role of gender, also surfaced as important and focused on the ways that the messages they internalized about gender taught them what it meant to be a woman leader and the ways that gender expectations influenced their involvement, the choices they made as leaders and thus their leadership identity development. This topic included the themes (a) gender roles, (b) strength and support of women and, (c) building on progress.

The final topic, impact of ethnicity, includes the themes (a) being a majorityminority, (b) using my leadership to help people of my ethnicity, and (c) cultural expectations.

\section{The Research Questions}

Five questions, first presented in chapter 1, were designed to assist the researcher in developing an understanding of the influences that contributed to the leadership identity development of the participants. The questions that guided this study, along with the findings presented in chapter 5 , are revisited in this section as a way to summarize the themes and answer the questions.

How do Hispanic women college students at an HSI develop an understanding of leadership? 
This question served as an introduction for the study. In order to comprehend how these participants developed a leadership identity I believed it was critical to first understand what leadership meant to them as well as to become aware of the ways in which they developed this understanding of leadership. The participants' understanding of leadership was clustered into three categories; emerging, intermediate and experienced, which were presented in Figure 3. To begin, each of the women came to FIU able to articulate what leadership meant to her. This understanding was based on involvement experience and was impacted by the influential people in her life up to that point which included family, mentors and peers. Once at FIU these women connected with the relational leadership philosophy espoused in FIU's leadership programs and engaged in a variety of leadership experiences in which they interacted with involved peers and staff or faculty who served as mentors. Experiences with involvement and the interactions they had with peers, staff and faculty through this involvement furthered their understanding of leadership. The influential data presented in each of the five topics together depict the commonalities and differences and thus weave the intricate story of how this select group of women students at FIU developed an understanding of leadership through interpersonal relationships and meaningful experiences.

As discussed in chapter 5, as their experience with leadership involvement progressed, their understanding of leadership changed from one that viewed leadership from the "great man" perspective to a more relational leadership perspective. It was not until they began to view leadership from the perspective that leadership is a relational process that they were willing to embrace the title leader for themselves. Although differences in their understanding of leadership existed between participants in the three 
leadership categories, the ways in which they developed their understanding of leadership were similar. The participants articulated intimately the ways in which their relationships with significant individuals and the meaningful experiences in which they engaged, helped them develop their concept of leadership. As one participant stated "it's through our groups and programs like by dealing with relationships and confrontations and frustrations." Or when another woman shared the ways that the more experienced women in her organization had impacted her understanding of leadership "I have educated myself on how to lead and how to be led by watching their example by watching their attributes of leadership and I think 'how can I get that'?" Others, shared epiphanies they experienced during particular programs: "We worked so hard but we weren't coming together. We weren't working toward the same goal, and then it clicked, one day, it just clicked, all our hard work paid off and it was beautiful!” These women developed an understanding of leadership through interpersonal interactions with others in activities such as team sports, leadership programs, student government, community service, student or community organizations and theater. Many developed a definition of leadership through co-curricular leadership training programs. As one woman articulated, "I think it [my understanding of leadership] has come from all my experiences here." Another participant stated;

The way that I actually learned my skills and what leadership is was from many workshops through the center for leadership and service and I've done the women who lead conference the past 2 years. I did the leadership summit the past 2 years. I also did the collegiate leadership development program.

These women's experiences with leadership were progressive, they learned by getting involved and engaging in leadership activities. Their development of a leadership 
identity was experiential, they learned by "doing leadership." As mentioned in chapter 5, while I recognize a progression in their leadership experience that can be defined broadly through the three categories emerging, intermediate and experienced, I reject a stage based model. The participants' leadership identity development cannot be described as a stage model. For example, there is no "ideal" ending point, as each described the ways that she continues to develop as a leader and recognized that this development is a life long process. In addition, as evidenced in Chapter 5, at times many described their understanding as views from two or three of the categories. And each of them described ways that they progressed in their leadership, but also re-learned aspects of leadership because of new roles, or how they felt like a "new" leader again because of a new or different experience in which they were engaged. As demonstrated in Figure 2, each of the five topics equally influenced the core leadership identity of the women in this study, contributing to an understanding of self as a leader and the incorporation of the term leader into their identity. Therefore, I have chosen a diagram that expresses a more fluid relationship between these topics rather than a stage based model to display the progression of a leadership identity.

In what ways are Hispanic, women college students leadership identity development similar and different?

As the data were collected and analyzed a pattern surfaced that outlined the ways that this group of Hispanic women students developed a leadership identity. Although each of the women was placed in one of three distinct categories in regards to their understanding of leadership; the data demonstrated that each had begun her leadership identity development process as an emerging leader. As depicted in Figure 3 some had 
moved into the intermediate category and then others into the experienced leader category. It is from the data that these categories were created. These categories describe commonalities in the ways participants understood leadership and viewed leaders. It was through their involvement experiences and interpersonal relationships that they progressed into each category and came to develop a leadership identity. Each participant described the impact that experiential learning through these meaningful experiences had on them. These experiences assisted them in developing an understanding of what it means to be a leader and their leadership skills, which made them confident in declaring the role of "leader" as part of who they were.

The emerging leaders had limited involvement before coming to FIU. Although only three of the participants were categorized in this group, all 11 women described a similar understanding of leadership at this initial point of her progression as a leader. Emerging leaders considered leadership as actions in which leaders engaged. "They make sure everything is taken care of and everyone knows what to do," or "They set the agenda," and "Leaders are the people everyone listens to, they command attention." Their view of leadership was external; they were involved but did not view themselves as leaders. For them leadership was positional, about power and delegating tasks to followers. As one participant stated; "A leader has power I think they have influence over that group because they can take control of that group and move it forward." There were also commonalities in the way the emerging leaders transitioned from this perspective. Each of the participants described how a more relational approach was modeled for her and how she learned to utilize this new approach, through trial and error, in leadership experiences. 
The intermediate leaders also shared commonalities in their leadership identity development. Their understanding of leadership was moving from the leader centric view to an understanding that leadership was a process. These participants had begun to take on numerous involvement experiences and positions, recognized that "The team has to be together to make things happen." And that, "You don't have to be a leader to take on something; you don't need the title." For them being a leader was about facilitating goal accomplishment of the group, the ability of an individual to develop relationships amongst group members and develop commitment to the cause. Claire shared this perspective of leadership and how she developed a leadership identity through her relationships and involvement experiences.

It's communication. You have to find a way to talk to people. Also, not being selfish; you have to learn how to be humble because I know a lot of people are set in their ways. But you're not always gonna find somebody that agrees with you, and you're gonna want to tell them to do it your way. But you have to step back and be humble and let them have the experience. It's a very hard lesson to learn. You have to help them be invested and have their experience, be humble, put your head down and say ok let's do it your way. Give it a try and even if it doesn't work it's not the end of the world and you can do it again.

The experienced leaders described the perspectives of the emerging and intermediate leaders as part of their own progression in developing a leadership identity. However, these women's understanding most closely mirrored the philosophy espoused by leadership programs within FIU. In addition, these women had incorporated "leader" as part of their identity. They described their progression to being an experienced leader as being wrought with trial and error. They utilized the knowledge they gained through their experience with leadership programs as well as behaviors that they witnessed older peers and mentors utilizing that they wished to integrate into their own leadership 
behaviors, to develop their leadership persona. They described the ways in which they "tried on" these behaviors and found what worked for them through trial and error.

The five women in this group all described their commitment to organizations that espoused their values and beliefs and strived to support a "cause." Their process of developing a leadership identity also involved interpersonal relationships and involvement experiences, but it was now about helping their younger peers develop as leaders. "We have to pay it forward and help the freshmen gain leadership experience," and "I'm mentoring my[sorority] sisters now, as was done for me." As they began to get ready to transition from FIU it was important that they empowered the next generation to move their group's causes and goals forward. Another commonality in their leadership identity development was connecting who they were as leaders to service activities centered around their values, to the causes they were committed to and that revolved around making the world a better place. The experienced leader's view of leadership was described as a process that engaged others in common goals and supported the development of future leaders.

There were other commonalities in the participants' leadership identity development. In relation to their Hispanic identity, one commonality surfaced for these participants, a recognition that the Hispanic influence was all around them, in everything they did, including leadership. From the members of their organizations, to those in leadership positions, to the students in their classes, the majority of students at FIU are Hispanic. It is clear that privilege resided within them as the majority population in Miami and as the majority student population enrolled at FIU. In addition, each of the women felt a connection to the philosophy of leadership espoused by FIU which was 
introduced to them in a variety of ways; through the sorority recruitment process, the Center for Leadership and Service presentation during Orientation, a flyer on the wall, or through the Orientation program. As one participant shared, "They [Orientation leaders] had something, they were so accomplished, and I wanted to be that." or "I knew it was through this experience that I would accomplish what I wanted to be." And "I saw the flyer, Academy of Leaders, and I knew I had to be a part of it." Their connection to FIU's leadership philosophy served as an entry point to their process, or provided an opportunity for them to continue their process of developing a leadership identity. FIU became the environment in which their leadership identity developed. And, as one participant said, once they connected to this philosophy "I was hooked," or "Involvement was like a drug for me, I just needed more." And, "It started with AOL, but then I started getting involved in everything." In the beginning, each shared how she sought to find community with people who had common values and desires; "It was important that they wanted to make a difference," and "I finally found a group of women that I had a lot in common with." Another commonality was that eight of the eleven women described themselves as "an overachiever," an individual who wanted to experience as much as possible.

Each participant also talked about people who encouraged her first steps towards becoming a leader. As one participant shared, "They're [sorority sisters] one of the biggest reasons I started getting involved; they pushed me, and they opened doors for me that I wouldn't have realized before." In addition, they each shared the ways leading group experiences helped them develop interpersonal skills and begin to see themselves as leaders. 
There were other commonalities in these women's experiences including the importance of family history, specifically the immigrant perspective as it related to a desire for them to be successful in America. The double message they received from their mothers that while there was an expectation to remain within ascribed gender roles and be a "good Hispanic woman." They should also follow their dreams and aspirations and work hard to achieve independence. Each of the women also spoke of learning by doing and that the experiences that they participated in were meaningful to them.

Differences also existed amongst the women. To begin, the categories themselves connoted differences in their leadership identity development. Most notable were the differences in the participants' view of leadership between leadership categories. For example, the emerging leaders defined leadership as a position and expected "leaders" to tell them what to do. The intermediate leaders were beginning to view leadership as a process and expected that the team would make things happen together. Finally, the experienced leaders viewed leadership as a process in which people are empowered through the attainment of group goals and experiences. The experienced leaders expected to facilitate the process.

Because of the differences in the way they viewed and approached leadership, the skills that they gained, the experiences they sought, and the influencers that were most meaningful were different for the participants between each of the categories. For example, the influence of encouraging relationships on the emerging and intermediate leaders was most profound as peers served as their mentors, introducing them to leadership opportunities, and role modeling what it meant to be a leader. While the experienced leaders were more impacted by their advisors and sought to serve as mentors 
to the emerging leaders. In addition, meaningful experiences had the most profound impact on the emerging and intermediate leaders as their view of leadership changed most significantly as they reflected upon their experience.

In addition, not all of them were in the same year in school, and one of the participants did not begin college immediately after completing high school. Their family lives were also different; some of their parents remained married, while others were divorced. In addition, some came to the United States as children while others were second or third generation immigrants. Their connection to a Hispanic identity also differed. For example, Optimus Prime, who lived with her European American mother since her parent's divorce, was not as connected to her Cuban American roots as Sally who lived in a tight Cuban American community with her first generation Cuban parents and grandparents. Interestingly, because so many involved students are also members of the Greek community this community either served as a connecting point for some women, making them feel a part of something larger, or made others feel disconnected because so many of their peers were members of Greek organizations and they were not. From their perspectives, what influences contribute to their leadership identity development?

The five topics shared in chapter 5 present the influences that contributed to these participants leadership identity development; (a) encouraging relationships, (b) meaningful experiences, (c) self development, (d) the role of gender and, (e) the impact of ethnicity. These five topics are interconnected in such meaningful ways that removing one from the others would render an incomplete representation of the influences that contributed to these women's leadership identity development. It is through these five 
major topics and influences that these women discovered the leader they wished to be. However, as gender and ethnicity were addressed as a separate question specifically, I reserve the influence of these two topics for question four.

Relationships, an interpersonal connection to other women and a desire to emulate aspects of them that they admired, were an intense influence on these participants leadership identity development, particularly early on in their experience. Family, mentors and peers were the ones that first encouraged them to engage in extracurricular activities and were often the reason they continued to engage in new and more challenging involvement experiences. Participants shared how these individuals contributed to their involvement: "My sense of being involved outside of school came from my mom." Another woman said "I watched my brother and sister be involved. I always learned a lot from them, and I like to follow in their footsteps." And, "A couple of friends were auditioning for the step team, and I went to check it out and thought it was cool." Once involved, the participants developed connections to the people in their organizations and deep commitment to these relationships which kept them involved and encouraged their development of a leadership identity. Sally shared the importance of these relationships and the way that these relationships encouraged her development as a leader passionately. "We're all such great friends, and we've accomplished so much together. We do so many great things in the community. One participants shared We're having fun, but I learn from it everyday." Another stated, "We're a family. These people will do whatever they have to do to help you, and you help them. And you develop skills and help the community, and it feels good." 
Meaningful experiences were the second major influence in these women's development of a leadership identity. Through their relationships they became connected to involvement programs and leadership opportunities which contributed to the leader each would become. Through their experiences with others who wanted to make a difference and reflection on these experiences, their view of leadership developed. It was through these experiences that they developed an understanding of what it means to be a leader and where their leadership identity evolved. As one participant stated, "I went to an ENGAGE workshop, and they talked about transformational leadership; and my friend leaned over and said 'that's you.' I almost cried because that is the leader I want to be!" Another woman shared how her experience as a Peer Advisor helped her develop into a leader;

Everything that they taught us, what to do and how to act and what to say for certain things--all those experiences have had an impact on the leader I am...You pick up more things, and you remember them; and you may not remember who said it or what they said, but its just things that you keep in the back of your mind. You may not even realize that you're changing something that you do because of what they said.

The third topic, self development, also had significant contributions to the participants' formation of a leadership identity. These women intentionally engaged in activities that helped them gain knowledge of themselves, develop their interpersonal and professional capabilities, and contribute to their value system of giving to others and making the world a better place. One woman shared, "I want to be the best me I can be and I'm learning I can do so much more." Another said, "Now I know what I want to do and how to accomplish it." And "Through listening, and communication, I understand how many different points of view their actually are." As one participant shared; 
It's having that vision, and that want to produce something better, to feel passionate about something and then to take that extra step, not just to be an onlooker but one of those individuals that think, "You know, recycling to me is important." But they don't just recycle, they decide we're going to start a program or we're going to go somewhere and we're going to do something about that. I feel like that's what it takes to be a leader. You don't just satisfy yourself with doing your part, you kind of want to help others make their part and even greater part of society and then you want to keep that going.

The women describe the cyclical nature of their experiences. As evidenced in Figure 4, encouraging relationships were closely tied to meaningful experiences as it was in these experiences that they developed relationships and through these relationships that they were introduced to meaningful experiences. Both of these topics were also connected to self development as they enhanced their interpersonal and competency skills through interactions with influential people in meaningful experiences. Having the opportunity to develop their skills in training experiences by modeling behaviors they learned and reflection on these experiences, were major influences to their development as leaders. In addition, their upbringing as women and the influence of people who were raised in a patriarchal society influenced their desire to continue their development as leaders and contribute to the development of other women so that change could occur. This awareness also produced an aspiration to challenge aspects of what they labeled Hispanic patriarchy.

How do Hispanic women college students describe the impact of other aspects of their identity (i.e., gender, ethnicity) on their leadership identity development?

The women in this study began the process of developing a gender and ethnic identity at a very young age. Each of the women shared the ways they struggled with self autonomy. This was most perceptible when they discussed their desire to engage in 
experiences that would support their personal definition of success and development, while battling to some degree the expectation to get married and have a family. Through their narratives it became apparent that the messages they internalized about gender and gender expectations heavily influenced their actions in leadership and thus their leadership identity. One participant shared, 'I've been told 'don't be a woman, be strong' and I thought, 'huh?' okay so it's ok to be proud to be a women but not label yourself as stereotypical, as dramatic and emotional."

For example, although these women engaged in numerous leadership experiences and were confident in their leadership abilities, they shared instances in which they acquiesced to a male peer's perceived authority sharing that "well we were co-chairs, but he had more experience, so I let him take the lead...but I was the one who planned the activity." At times, they even belittled their work styles by sharing, "You know girls have their little agendas and things." Although those who engaged in female only activist groups shared the ways that these concepts were challenged, it was evident that in mixed gender environments the participants themselves maintained some aspects of the masculine leadership script which were not challenged. As they were able to articulate these points, it is interesting that they still hold onto the myth that things are currently different and will be different for them in the future because their generation does not ascribe to "leader as great man" theory. It is clear that while they espouse a more relational leadership style, the "great man" script remains ingrained at some level in their paradigm of a leader.

Interestingly, eight of the participants had engaged in all female leadership environments, and each of them discussed the impact that the empowering nature of these 
environments had on their leadership identity. "We just understand each other better and have the same way of working together," or "I was able to focus and really achieve a lot that I never thought I could." And, "I knew how motivating and how great of an experience it was to have that close knit bond with these women that share my morals, share my ideals; they share my vision." These were common statements in their narratives. Empowering other women was important in their development of a leadership identity and was expressed through statements like, "You know women are being dominated. There's still the glass ceiling, so we have to gain these skills and teach them to others." Or, "There's a femicide going on and these projects [Vagina Monologues] tell that story and educate." And, "I want all women to stand up and go together, I want us to rule the world. We don't have to diminish any man, but I just feel like I want to be at that same level so badly, that I'm always quick to assume that role."

The participants recognized that women, especially non European American women, are not proportionately represented in top leadership roles within our society. However, at some level, they hold the illusion that their generation is the one that will change this dynamic. This desire to hold onto the myth of equality may in part be due to the message they received from their parents that they can accomplish anything within the reach of their minds. But this message was tempered with, "as long as you are a good girl and get married and have babies." In addition, although a few of the women shared that they "had no desire to be president," none of these women articulated experience with direct gender discrimination in their involvement experiences from their peers, family or mentors. Although they described experiences that many would consider discriminatory, they chose not to label it as such. One participant shared, "I think it's 
more our skills, abilities and drive rather than being a woman or a man that impacts

where we go as leaders." But when probed, one participant articulated the following;

When you get out into the real world it's about connections. Sadly that's how the world is. You can have all the knowledge in the world but you need connections. That's why it's statistically more white men - they have more connections. In the real world yes, you need to have skills, yes you need to be a team player and have things under your belt, but it's also who you know. Sometimes you'll know a lot more than somebody else but they'll know a person in high places and they'll get up there. That's why now it's important that leadership studies emphasize networking and working that network. Relationships are very important because you never know when you'll see that person again.

These women did share explicit ways in which their gender affected their development of a leadership identity. For example many of the women shared the ways that their sense of connection with others, especially to the people who were important in their lives, impacted this development. For some this came out in the commitments they made. "It's hard for me to disappoint people, so if I say I will do something, I will do it no matter what." Or, "I'm a giver and don't want to let people down, so if you think I can do something, I will try my hardest." For others, it was in taking on more of the work. 'See, I'm so detailed and he's like, 'don't worry I got it,' but then the day before he don't got it and I have to pull it all together...I mean he'll get it done but it just won't be anything compared to what I would do.” From their statements, it was clear that they had internalized the script "good girls work hard and are helpers; they put others first instead of taking care of themselves first."

The impact of ethnicity on their evolution of a leadership identity also emerged as an influence. Interestingly, their status as a majority population had the greatest impact as it had substantially reduced the influence of oppression. These participants felt a sense 
of belonging and did not feel as many limitations in their involvement or in taking on leadership roles because of this majority population status. As one participant shared,

Being here in Miami, I've grown up in sort of a bubble almost. Everyone that I run into or people as a child that I knew were Hispanic so I guess I familiarized myself as not even Hispanic at that point because I thought everyone else was just like me. I knew I was a U.S. citizen and that's it.

When asked if being Hispanic influenced their leadership experiences six of the women were unable to conceptualize the impact being Hispanic could have. As one participant stated, “I really wouldn't know. I don't think I have enough experience or have witnessed enough to see that." Another shared the positive influence being Hispanic in Miami had on her leadership experience;

In terms of leadership here, I think it was just easier. There were so many doors open for me... I wasn't comfortable with my accent, and speaking in front of other people, but other people [in these organizations] had accents and they talked in front of other people. That helped me, I just felt more comfortable. It did two things for me. It helped welcome me and transition me to college life and what I could do with my time other than study. It also urged me to just be better, just work on my inhibitions and my insecurities of, you know, who cares if I have an accent?

What is especially interesting about this quote is the contradiction that was expressed. The participant shared that Miami is a great place, and that she did not feel oppressed in Miami because so many Hispanics reside in the city. However, at the same time she describes feeling uncomfortable because of her accent. Although it is clear that the participants are not immune to discrimination, it is evident that in their experience the predominately Hispanic environment lessens this discrimination from their perspectives.

Because of their experience as the majority population in Miami, their gender trumped this ethnicity experience. Even so, five of the women described the ways that cultural expectations they were raised with impacted their development of a leadership 
identity. For example, messages about being a "good Hispanic woman" challenged them as they felt the struggle to be subservient in leadership experiences with men "to not be too smart or always have the right answer" and "to do it their way." These are clear examples of their holding onto the myth that their generation is different and is making the change. But, this struggle also infuriated them and made them more determined as evidenced in the following quotes by Lara and Sally respectively.

I'm quick to take on a leadership role and demonstrate my skills because at least in our culture, for any Cuban man, you'll see that they're very macho. They think that they're better, and it frustrates me, so I stand up and take on these roles.

I think being Hispanic, there are certain things that have pushed me because I've seen in the past certain limitations that have been set. And it's about going beyond that and proving that it's not ok and that there could be so much more done.

Their ethnicity, specifically the immigrant mentality to pay it forward, also impacted these women's leadership identity development. The women who were first or second generation immigrants spoke specifically of the sacrifices their families had made to come to the United States. They were thankful for this opportunity and had a strong desire to give back to those who were less fortunate than them. There was an expectation to pay it forward that was instilled in them at a young age and that continued to resonate with them. Particularly they hoped to help other women and Hispanics who are not as fortunate as them.

Do the ways in which these women describe their leadership identity development align with the process described in the LID model? If so, in what ways are they similar and/or different? 
While limited research has been conducted on an individual's construction of a leadership identity, Komives et al. $(2005,2006)$ research is most commonly referred to in this focus of knowledge. Their research is beneficial in understanding how college students form a leadership identity, but it is incomplete as it does not include the specific influence gender, race, ethnicity and culture may have on this process. Their research was based on a purposeful sample of 13 college students who represented a diverse group in terms of race, gender, sexual orientation and ability backgrounds at a PWI. However, given the small number of students representing women, the lack of Hispanics in the sample, and the context of the PWI, their study was unable to describe any specific impact gender and ethnicity may have on the development of a leadership identity. Even so, some of the influences that emerged from this study clearly support their findings.

The participants in my study shared the major influences that contributed to their development of a leadership identity that in many ways resonated with Komives and her colleague's (2005) illustration of the cycle their participants experienced. This cycle, represented in Figure 5, was the precursor of the LID model (see Figure 2), published in 2006. Although I recognize similarities between components of this cycle and the experiences described by the participants in my study, I reject the stage based assumption of the LID model from a theoretical perspective because it does not fit the data completely. The LID describes specific steps an individual progresses through in their development of a leadership identity. These steps reflect definite stages, each marked by transitions, and each with a start and end point. The participants in this HSI study do describe a progression of leadership. However, their progression is not as defined as the LID model and hinges on context and experience, rather than stages. Movement was 
experienced as their understanding of leadership was enhanced through their experiences with involvement and the relationships they engaged in during these experiences. An individual could feel experienced as a leader in one aspect of their involvement because of their comfort and experience in that arena, but feel completely new or emerging in another experience. This change in progression could occur due to a new involvement experience, a more intense leadership experience, or graduation. It could also occur because of an experience the individual had with one of the other influences, for example an incident within a meaningful experience. While I reject the stage based model I also recognize that similarities and differences existed in these participants' leadership identity development which I have chosen to visually depict based on their experience as a leader in the format presented in Figure 3. While this image does demonstrate the similarities and differences these women described as part of their leadership identity development, it is more fluid than the LID model with no specific transitions or steps. In addition, the five topics of influence that emerged in my study interacted with each other differently at various points in their progression of a leadership identity. For example, encouraging relationships had more influence on self development early in their involvement experiences. The key categories Komives and her colleagues describe in Figure 5 to some degree align with the influences described by my participants. However, my study was exploratory; it was important that the participants' voices, and the language they used, be employed in developing a visual representation of their experience. The LID model did not capture the voices of my participants. In addition, it is clear that the particular context of sociopolitical movements and immigration patterns 
that exist in the city of Miami, cannot be separated from these participants' leadership identity development experience.

Even though I reject the stage model and it is clear that a number of other factors make these participants' experiences unique, the LID model is useful in examining influences on college students' development of a leadership identity. To begin, all five of the key categories that emerged from their study were apparent in the major influences that emerged in the narratives of the students in my study.

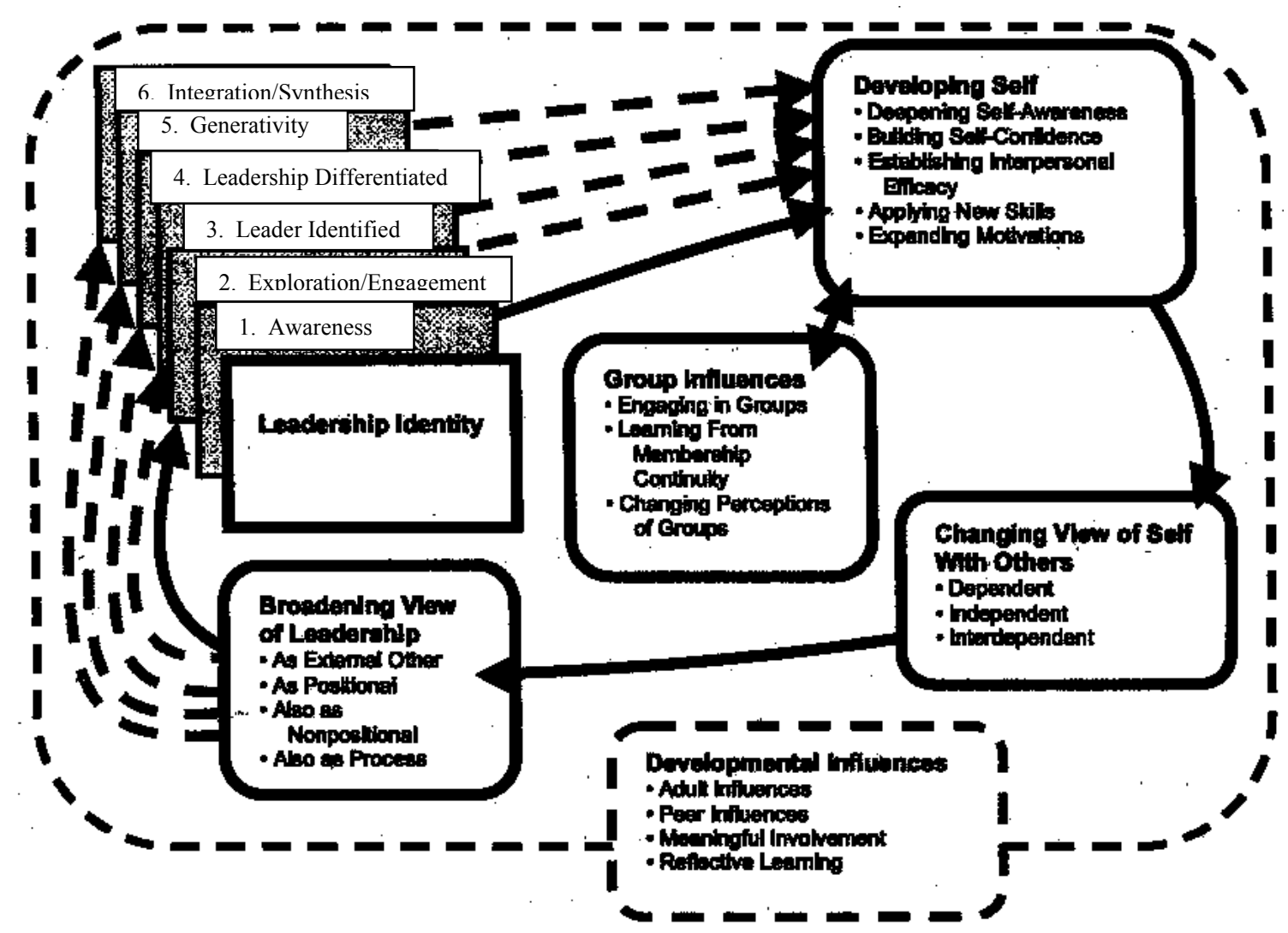

Figure 5: Developing a leadership identity: Illustrating the cycle

Komives, S. R, Owen, J. E, Longerbeam, S. D, Mainella, F. C., \& Osteen, L. (2005). Developing a leadership identity: A grounded theory. Journal of College Student Development, 46(6), 593-611.

For example, while labeled differently in either study, the importance of encouraging relationships and meaningful experiences were revealed as influential to the 
leadership identity development of participants in both studies. Participants in both studies disclosed the impact that their relationships with family members, mentors, teachers and peers had on their construction of a leadership identity. This influence was most apparent as they chose which experiences to be involved. Komives and her colleagues' key category developmental influences described the impact that adults, peers, meaningful involvement, and reflective learning had on their participants' leadership identity development. The topic encouraging relationships in my study describes the influence that family, mentors and peers had on the participants' leadership identity development. However, it focuses on the impact of these relationships alone while developmental influences in their study, incorporates the people and the experiential influences on the participants' development. In my study meaningful experiences comprises its own topic and describes the ways that these participants' involvement, reflection of their involvement and their changing view of leadership, influenced their development. I chose to separate the influences on their leadership identity development into separate spheres and to continue to use the terminology established in chapter 4, which separates the sociological and psychosocial development into two categories, as it emerged directly from the voices of these participants.

The topic meaningful experiences from my study also related to some aspects of the key category group influences in their study. Group influences in their study described the meaningful ways in which leadership activities, group experiences and a sense of connection contributed to an expanded understanding of what it means to be a leader. Aspects of the group influences relate to the topic meaningful experiences in my study which also focuses on the intricate ways that developing a sense of connection to a 
group, experiential leadership learning, and reflection contributed to a changing view of leadership for these participants.

In addition, the influence of personal growth and development was significant in both studies as participants from both studies described how an expanding sense of who they were and what they were capable of, contributed to who they were as leaders. In my study this is evident in the topic self development. In their study it is described within the category developing sense of self. In comparing this study with their study it is these two categories that are most closely aligned as both focus specifically on the impact of self awareness, personal growth and development. However, Komives et al. (2005) describe expanding motivations, the change from viewing leadership as a purely social opportunity to a cause through which they hope to create change within this category. In my study this change in approach emerged as the theme being a part of something within the topic meaningful experiences as it was through their desire to be a part of something they believed in that their reason for being involved became more directed. The participants in this study described a desire to be involved with their peers, which connected them to likeminded people and groups and developed into a passion for a cause, as a process that occurred through engagement in meaningful experiences with others.

In addition, in my study the change in locus of control was most evident as the participants described the personal development and self competency they gained through experiences. Komives et al. describe this process within the category changing view of self with others. However, they do point to a strong interaction between the category changing view of self with others and development of self. The theme changing view of 
leadership within the topic meaningful experiences in my study also held parallels with the key category broadening view of leadership in their study. Each of these influences describe the ways in which participants in both studies moved from an understanding that leadership was positional, happening around them but external to whom they were as individuals, to the belief that they were leaders, whether they had a position or not, because they made things happen with other people.

While the key categories from Komives and associates illustrated in the cycle in Figure 5 more closely resonates with the data that emerged from this study, similarities can also be drawn between the process the participants in this study shared, which became the three leadership categories, and the six stages of development described in the LID model (see Figure 2). For example the pre-collegiate experiences of the women in this study resound with the participants in stage one and two of the LID model. Awareness is the first stage in the LID model and refers to recognition that leadership is happening around the follower and exploration/engagement depicts the intentional involvement students begin to engage in by joining groups, taking on responsibilities and becoming an "active" follower or member. In their pre-collegiate experiences none of the women in this study identified them self as a leader, but each described people in their lives that they considered to be leaders. For the majority of these women it was adults in their lives. When they were young, they considered parents, teachers and older family members, leaders, as is articulated in the following statements, "My mom, she was a trooper, and I saw her as a leader because of what she could do - go to school, work, be my rock." And, "I thought and still think that a leader is a good role model, someone that you can look to for some sort of guidance, even your sister, or a parent, you look up to 
them, they're a leader to you." In both studies, early in their involvement experience this term "leader" was external to participants. Although they recognized that leadership existed, they did not see themselves involved in leadership.

All but one of the participants in this study were involved in pre-college activities like girl scouts, theater, sports and student government that provided group interaction and opportunities to take on responsibilities. However, at this time in their lives their leadership involvement was not "positional." Similar to the students in the LID model stage two, they sought social involvement and received affirmation from adults and peers and began to identify and develop personal skills, strengths and challenges.

In addition, parallels can be made between the emerging leaders in this study and stage three of the LID model leader identified. Stage three characterizes a leaders' centric view in which positional leaders are responsible for group outcomes, students described themselves as a leader or follower and modeled older students they considered leaders. Similarly, the emerging leaders in this study did not yet identify themselves as leaders but as members, who belonged to a team. They sought direction from those they perceived as leaders, and, through the involvement experiences, were transitioning to a view of self as a leader. These students expressed leadership in the following ways, "I think there has always got to be someone who can stand up and say this is what we are going to do," and their involvement as "my preference is to be involved not necessarily have to make decisions or to lead the group," and "I'm not a leader yet."

Parts of the narratives of the intermediate leaders in this study resound with the experiences of participants described in stage four, leadership differentiated, of the LID model. The leadership perspectives of students in stage four of the LID model 
incorporates the knowledge that leadership is a process that people engage in together, regardless of an individual's role. Students in this stage join with others to accomplish shared goals and seek to facilitate effective group processes no matter what their "role" in the group. The intermediate leaders in this study shared this perspective in many ways articulating, "It's whoever takes the initiative." Or, "You could be director or president but if somebody else takes the initiative then the titles disappear." And, "It's working with a group of people and seeing their talents and helping them learn to work together and trust each other, cause we all have our part to do."

The narratives of the experienced leaders in this study can be related to the experiences of students in stage five, generativity, and stage six, integration/synthesis, of the LID model. For students in the generativity stage leadership was a form of activism, they described being committed to groups that sought to create change. In addition they felt a sense of responsibility to mentor younger group members in order to promote group continuity. The experienced leaders in this study also described the ways their involvement commitments became more closely related to their values and passions as well as a desire to empower other women's leadership development. They shared; "Now my involvement is about taking something on, wanting to make some kind of change, and wanting it to change for the greater good." And, "I recognized that being involved in Stonewall gave me an opportunity to change things, to make a bigger difference so I ran for president." As well as "It's about giving them the experience, making sure they develop the confidence and the skills to be leaders."

For students in the LID model final stage integration/synthesis leader had become a part of their self identity, leadership for them was about continued self-development, 
leaving things better than when they started and role modeling to others. The experienced leaders in this study illustrated many of these concepts sharing; "Yes, now I know I'm a leader, it's just part of who I am and what I do." And, "I hope that when I graduate, I made a difference in someone's life, or helped FIU be a better place." Although the LID describes two phases as part of this process, the voices of participants in this study merged the experienced leader categories in this study.

While similarities have been shared between the participants' experiences in the Komives et al. (2005) study and subsequent development of the LID (Komives et al., 2006) and this study, there are several differences. I describe those here along with points of caution in making connections between the topics and themes that emerged from this study with the Komives et al. (2005) study. First, while the Komives et al. (2005) study was approached from a psychosocial lens, the model did not specifically address the influence of gender and ethnicity on college students' leadership identity development, nor the influence of institutional context. As the current study sought to explore these influences several additional findings emerged through the narratives of these students, in this particular context. It became clear that other factors of their identity do influence their development of a leadership identity and therefore a multidimensional perspective is more appropriate in understanding the complexities of Hispanic women college students' experiences with leadership development. While the LID model attempts to describe a complicated process by giving it a starting and ending point, I argue that there are inherent limitations in using a stage-based model as these models assume homogeneity of experience and indicate a possible deficit in participants who never achieve the "optimal" end point. 
While the data from this study suggest some alignment in the overall topics derived in both studies, it also suggests differences that may relate to the impact of gender and ethnicity. For example, many of the women who would be considered stage six in the LID model did not desire the title "leader" as they felt it separated them from their group members and indicated "superiority" in their status. In addition, as a group, the women in this study struggled with issues of power in ways that connected to the messages they have received since birth about what it means to be a "good girl" in our society, putting other's needs first, being a giver, and taking a subservient role to men. Although Komives et al. (2005) refer to gender as an aspect of their participants self that led them to view leadership contexts differently, they do not address gender as a specific influence in the LID. The data in this study suggests that gender plays a pivotal role in the leadership identity development of these students.

Due to these participants majority population status, the overall impact that ethnicity has on their leadership identity development remains unclear. However, the data suggest a few implications including a desire to stand up for or rectify injustices and prove their abilities. Although this data cannot speak to the experience of Hispanics at a PWI, in an HSI environment, ethnic oppression was not as relevant an issue. However, at a PWI it may warrant more exploration and attention. As Jones's (1997) research indicated, the development of identity is multi-faceted. Therefore, because of the limited participation of women and Hispanics in the LID model data, and the finding in both studies that the influence of the "privileged" status students in both studies held (European American students at a PWI in Komives et al. study and Hispanic students at an HSI in this study), it is important to continue researching the ways that intersecting 
social identities impact the development of a leadership identity. Komives et al. (2005) identified this as a limitation to their study.

\section{Conclusions}

Based on an examination and analysis of the findings several conclusions were

drawn. Conclusions are based upon my interpretation of the findings and follow:

1. Development of a leadership identity is a complicated and continuing process influenced strongly by relationships and the experiences in which a student chooses to participate. The Hispanic women in this study spoke of their evolution as leaders as a process, and their current experience as a snapshot of the ongoing process of developing a leadership identity. Relationships played a key role in this developmental process. Their sense of what it means to be a leader developed through their relationships and experiences with others and the choices they made regarding experiences in which to participate was led by their relationships with others. This conclusion resonates with the findings of Logue, Hutchins and Hector (2005) who found relationships key in the leadership development of students and with McEwen (2003) who asserted that identity development is a complex process and a progression of personal and social identities. Identity is often considered from a macro perspective but can also be viewed from a specific standpoint such as a leadership identity, as was done in this study. This study also suggests that thinking about leadership identity development from a strictly psychological or strictly sociological lens is incomplete. 
2. Gender expectations pose particular challenges for women student leaders. It was apparent that many of these women were conflicted in their interpretation of the messages heard about being a female growing up, and their ability to be strong leaders. A cognitive dissonance occurred as these women struggled to intertwine what they perceived as obligations for their gender with their desire for independence as they had an implicit understanding that both were important. When they spoke about the influence of gender on their leadership identity development, it was clear that they still struggled in some ways to incorporate gender role expectations with a strong leadership identity. On the surface they shared that they believe they are capable of anything, probably because this is the verbal message they received from parents. In addition, their experience in the university setting, while still sexist to some extent, is much less so than their family environments that for the most part remains bound by gender role expectations. They understood that gender role expectations affect how they are perceived as leaders, both within Hispanic and broader culture. This finding resounds with what Eagly (2007) described as the double-bind for women leaders. The double-bind refers to the evaluation of women who possess traditional leadership characteristics, those that are more masculine and decisive as "too aggressive" and women who take on more feminine or relational attributes in their leadership style as "too soft." It is also clear that these messages about gender were incorporated early and had a lasting impression on many of the women in this study. 
3. The meaningful ways that gender was integrated into a leadership identity. A majority of the participants in this study chose to become involved in organizations and programs which promoted equality, the empowerment of women and addressed critical issues that women face. Their leadership identity is in part defined by activism around these issues. As Hispanic women they saw unequal treatment that they did not view in "American" culture which influenced their leadership identity because they wished to rectify those injustices, educate and empower other Hispanic women to understand that they have choices. In addition, the women in this study describe a leadership style that is egalitarian and collaborative, which Arminio et al. (2005) found in their study of non-European American student leaders and Whitt (1994) found in her study of women student leaders at all women's colleges. Another factor related to their leadership identity development and gender includes taking personal responsibility for the outcomes of their programs and organizations when others do not follow through. This was evidenced via the avoidance of conflict and not wanting to ask for help because of the belief that doing so might negatively hurt their relationships with group members. One final implication related to gender was not wanting to take on the title of leader, for them, this carried the connotation of being "better than" others which was antithetical to their egalitarian beliefs. Only the experienced leaders, those whose understanding of leadership carried the connotation that leadership is about involving others in the process of creating change together, were comfortable with this title. Arminio et al. (2000) also found students in their study reluctant to accept the title leader. 
4. The impact of a minority serving institution. As a majority minority population their experiences are unique and somewhat sheltered from the influence of racism. The impact of this on their leadership identity development is profound; Hispanics are the student leaders at every level in every organization on campus. Therefore, these students possess privilege. As Bridges et al. (2005) asserted MSIs can be powerful and nurturing to students' learning and provide shelter from the effects of ethnic and gender discrimination that can be prevalent in an individual's construction of identity. The data in this study demonstrates that these participants' experience with leadership identity development at this HSI resonates with this sheltered status that Whitt (1994) found in the leadership experiences of women at all women's institutions and what Harper et al. (2004) found to be the experiences of Black leaders at an HBCU. Jones (1997) found that the most prominent aspect of students' identity was the aspect related to minority status and that race was integrated into students' identity in different ways that depended on their family background and life experience. The dichotomy of privilege and inequality affected the manner in which race was relevant to the identity development of the students in her study. Similar to the implications of race on the overall identity development of the European American students in her study, ethnicity was not a major factor in the leadership identity development of the Hispanic students in this study.

5. Understanding the role of power. The data from this study support research indicating that although women's roles and status in leadership are gradually 
changing (Catalyst, 2007); it is generally assumed that women have less positional power in organizations than do men. While changing conceptualizations of power undoubtedly contribute to gender differences in leadership, the data from this study suggests that power over others is still considered a negative implication of leadership by women. However, as indicated in the relational leadership perspective, power takes on two forms; power over others and empowerment of others. The participants in this study embraced the empowering form of power, power that Klenke (p. 154) describes "as an expandable resource that is produced and shared through actions between leaders and followers."

6. Leadership is not gender, race or ethnicity neutral. A plethora of research indicates that leadership is not gender, race or ethnicity neutral. While an individual need not be a man nor European American to possess leadership qualities or to become a leader, research has demonstrated the negative ways in which gender, race and ethnicity impact an individual's ascension to leadership roles (Cantor \& Bernay, 1992; Catalyst, 2007; Chao \& Rhones, 2007; Eagly \& Carli, 2004; Hoyt, 2007; Klenke, 1996). The experiences of the women who participated in this study indicate that although they struggle with articulating the ways that their gender and ethnicity impact their development of a leadership identity, they recognize differences between what is expected of men and women in leadership roles. Generally speaking, they believe women are the ones who make things happen, who get things done, and men direct others. The women in this study took on a number of leadership roles. However, when co-directing 
experiences, or when involved in experiences led by men, the issue of power and privilege becomes clear. Women are expected to acquiesce to the man and assume their supportive role. This was a point of contention for many of the women in this study and why the majority were most successful in organizations and programs led by women.

Interestingly, while they were aware of the dramatic underrepresentation of women in at the higher rungs of leadership within our society, at some level they believe that their generation will eliminate this discrepancy because they (both men and women) see leadership as gender, race and ethnicity neutral. I found this interesting given the clear power differential that exists even though the majority of students in leadership roles at FIU are women. While these participants clearly articulated the differences in gender expectations they experienced in their households growing up, they saw these experiences and leadership as completely separate and believe that their own experiences with gender role expectations as well as these men's experiences with gender role expectations will not affect their beliefs and actions regarding what women can, or should do. These participants share a leadership perspective that is generally blind to gender and ethnic oppression. They do understand that discrepancies currently exist in our society between men and women, particularly women of different ethnicities in leadership positions. However, they believe the disparity experienced in society today is due to the discrimination that exists in their parents' generation and that their generation thinks differently, therefore they will not experience the same discrimination when they compete with men for the same 
leadership positions. This belief may well be due to the sheltered experience of the participants thus far.

\section{The LID model may not provide a complete picture of a college student's} leadership identity development. While the findings of this study indicate that the LID model provides a framework for understanding college students' leadership identity development, it is incomplete. To begin, the LID does not include the specific influence gender, race, ethnicity, culture and an MSI may have on this process. In addition, this study demonstrates inherent complications to the stage based model. For example, the detail of each stage and the progression between stages was not as delineated in my study as in the Komives et al. study. The LID describes a starting point, specific steps, with clear transitions and an optimal ending point. While the leadership categories described in my study still represent "stages" they are broad enough to include the experiences of the participants in my study. In addition, the 3 categories represent the women in this study without attempting to develop a general framework for college students' leadership identity development. A model that considers the implications of gender, ethnicity and the impact of MSIs as well as other identity differences amongst students is warranted. In addition, I recommend a more fluid model that does not delineate a step by step progression.

\section{Recommendations}

My research findings and conclusions suggest several implications for practice, as well as recommendations for further research. While the recommendations for practice are proposed as a result of this particular study, it is supposed that higher education 
administrators working with leadership development programs, as well as faculty teaching in the leadership discipline may utilize these recommendations in similar context.

\section{Recommendations for Practice}

1. Utilize the available research on the implications of gender and ethnicity (as well as race, sexual orientation, ability, and socioeconomic status) to bring awareness of oppression in leadership contexts and develop curricular and co- curricular courses and leadership training experiences that support the understanding that leadership is not gender, race, ethnicity, basically "other" neutral. In addition, staff must be trained to challenge behaviors that are incongruent with equality. In developing this understanding, help college students recognize steps they can take to reduce the prevailing perspective amongst their peers, develop skills to combat the negative effects of this reality, and create change as they enter the workforce and take on leadership roles after graduation. By educating tomorrow's leaders to be well prepared to articulate and take a stand against discrepancies in leadership, we will progress toward the development of more inclusive leadership in our society.

2. Develop curricular and co-curricular courses and programs that promote a cognitive shift in understanding leadership as both content (accomplishing goals) and processes (identity development) oriented. Involvement in women's issues and issues of social justice promoted the development of a leadership identity for the women in this study. They found opportunities to involve themselves in activist causes that related to their identity as a woman and/or as Hispanic. It was here that they found their passion, made meaning of their experiences, and began to understand that they can make a 
difference in causes that are important to them. Students, who develop an internalized understanding of self as a leader and as an individual capable of creating social change that is sustained over a lifetime, will ultimately change society.

3. Encourage student leaders to hone their involvement to a particular group or issue for which they are passionate (depth as opposed to breadth). It was clear that the students who focused their involvement to one or two groups, utilizing their involvement with those groups to engage in projects they were passionate about and accomplish their goals, reaped more in depth benefits to their own development and the development of meaningful relationships. It was in these in depth experiences that the most reflection and engagement occurred.

4. Learning outcomes for leadership activities, processes, trainings and courses should be defined and include opportunities for reflection and meaning making as well as relationship building across contexts.

5. Develop strategies that help students form networks across organizations and provide opportunities for identity based groups and non-identity based groups to form coalitions and create change around larger issues. As research has demonstrated that students' multiple identities impact the involvement opportunities in which they choose to engage, coalitions among diverse groups will assist in developing awareness and understanding of the implications of difference and aid in developing an understanding of the importance of including diverse perspectives.

6. Consider developing leadership tracks based upon students' experience with leadership. For example, the emerging, intermediate, and experienced leaders in this study placed different meaning on leadership, were at different places in their 
leadership identity development, and therefore had different needs regarding leadership development. Tracks or experiences that cater to students at these different levels would support their specific needs and provide for commonality of experience. Opportunities to engage with older peer mentors, faculty and staff in these contexts are also important.

7. Student affairs administrators must become educated regarding the implications of gender and ethnicity on leadership. As evidenced in the data from this study, advisors served a critical role in the leadership identity development of the participants. Student affairs administrators must be prepared to advocate on behalf of Hispanic women leaders, promote their leadership identity development and challenge behavior that promotes a masculine centered leadership approach. In addition, interventions must be developed that specifically address the issues of "being a good Hispanic woman," or a "good woman" in general. As the staff that advises students and develops curricular and co-curricular leadership programming, it is critical that they be aware of the literature regarding the influence of gender and ethnicity on a student's leadership identity development and the influential ways that leadership is not gender, ethnicity nor race neutral.

8. Non-Hispanic student affairs administrators must also become educated regarding Hispanic culture as it pertains to their particular campus. At FIU the majority of student affairs staff members are not Hispanic, yet the majority of students are. Understanding the culture of these students and the implications of their ethnicity on their experience at FIU is important. Specifically administrators must understand the 
double messages that parents are giving these women; be all you can be, but be a homemaker first.

\section{Recommendations for Research}

1. There is much to learn about identity based leadership in general and Hispanic women college student leadership in particular. The LID could be an influential tool in understanding the implications of the multiple perspectives of identity on leadership. Connections were found between the experiences of the Hispanic women student leaders in this study and the data depicted in Komives's et al. $(2005,2006)$ LID model. Research exploring the ways that identities (sexual orientation, ability, race, ethnicity, gender and socioeconomic status) impact a college student leader's development of a leadership identity, as well as any differences that might exist within educational contexts (single gender, HBCU) or between groups within particular educational contexts (European American compared to Hispanic, or men compared to women, at a PWI) would provide rich data to add to the field of knowledge on college student leadership identity development. In addition, understanding the process by which students develop an understanding of power differentials as they relate to gender and ethnicity (as well as race, ability, sexual orientation and socioeconomic status) could provide data that support the development of co-curricular and curricular experiences that align with \#1 above. This study suggests that leadership training is working but we know little about how.

2. The data reveal that the participants in this study did not embrace the title leader until their understanding of leadership changed from "leader as a person who is in charge" to "leader as a person who engages people in a process and builds meaningful 
relationships with a team which helps them accomplish goals." Further exploration of this phenomenon would be interesting. Does this occur because the term "leader" has now been "brought down to" their level? Is this connected to the gender role expectation that "good girls are helpers and shouldn't tell others what to do?" Do male college students have the same issues with the title "leader?"

3. Conduct studies exploring a student leader's identity after she graduates from college. The participants of this study were bounded as a case in a particular context; data emerged suggesting that this context had particular implications on their development of a leadership identity and that their leadership identity at that point in time was a snapshot that would change based upon future experiences. Exploring the ways that these students' leadership identity changes upon graduation from an HSI, particularly for those who may leave the Miami area, could provide interesting data for understanding the life long development of a Hispanic woman's leadership identity development.

4. Study the leadership identity development of Hispanic men at an HSI. The data from this study suggest that gender role expectations in Hispanic culture influence the development of a leadership identity. Men appear to be expected to develop an executive set of skills. Therefore a study exploring whether there are holes in their skill set would provide interesting data. In addition, a comparative exploration would be interesting and provide some insight regarding the ways that gender differences impact Hispanic men's and women's leadership identity development differently. In addition, a study comparing the leadership identity development process of Hispanic men and women at a PWI would provide comparative data. 
5. This study explored the leadership identity development of Hispanic women as a group without accounting for the diversity amongst the Hispanic population. A study exploring any differences between nationalities within the Hispanic culture, particularly between Cubans and other groups of Hispanic women student leaders, would be interesting given the status of power that Cubans possess in south Florida.

6. As this study found comparisons with the Komives and associates results, replicating this study at a different institution to further examine the stage based verses interactive leadership development models would also be of interest.

7. A study exploring any connections between leadership identity development and the cognitive development of student leaders, particularly those who have participated in identity based leadership programs, would also generate interesting data that would increase our understanding of college students and leadership.

\section{Interpretation Parameters}

There were two parameters for interpretation of this study that are important to address. The bounded nature of this study posed the first. The study was bounded to a particular group of Hispanic women at a public, 4-year HSI in the city of Miami, Florida. While this context is a strength of the study as it shows the development of Hispanic individuals outside of the "other" in oppositional contexts, demonstrating a more "natural" developmental process. As a result of the site selections, the findings may not be transferrable to other Hispanic women attending another campus. Hispanic women who attend private institutions, PWI, or any institution other than an HSI may reveal different experiences in their leadership development identity process. In addition, the unique aspects of Miami, as a predominately Hispanic city, are not necessarily 
transferable to other traditional college cities. Even so, it is left to the reader to determine the applicability of their context.

Second, the participants in this study expressed the diversity of the Hispanic community. They were from the Caribbean, Central and South America. The heterogeneity of the Hispanic community is prevalent in Miami, but it is also a predominately Cuban community. This study did not explore similarities or differences amongst the Hispanic population. It is possible that individuals from specific Hispanic groups (Cuban or Colombian) may experience similarities and differences in their development of a leadership identity.

\section{Summary}

The purpose of this study was to explore the experiences of Hispanic women leaders attending a 4-year public HSI in order to develop insight and in depth understanding regarding how they developed a leadership identity and the influences that were strongest in this development. This was accomplished by conducting in-depth individual and focus group interviews with 11 self-identified Hispanic women who were of sophomore, junior or senior status at the time the interviews were conducted. All of the participants had attended FIU for at least one year. Each of the women had varying degrees of involvement and leadership experience but were referred to the study based on a minimum level of involvement. From the data emerged five topics: (a) encouraging relationships, (b) meaningful experiences, (c) self-development, (d) the role of gender, and (e) impact of ethnicity. These themes connected to each other and influenced the development of each woman's leadership identity. Based on this study, it can be 
concluded that for Hispanic women, the process of developing a leadership identity is complex.

How we define leadership influences how we study and measure it, the symbols and metaphors we apply to it, and the way we practice leadership. In our society, the paradigm of a leader is still based on patriarchal models derived from the "Great Man" theories of leadership. Although the paradigm of leadership within student affairs organizations and programs at FIU is relational, the participants in this study hold onto some of the scripts of the "Great Man" theories. For over 30 years researchers have questioned if differences exist in the leadership effectiveness, development and progression of women leaders and leaders from a diversity of ethnic groups. Our understanding of the ways gender and ethnicity role expectations have shaped society is changing, and the increase of women and people of different ethnicities in leadership positions has led to this scholarly interest in broadening leadership studies, which is beginning to change the way we view, define and study leadership. This study corroborates with much of this research which demonstrates that gender and ethnicity do in fact impact leadership. Therefore, leadership must be looked at through a multidimensional lens, one that provides greater insight to the exploring a population of individuals who have been largely underrepresented in the literature.

The core mission of student affairs is to develop students holistically by connecting curricular and co-curricular initiatives on campus. Institutions of higher education are uniquely positioned to educate tomorrow's leaders and initiate change in the number of women, and women of different ethnicities, in leadership roles. The findings and recommendations of this study have been summarized and presented in this 
chapter for administrative and academic members of the academy in the hopes that it will enable those who work with diverse populations an opportunity to better understand a growing population within the academy as well as the biases that still exist in leadership paradigms. 


\section{References}

Alverez, C., Bliss, L. A., \& Vigil, P. (2001). Cuban identity: A preliminary study. No. ED 454 316) Retrieved from ERIC database.

Amer, M. (2008). Women in the United States congress 1917-2008. Congressional Research Services, RL 32061. Retrieved June, 7, 2008, from http://www.senate.gov/reference/resources/pdf/RL30261.pdf

American College Personnel Association (ACPA). (1994). The student learning imperative: Implications for student affairs. In E.J. Whitt (Ed.), College student affairs administration, ASHE Reader Series, (pp. 36 - 40). Needham Heights, MA: Simon and Schuster.

American College Personnel Association \& National Association of College Personnel Administrators, (2004). Learning reconsidered: A campus wide focus on the student experience. Washington, DC: Authors.

Arminio, J. L., Carter, S., Jones, S. E., Kruger, K., Lucas, N., Washington, J., Young, N. , \& Scott, A. (2000). Leadership experiences of students of color. NASPA Journal, 37, (3) 49-510. Retrieved August 13, 2007, from http://publications.naspa.org/naspajournal/vol37/iss3/

Astin, A. W. (1985). Achieving academic excellence: A critical assessment of priorties and practices in higher education. San Francisco: Jossey-Bass.

Astin, A. W. (1993). What matters in college: Four critical years revisited. San Francisco: Jossey-Bass.

Astin, A. W., \& Astin, H. S. (2000). Leadership reconsidered: Engaging higher education in social change. Battle Creek, MI: W.K. Kellogg Foundation.

Astin, H., \& Leland, C. (1991). Women of influence, women of vision: A crossgenerational study of leaders and social change. San Francisco: Jossey-Bass.

Bass, B. M. (1990). Bass \& Stogdill's handbook of leadership ( $3^{\text {rd }}$ ed). New York: Free Press.

Baxter Magolda, M. (1992). Knowing and reasoning in college: Gender-related patterns in students' intellectual development. San Fransisco: Jossey-Bass.

Belenky, M. F., Clinchy, B., Goldberger, N. R., \& Tarule, J. M. (1986). Women's ways of knowing: The development of self, voice, and mind. New York: Basic Books.

Bennis, W. (2003). On becoming a leader. Reading, MA: Addison-Wesley. 
Black, S., Stephens, G., \& Rosener, J. (1992). Women in management around the world: Some glimpses. In U. Sekaran \& F. Leong (Eds.), Womenpower. Newbury Park, CA: Sage.

Boatwright, K. J., \& Egidio, R. K (2003). Psychological predictors of college women's leadership aspirations. Journal of College Student Development 44, 653-669. Retrieved May 16, 2007, from http://muse.jhu.edu.ezproxy.fiu.edu/journals/journal_of_college_student_develop $\underline{\text { ment/toc/csd44.6.html }}$

Bogdan, R. C., \& Biklen, S. K. (2007). Qualitative research for education: An introduction to theories and methods ( $5^{\text {th }}$ ed.). Boston, MA: Pearson.

Bridges, B. K., Cambridge, B., Kuh, G. D., \& Leegwater, L. H. (2005). Student engagement at minority serving institutions: Emerging lessons from the BEAMS project. In Gaither, G. H. (Ed.), Minority retention: What works? (pp. 25-43). San Francisco: Jossey-Bass.

Cantor, D., \& Bernay, T. (1992). Women in power. New York: Houghton Mifflin.

Casanas, D. I. (September 11, 2005). Hispanic vs Latino: Which one is right? American Chronicle. Retrieved January 25, 2009 from http://www.americanchronicle.com/articles/view/2336

Catalyst (2007). 2007 Catalyst census finds women gained ground as board committee chairs. Retrieved June, 9, 2008, from http://www.catalystwomen.org/pressroom/press 2007 census.shtml

Chao, E. L., \& Rones, P. L. (2007). Women in the labor force: A databook. Department of Labor Services Report Number 1002. Retrieved June, 9, 2008, from http://www.bls.gov/cps/wlf-databook-2007.pdf

Chickering, A. W., \& Reisser, L. (1993). Education and identity (2 ${ }^{\text {nd }}$ ed.). San Francisco: Jossey Bass.

Council for the Advancement of Standards in Higher Education (1999). CAS standards for leadership programs. Washington, DC: Author.

Cress, C. M., Astin, ,H. S., Zimmerman-Oster, K., \& Burkhardt, J. C. (2001). Developmental outcomes of college students' involvement in leadership activities. Journal of College Student Development, 42, 15-27.

Cross, W. E., Jr. (1995). The psychology of Nigrescence: Revising the Cross model. In J.G. Ponterotto, J.M. Casas, L.A. Suzuki, \& C.M. Alexander (Eds.), Handbook of multicultural counseling (pp. 93-122). Thousand Oaks, CA: Sage. 
Denzin, N. K., \& Lincoln, Y. S. (1994). Handbook of qualitative research. Thousand Oaks: Sage.

Dugan, J. P., \& Komives, S. R. (2007). Developing leadership capacity in college students: Findings from a national study. A Report from the Multi-Institutional Study of Leadership. College Park, MD: National Clearinghouse for Leadership Programs.

Dugan, J. P. (2006). Explorations using the social change model: Leadership development among college men and women. Journal of College Student Development, 47, 217-225. Retrieved May 16, 2007, from http://muse.jhu.edu.ezproxy.fiu.edu/journals/journal_of_college_student_develop ment/toc/csd47.3.6.html

Eagly, A. H. (2007). Female leadership advantage and disadvantage: Resolving the contradictions. Psychology of women quarterly, 31, 1-12.

Eagly, A. H., \& Carli, L. L. (2004). Women and men as leaders. In J. Antonakis, R.J. Sternberg, \& A.T.Cianciolo (Eds.), The nature of leadership (pp. 279-301). Thousand Oaks, CA: Sage.

Eagly, A. H., \& Carli, L. L. (2003). The female leadership advantage: An evaluation of the evidence. The leadership quarterly, 14, 807-834.

Eagly, A. H., \& Johnson, J. (1990). Gender and leadership style: A meta-analysis. Psychological Bulletin, 108, 233-256.

Erikson, E. H. (1968). Identity: Youth and crisis. New York: Norton.

Evans, N. J., Forney, D. S., \& Guido-DiBrito, F. (1998). Student development in college. San Francisco: Jossey-Bass.

Fleming, J. (1984). Blacks in college: A comparative study of students' success in Black and in white institutions. San Francisco: Jossey-Bass.

Gilligan, C. (1982). In a different voice. Boston: Harvard University Press.

Gonzalez, R. G. (2008). College student civic development and engagement at a Hispanic serving institution. Journal of Hispanics in Higher Education, 7, 287-300.

Guiffrida, D. A, (2003). African American student organizations as agents of social change. Journal of College Student Development, 44(3), 304-319. http://muse.jhu.edu.ezproxy.fiu.edu/journals/journal_of_college_student_develop ment/v044/44.3guiffrida.pdf 
Harper, S. R., Carini, R. M., Bridges, B. K., \& Hayek, J. C. (2004). Gender differences in student engagement among African American undergraduates at historically black colleges and universities. Journal of College Student Development, 45(3), 271-283 . Retrieved June 6, 2007, from http://muse.jhu.edu.ezproxy.fiu.edu/journals/journal_of_college_student_develop $\underline{\text { ment/toc/csd45.3.html }}$

Hatch, J.A. (2002). Doing qualitative research in education settings. New York: SUNY Press.

Helgesen, S. (1990). The female advantage: Women's ways of leadership. New York: Doubleday.

Helms, J. E. (1990). An overview of Black racial identity theory. In J.E. Helms (Ed.), Black and White racial identity: Theory, research, and practice (pp. 9-32). New York: Greenwood Press.

Hoyt, C. (2007). Women and leadership. In P.G. Northouse. (Ed.), Leadership: Theory and practice ( $4^{\text {th }}$ ed., pp. 265-299). Thousand Oaks, CA: Sage.

Johnson, B., \& Christensen, L. (2004). Educational research: Quantitative, qualitative and mixed approaches $\left(2^{\text {nd }} e d\right.$.). Boston, MA: Pearson.

Jones, L., Castellenos, J. \& Cole, D. (2002). Journal of Hispanic Higher Education, 1(1), 19-39. Retreived February 27, 2010 from http://jhh.sagepub.com.ezproxy.fiu.edu/cgi/reprint/1/1/19.

Jones, S. R. (1997). Voices of identity and difference: A qualitative exploration of multiple dimensions of identity development in women college students. Journal of College Student Development, 38, 376-386.

Jones, S. R., \& McEwen, M. K. (2000). A conceptual model of multiple dimensions of identity. Journal of College Student Development, 41(4), 405-414. Retrieved June 2, 2007, from http://muse.jhu.edu.ezproxy.fiu.edu/journals/journal_of_college_student_develop ment/toc/csd45.3.html.

Josselson, R. (1987). Finding herself: Pathways to identity development in women. San Francisco: Jossey-Bass.

Kezar, A., \& Moriarty, D. (2000). Expanding our understanding of student leadership development: A study exploring gender and ethnic identity. Journal of College Student Development, 41(1), 55 - 69. 
Kinzie, J., Thomas, A. D., Palmer, M. M., Umbach, P. D. and Kuh, G. D (2007). Women students at coeducational and women's colleges: How do their experiences compare? Journal of College Student Development, 48(2), 145 - 165. Retrieved July 11, 2007, from http://muse.jhu.edu.ezproxy.fiu.edu/journals/journal_of_college_student_develop ment/toc/csd48.2.html

Klenke, K. (1996). Women and leadership: A contextual perspective. NY, NY: Springer Publishing Co.

Kolb, J. A. (1999). The effect of gender role, attitude toward leadership, and selfconfidence on leader emergence: Implications for leadership development. Human Resource Development Quarterly, 10, 305-320.

Komives, S. R. (1994). Women student leaders: Self-perceptions of empowering leadership and achieving style. NASPA Journal, 31, 102-112.

Komives, S. R., Lucas, N., \& McMahon, T. R. (2007). Exploring leadership: For college students who want to make a difference ( $2^{\text {nd }}$ ed.). San Francisco, CA: Jossey-Bass.

Komives, S. R, Owen, J. E, Longerbeam, S. D, Mainella, F. C., \& Osteen, L. (2005). Developing a leadership identity: A grounded theory. Journal of College Student Development, 46(6), 593-611. Retreived May 2, 2007, from http://muse.jhu.edu.ezproxy.fiu.edu/journals/journal_of_college_student_develop ment/toc/csd46.6.html

Komives, S. R., Owen, J. E., Longerbeam, S., Mainella, F. C., \& Osteen, L. (2006). Leadership identity development model: Applications from a grounded theory. Journal of College Student Development, 47(3), 401-419. Retrieved May 2, 2007, from http://muse.jhu.edu/journals/journal_of_college_student_development/v047/47.4k omives.pdf

Kouzes, J. M., \& Posner, B. Z. (2002). The leadership challenge: How to get extraordinary things done in organizations. San Francisco: Jossey-Bass.

Kouzes, J. M., \& Posner, B. Z. (2008). Student leadership practices inventory $\left(4^{\text {th }}\right.$ edition). San Francisco: Jossey-Bass.

Kuh, G. D., Schuh, J. H., Whitt, E. J., Andreas, R. E., Lyons, J. W., Strange, C. C., Krehbiel, L. E., \& MacKay, K. A. (1991). Involving colleges: Successful approaches to fostering student learning and development outside the classroom. San Francisco: Jossey-Bass. 
Lavant, B., \& Terrell, M. (1994). Assessing ethnic minority student leadership and involvement in student governance. New Directions for Student Services, 66, 5971.

Leonard, M. M., \& Sigal, B. A. (1989). Empowering women student leaders: A leadership development model. In C.S. Pearson, D.L. Shavlik \& J.G. Touchton (Eds.), Educating the majority: Women challenge tradition in higher education (pp. 230-249). New York: Macmillan.

Logue, C. T., Hutchens, T. A., \& Hector, M. A. (2005). Student leadership: A phenomenological exploration of postsecondary experiences. Journal of College Student Development, 46(4), 393-408. Retrieved July 18, 2007, from http://muse.jhu.edu.ezproxy.fiu.edu/journals/journal_of_college_student_develop $\underline{\text { ment/toc/csd46.4.html }}$

McCauley, C. D., \& Van Velsor, E. (2004). The Center for Creative Leadership handbook of leadership development. San Francisco: Jossey-Bass.

McEwen, M. K. (2003). New perspectives on identity development. In S.R. Komives \& D.B. Weedard Jr. (Eds). Student services: A handbook for the profession $\left(4^{\text {th }}\right.$ ed., pp. 203-233). San Francisco: Jossey-Bass.

Merriam, S. B. (2002). Introduction to qualitative research. In Merriam, S.B. \& Associates (Eds). Qualitative research in practice: Examples for discussion and analysis. San Francisco: Jossey-Bass.

Montell, F. (1999). Focus group interviews: A feminist method. NWSA Journal, 11(1), 44-65. Retreived from

http://muse.jhu.edu.ezproxy.fiu.edu/journals/nwsa journal/v011/111/11.1montell. $\underline{\mathrm{html}}$

Morgan, D.L. (1998). The focus group guidebook. Thousand Oaks, CA: Sage.

Nanus, B. (1992). Visionary leadership: Creating a compelling sense of direction for your organization. San Fransisco: Jossey-Bass.

National Center for Education Statistics. (2008). Characteristics of minority serving institutions and minority undergraduates enrolled in these institutions. Retrieved June 9, 2008, from http://nces.ed.gov/pubs2008/2008156.pdf

National Center for Education Statistics. (2005). Trends in educational equity of girls and women. Retrieved June, 9, 2008 from http://nces.ed.gov/pubs2005/2005016.pdf 
Northouse, P. G. (2007). Leadership: Theory and practice $\left(4^{\text {th }}\right.$ ed.). Thousand Oaks, CA: Sage.

Owles, V. O. (2009). An examination of the experiences of Cuban American women attending a Hispanic serving institution and the influences on identity development. Unpublished doctoral dissertation, Florida International University.

Pascarella, E. T., \& Terenzini, P. T. (2005). How college affects students: A third decade of research. San Francisco: Jossey-Bass.

Pascarella, E. T, Whitt, E. J, Edison, M. I., Nora, A., Hagedorn, L. S., \& Yeager, P. M. (1997). Women's perceptions of a "chilly climate" and their cognitive outcomes during the first year of college. Journal of College Student Development, 38, 109-124.

Phinney, J. S. (1993). A three stage model of ethnic identity development in adolescence. In M. E. Bernal \& G. P. Knight (Eds.), Ethnic identity: Formation and transmission among Hispanics and other minorities (pp. 61 - 79). Albany: SUNY Press.

Patton, M. Q. (1990). Qualitative evaluation and research methods (2 ${ }^{\text {nd }}$ ed.). Newbury Park, CA: Sage.

Portes, A., \& Stepick, A. (1993). City on the edge: The transformation of Miami. Berkley, CA: University of California Press.

Posner, B. (2004). A leadership development instrument for students: Updated. Journal of College Student Development, 45, 443-456. Retrieved June 5, 2008, from http://muse.jhu.edu.ezproxy.fiu.edu/journals/journal_of_college_student_develop $\underline{\text { ment/toc/csd45.5.html }}$

Rankin, S. R., \& Reason, R. D. (2005). Differing perceptions: How students of color and white students perceive campus climate for underrepresented groups. Journal of College Student Development 46(1), 43-61. Retreived February 27, 2010, from http://muse.jhu.edu.ezproxy.fiu.edu/journals/journal_of_college_student_develop ment/v046/46.1rankin.pdf

Renn, K. A., \& Bilodeau, B. L. (2007). Leadership identity development among lesbian, gay, bisexual, and transgender student leaders. NASPA Journal 42(3), 342-367.

Romano, C. R. (1996). A qualitative study of women student leaders. Journal of College Student Development, 37(6), 676-683.

Rothenberg, P. S. (2005). White privilege: Essential readings on the other side of racism. New York: Worth. 
Ruderman, M. N. (2004). Leader development across gender. In C. D. McCauley \& E.Van Velsor (Eds.), The Center for Creative Leadership handbook of leadership development (pp. 383-414). San Francisco: Jossey-Bass.

Siedman, I. E. (1991). Interviewing as qualitative research: A guide for researchers in education and the social sciences. New York: Teachers College, Columbia University.

Stake, R. (1995). The art of case study research. Thousand Oaks, CA: Sage.

Stearns, C., Watanabe, S., \& Snyder, T. D. (2002). Hispanic serving institutions: Statistical trends from 1990-1999 (NCES Publication No. 2005-051). Washington, DC: U.S. Department of Education, National Center for Education Statistics.

Stepick, A., Greneir, G., Castro, M., \& Dunn, M. (2003). This land is our land: Immigrants and power in Miami. Berkeley, CA: Univeristy of California Press.

Sutton, E., \& Terrell, M. (1997). Identifying and developing leadership opportunities for African American men. New Directions for Student Services, 55-64. Retrieved February 21, 2010, from Education Full Text database.

The Brookings Institute (2003). Miami in focus: A profile from census 2000. Washington, DC: The Brookings Institution Center on Urban and Metropolitan Policy http://www.brookings.edu/ /media/Files/rc/reports/2003/11_livingcities_Miami/ $\underline{\text { miami.pdf }}$

Torres, V. (2003). Influences on ethnic identity development of Latino college students in the first two years of college. Journal of College Student Development, 44(4), 532-547.

Torres, V., \& Baxter Magolda, M. (2004a). Reconstructing Latino identity: The influence of cognitive development on the ethnic identity process of Latino students. Journal of College Student Development, 45, 333-347. Retrieved June 7, 2007, from http://muse.jhu.edu.ezproxy.fiu.edu/journals/journal of college student develop $\underline{\text { ment/toc/csd45.3.html }}$

Torres, V. (Spring 2004b). The diversity among us: Puerto Ricans, Cuban Americans, Caribbean Americans, and Central and South Americans. New Directions for Student Services, (105), 5-16.

U.S. Census Bureau (2006). Women owned firms: 2002. Retrieved, January 16, 2010, from http://www.census.gov/prod/ec02/sb0200cswmn.pdf 
U.S. Census Bureau. (2005). Miami-Dade county, Florida general demographic characteristics: 2005. Retreived, January 16, 2010 from http://factfinder.census.gov/servlet/ADPTable? bm=y\&-context=adp\&qr_name $=$ ACS 2005 EST_G00 DP1\&-ds name $=$ ACS 2005 EST_G00 \&tree $\mathrm{id}=305 \&$-redoLog $=$ true $\&-$ caller $=$ geoselect\&-geo $\_$id $=05000 \mathrm{US} 12086 \&$ format $=\&$ - lang $=$ en

U.S. Office of the Clerk (2009). Women in Congress. Retrieved February 28, 2009, from http://womenincongress.house.gov/index.html

Van Velsor, E., \& Drath, W. H. (2004). A lifelong developmental perspective on leader development. In C. D. McCauley \& E. VanVelsor (Eds.), The Center for Creative Leadership handbook of leadership development (pp. 383-414). San Francisco: Jossey-Bass.

Walsh, B. O. (2001). The history of operation Pedro Pan. (March 1, 2001). Retrieved October 29, 2009, from http://www.pedropan.org/history.html

Whitt, E. J. (1994). "I can be anything!": Student leadership in three women's colleges. Journal of College Student Development, 35, 120-124.

Whitt, E. J., Pascarella, E. T., Nesheim, B. S., Marth, B. P., Pierson, C. T. (2003). Differences between women and men in objectively measured outcomes and the factors that influence those outcomes, in the first three years of college. Journal of College Student Development, 44, 587-603. Retrieved June 7, 2007 from http://muse.jhu.edu.ezproxy.fiu.edu/journals/journal_of_college_student_develop ment/toc/csd44.6.html

Wielkiewicz, R. M. (2000). The Leadership Attitudes and Beliefs Scale: An instrument for evaluating college students' thinking about leadership and organizations. Journal of College Student Development, 41, 335-347.

Webster's New World College Dictionary (2005). Ohio: Wiley Publishing. Retrieved October 29, 2009 from http://www.yourdictionary.com/self-development 
Appendix A

Email Sent to University Administrators to Solicit Involvement

Dear [University Administrator],

Hello, I am writing to ask for your assistance in identifying students to participate in my doctoral research study.

The purpose of this study is to explore and describe the leadership identity development of Hispanic women leaders at FIU. In total, I plan to interview $12-15$ women. Each woman will participate in two individual interviews lasting approximately 1 to $1 \frac{1}{2}$ hours each and a focus group interview lasting about $1 \frac{1}{2}$ hours in duration.

As a university administrator who advises and/or supervises women student leaders, I am asking for your assistance in identifying positional and non-positional Hispanic women student leaders who are interested in participating in my study. I hope to solicit participants who represent the diversity of positional and non-positional leadership roles.

Three criteria are established for participation in this study;

1. Identification as a woman, of Hispanic descent,

2. Currently enrolled student at FIU, and

3. Involved (i.e. member or position of leadership) with one of the following groups

Team athletics

Student organization

Resident Assistant

Peer Advisor

Sorority

Center for Leadership and Service programming (i.e. AOL participant, LEAD team member etc.)

If you would, please speak with individuals whom you believe will best represent these criteria and ask if they are willing to participate in this study. Then, please forward the names, emails and phone numbers of these individuals to me at your earliest convenience.

If you have any questions, or need additional information, please do not hesitate to contact me at onoratos@fiu.edu or at 305.348.3692.

Sincerely,

Suzanne Onorato

EdD Candidate, Educational Leadership and Policy Studies 
Appendix B

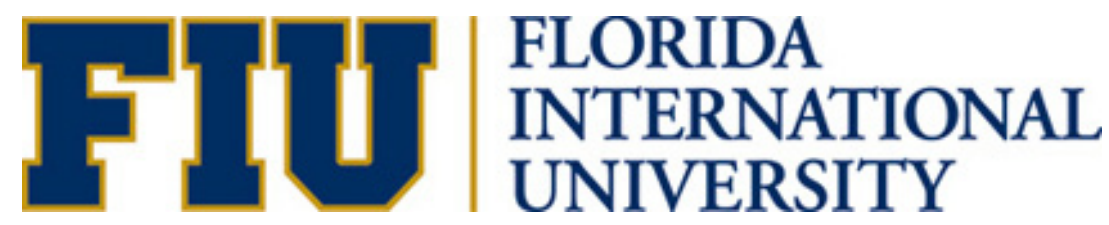

Letter of Informed Consent to Interviewees Participating in the Research Study

Title: Developing a Leadership Identity: A Case Study Exploring a Select Group of Hispanic Women at a Hispanic Serving Institution

July 7, 2009

Dear ,

You are being asked to participate in a research study. The principal investigator of this study is Suzanne Onorato, a doctoral candidate in the Higher Education Program, Department of Educational and Leadership Policy Studies in the College of Education at FIU. The study will include about 12 Hispanic women students at FIU who are currently involved in student organizations. Your participation as an interviewee will require a total of approximately 5 hours of your time. I want to learn more about your experiences as a college student who is involved.

The purpose of the study is to learn about the journey of Hispanic women students who are involved on campus, through their words and experiences. The study will include two interviews, each approximately 1 to $1 \frac{1}{2}$ hours with each woman who participates and a $1 \frac{1}{2}$ hour group interview, for a total time commitment of approximately 5 hours. I am seeking to understand how your experience with involvement and understanding of what it means to be a person who is involved, have guided you to become the woman you are today, and, how these experiences and understanding may guide your future.

During the interview you will be asked questions about your childhood experiences, your schooling, people who have impacted your life, your leadership experience, and your future goals. These questions will serve as a guide to the interview, but the format of the interview is open to reflect what you wish to share and you may elect to skip any questions that you do not want to answer. You are not required to participate in this study for any reason and you have the ability to end your participation at any time, for any reason. In addition, I will answer any questions you may have concerning this project. To thank you for participating, you will receive a $\$ 5$ gift certificate from one of our local food vendors. In addition, you may find that participating in this study provides a unique opportunity to reflect upon the ways that your experiences have guided and will continue to guide you. The transcripts of each interview will be provided to you for your 
review prior to my analysis of data. I do not expect any harm to you by being in the study.

All of your answers are private and confidentiality will be maintained in the following ways:

1) The recording and transcript of your interview will be identified by a special number (not your name or student number).

2) I will ask that you develop a pseudonym that will be used in all written documentation.

3) In addition, the recorded interviews will be deleted at the conclusion of the dissertation process.

If you would like more information about this research, please feel free to contact Dr. Glenda Droogsma Musoba, Major Professor, at (305) 348-2450. If you would like to talk to someone about your rights of being a subject in this study, you may contact Dr. Patricia Price, FIU Institutional Review Board chairperson at (305) 348-2618. If you have questions, need to contact me, or would like additional information, you may contact me at any time at (305)608-1860 or via email at onoratos@,fiu.edu.

Your signature below indicates that you have read this document, that all of your questions have been answered, that you are aware of your rights, and that you would like to participate in this study.

Signature of Participant

Printed Name

Date

I have explained the research procedure, subject rights, and answered questions asked by the participant. I have offered her a copy of this consent form.

Signature of Researcher

Date 


\section{Appendix C}

Interview Protocol

As the LID model serves as a theoretical foundation for this study, the interview protocol is derived from Komives et.al. (2007) protocol and will focus discussion on the following concepts, experiences and influences that guided Komives et al. (2005) study:

The concept or definition of leadership - what does it mean to her

People she consider to be leaders - characteristics, behavior Influences that led to her involvement in leadership

Any role personal/family values might play in her leadership development

The following concepts have been added to guide the discussion:

Any role gender might play in her leadership development

Any role ethnic identity might play in her leadership development

\section{Guiding questions for individual interviews:}

Introduce myself and share informed consent, ask to create a pseudonym

1. Tell me about yourself, who is name

2. I would like to start with some demographic questions. How do you describe your heritage?

why do you use this label instead of others?

what does it mean to be "xyz ethnicity"

3. Tell me about a key experience from elementary school

how about from high school?

and in college?

prompts (if needed)

what about those experiences was significant?

who was involved and what role did they have?

how did (experience) change how you saw yourself?

did being female influence these experiences?

what messages did you hear about being female and being "xyz ethnicity"

growing up?

did these messages affect you?

4. Tell me about someone you admire or consider a role model?

what about him/her do you admire?

5. Tell me why you got involved and when

a. How did you begin to think of yourself as a person who could engage with others and get things done?

prompts (if needed)

tell me about an experience that worked really well

who led that experience? 
what was your role?

and tell me about an experience that didn't work well

6. Tell me more about experiences you had learning to work with other people?

prompts (if needed)

what about working with people different than you?

does your leadership change if men are involved?

does ethnicity matter?

you seem to be "xyz" focused, when did you switch to using this style of working with others?

7. Who has the power/influence in a group and how do you know that individual has the power?

8. When you are in a group who gets things rolling and how do you know they are moving things forward?

9. How do you react to people calling you a "leader"?

10. What's your philosophy of leadership and has it changed? If so, how?

11. How has FIU shaped your leadership? (talk about FIU as an HSI)

12. Is there anything else you would like to add?

\section{Guiding questions for focus group interview:}

Introduction of participants: Share why I have brought them together, purpose of focus groups - member check, expound upon and/or confirm themes generated in individual interviews

1. Some of you talked about "xyz" in your interviews, what does "xyz" mean to you?

2. One of the themes that emerged was "xyz," is this an accurate interpretation? Is it true to your experience?

3. Continue with this type of interaction

4. Anything else you would like to add? 


\section{SUZANNE M. ONORATO}

January 30,1970

1993

1995

$1993-1995$

$1995-1997$

$1997-2000$

$2000-2004$

$2001-2007$

2004 - present

2007 - present
Born, Worcester Massachusetts

B.F.A, Art Education

University of Massachusetts, Amherst

Amherst, Massachusetts

M.Ed, Higher Education Administration University of Massachusetts, Amherst

Amherst, Massachusetts

Graduate Research Assistant

Student Affairs Research and Evaluation Office University of Massachusetts, Amherst

Amherst, Massachusetts

Residence Director

Eastern Washington University

Cheney, Washington

Residence Life Coordinator University of Nevada, Las Vegas

Las Vegas, Nevada

Coordinator for Residential Life

Florida International University

Miami, Florida

Adjunct Instructor

Freshman Seminar, SLS 1501

Florida International University

Miami, Florida

Associate Director/Director, Women's Center

Florida International University

Miami, Florida

Adjunct Instructor

Women and Leadership, WST 4941/5936

Florida International University

Miami, Florida 
Publications and Presentations

Bares, B. and Onorato, S.M. (2010). Women who lead: Utilizing a strong collaboration between academic and student affairs to facilitate the professional development of our students. NASPA Journal About Women in Higher Education. 3, (1) 261-63.

Onorato, S.M. (June, 2009). Discovering your strengths. Workshop presented to the Office of Career Services, University of Miami, Miami, FL.

Bares, B. and Onorato, S.M. (March, 2009). Women who lead: Developing partnerships between student affairs and academic affairs. Paper presented at the National Meeting of the National Association of Student Personnel Administrators.

Onorato, S.M. (March, 2008). The difference, difference makes: Gender and leadership. Workshop presented for the United Way, Miami Leadership Group, Miami, FL.

Onorato, S.M. (June, 2006). Discovering your strengths. Workshop presented to the Dean of Students Office, University of Florida, Gainesville, FL.

Onorato, S.M. (October, 2005). CEO of my life. Program presented at the South Florida, Educational Leadership Enhancement Program, Sanibel Island, FL

Onorato, S.M, Thompson, R., and Vega, G. (2004, March). Exploring the impact of peer tutoring on students 'academic success. Paper presented at the National Meeting of the American College Personnel Association, Philadelphia, PA.

Onorato, S.M. and Thompson, R., (2004, March). Exploring values, choosing ethics and inviting excellence. Paper presented at the National Meeting of the American College Personnel Association, Philadelphia, PA.

Onorato, S.M. and Vega, G. (2003, February). Global understanding: Challenging our voice of acceptance. Paper presented at the Florida Association of Women in Education conference, Fort Lauderdale, FL.

Onorato, S.M. and Kollet, G. (1994, November). Practical applications for retaining students of color at a predominately white institution. Paper presented at the Region I meeting of the National Association of Student Personnel Administrators, Burlington, VT

Onorato, S.M. and Tyrol, W. (1993, November). Women's health issues: Informing student affairs professionals. Paper presented at the Region I meeting of the National Association of Student Personnel Administrators, Hartford, CT. 